\title{
CONTROLADORES PID INDUSTRIAIS COM SINTONIA AUTOMÁTICA POR REALIMENTAÇÃO A RELÊ
}

José Roberto Caon Júnior

Dissertação apresentada à Escola de Engenharia de São Carlos da Universidade de São Paulo como parte dos requisitos para obtenção do título de Mestre em Engenharia Elétrica

Orientadora: Profa. Dra. Vilma Alves de Oliveira

São Carlos

1999 
À Professora Dra. Vilma Alves de Oliveira, pela excelente orientação fornecida durante a elaboração deste trabalho.

Ao Conselho Nacional de Desenvolvimento Científico e Tecnológico (CNPq) pela bolsa de estudo concedida.

A todos os colegas, professores e funcionários do Departamento de Engenharia Elétrica da EESC/USP pela colaboração.

A empresa INCON Eletrônica Ltda. pela documentação e aparelhos fornecidos para uso nos experimentos. 


\section{SUMÁRIO}

1. Introdução...........................................................................................

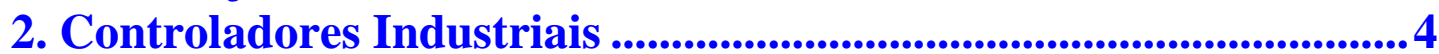

2.1 Efeito Reset - Windup.............................................................................6

2.2 Filtragem (atraso) no termo derivativo ................................................................. 7

2.3 Ponderação da referência no termo proporcional ............................................8

Ganho do processo normalizado elevado $(2.25<\mathrm{k}<15)$.............................................................. 10

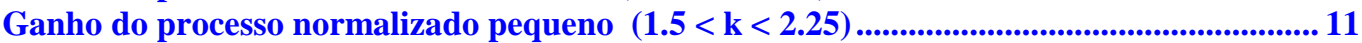

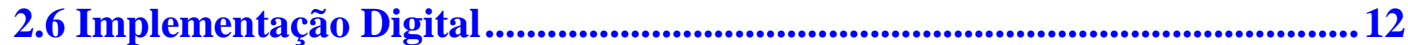

Discretizacão ........................................................................................................................ 12

Ação proporcional .................................................................................................................................. 13

Ação integral .................................................................................................................................... 13

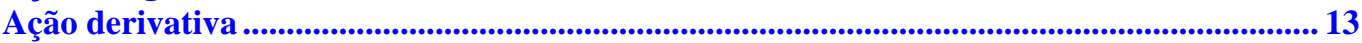

Forma incremental .......................................................................................................................... 15

3. Sintonia de Controladores PID....................................................................16

3.1 Sintonia Automática pelo Método de Astrom-Hagglund ..........................18

Sintonia pela especificação da margem de ganho ........................................................................... 19

Sintonia pela especificação da margem de fase ............................................................................... 20

3.2 Sintonia pelo Método de W. Khuen Ho, C. Chieh Hang, L. S. Cao ...........222

Fórmula para sintonia PI...

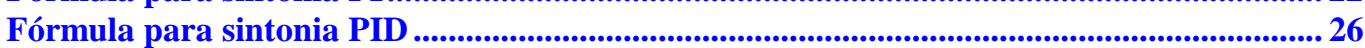

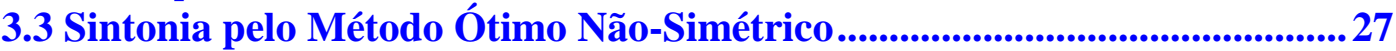

Modelo da planta ..................................................................................................................27

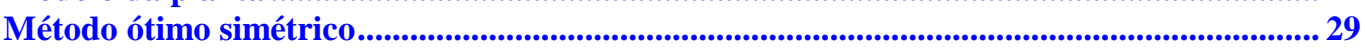

Otimização do ganho e ponto ótimo de tangência.......................................................................30

3.4 Re-sintonia Automática de Controladores PI em Malhas de Controle

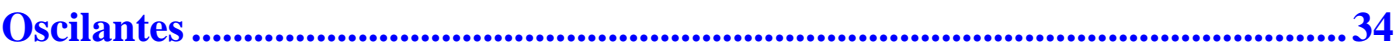

Identificação do Sistema................................................................................................34

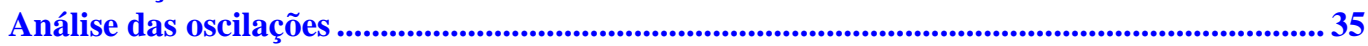

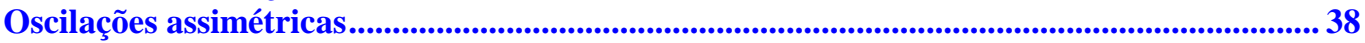

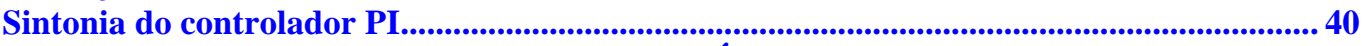

3.5 Critérios de Otimização Baseados em Índices Quadráticos de Desempenho

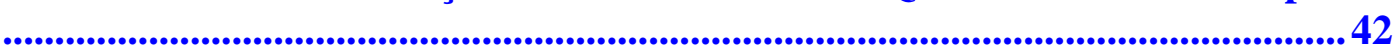

Critérios de otimização.......................................................................................4

Sintonia de controladores PID ótimos.................................................................................44

Critério de desempenho integral utilizado..........................................................................4 45

Sintonia ótima dos parâmetros usando o ganho e freqüêência críticos ...................................45

Sintonia ótima dos parâmetros pelas margens de fase e ganho (MFG) ..................................... 48

4. Processos Industriais de Temperatura de $1^{\text {a }}$ Ordem com Tempo

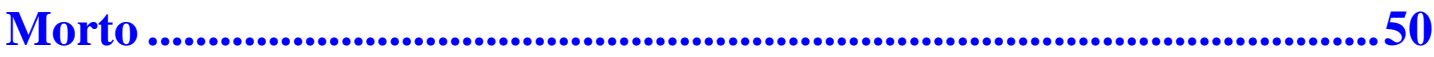

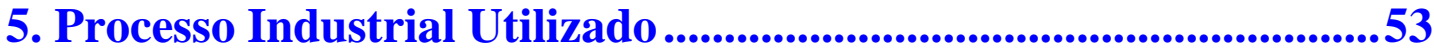

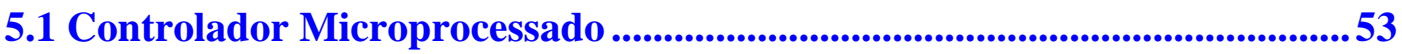

5.2 Sensores de Temperatura ..............................................................................556

5.3 Acionamento da Planta por PWM.......................................................58

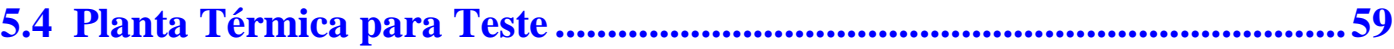

6. Simulações....................................................................................................62

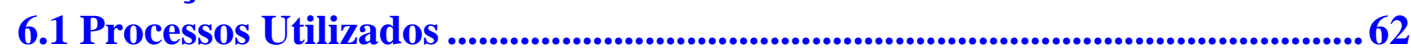

Ciclo Limites e Sintonia Automática .............................................................................................6 63

Comparações e Discussões .................................................................................................69 
6.2 Diagramas de Simulação ........................................................................................71 7. Implementação da Técnica de Auto-Sintonia por Realimentação a

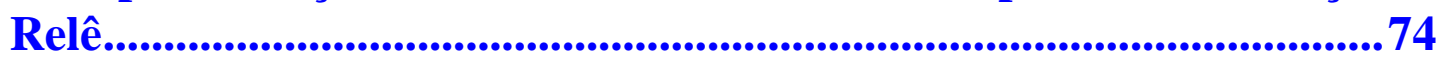

7.1 Linguagem, Descrição dos Parâmetros do Controlador PID em termos de Bandas e Condições Necessárias para Oscilação Simétrica a Relê......................75

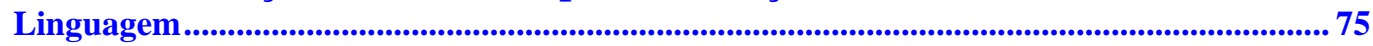
Descrição dos parâmetros do controlador PID em termos de bandas.................................. 75 Condições Necessárias para obter Oscilação Simétrica no Experimento a Relê.................... 78

7.2 Questões Práticas de Implementação ....................................................................80

Ação integral .........................................................................................................................................8 80

Reconhecimento de picos e vales ..........................................................................................8 80

Influência do período do PWM na resposta do controlador PID.........................................81

7.3 Algoritmo de Sintonia Automática e Descrição das Rotinas Desenvolvidas82

8. Resultados Experimentais ........................................................................86

8.1 Identificaçã̃o de Modelo do Processo e Experimento a Relê ............................ 86

8.2 Estabilidade ...................................................................................................................88

9. Conclusões...........................................................................................91

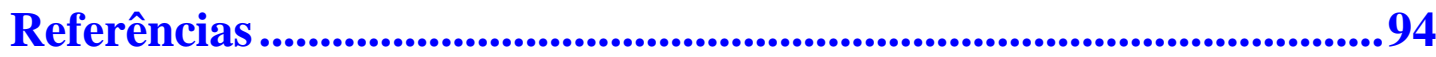

Apêndice A ...........................................................................................98

Apêndice B ..............................................................................................................109 


\section{LISTA DE FIGURAS}

FIGURA 01. (a) Diagrama de bloco do controlador on-off; (b) forma de onda típica da saída. ......... 4 FIGURA 02. (a) Diagrama em bloco do controlador on-off com histerese; (b) forma de onda típica da saída.

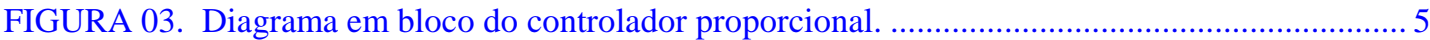

FIGURA 04. Diagrama em bloco do controlador PID. .......................................................... 6

FIGURA 05. Sobre-sinal excessivo na resposta ao degrau para controle PID por Ziegler-Nichols, e

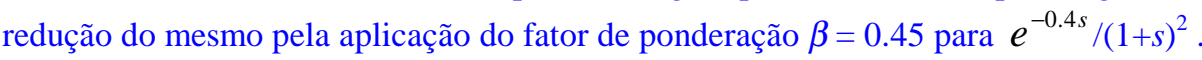

FIGURA 06. Porcentagem de sobre-sinal e sub-sinal para controle PID por Ziegler-Nichols.......... 10

FIGURA 07. Fator de ponderação para controle PID . ................................................................ 11

FIGURA 08. Fator de ponderação e taxa de modificação do tempo integral para controle PID......... 12

FIGURA 09. Diagrama em bloco da auto-sintonia. O sistema opera com um controlador a relê no modo sintonia (t) e como controlador PID no modo (c).

FIGURA 10. O ponto dado pode ser movido para uma posição arbitrária no plano- $G$ pelos controladores PI, PD ou PID. O ponto A pode ser movido nas direções $G(j w), G(j w) / j w$ e $j w G(j w)$ pela variação dos ganhos proporcional, integral e derivativo, respectivamente.

FIGURA 11. Aproximação da função arco-tangente.

FIGURA 12. Região de especificação para margem de fase e ganho ...........................................26

FIGURA 13. (a) Sintonia pelo Método Ótimo Simétrico; (b) Sintonia pelo Método Ótimo Não Simétrico;

FIGURA 14. Arranjo do experimento "controlador PI saturado", consistindo de um controlador PI convencional e níveis de saturação sobre a entrada do processo e o processo.

FIGURA 15. Sinais de entrada $(u)$ do processo e saída $(y)$ durante o experimento de identificação. $\mathrm{O}$ processo é $\exp (-80 s) /(455 s+1)$ com referência $r=50$, níveis de saturação 0 e 100 e controlador PI dado por $K_{c}=10$ e $T_{i}=200$.

FIGURA 16. Não linearidade saturação ideal.

FIGURA 17. O ponto $\mathrm{P}$ sobre a curva de Nyquist é identificado no terceiro quadrante pelo ângulo de identificação $\phi_{P}$. Com um controlador PI este ponto pode ser movido para o ponto $\underline{S}$ que é especificado pelo ângulo $\phi_{S}$ e magnitude $r_{S}$

FIGURA 18. A proposta da função descritiva mais bias é estimar um ganho médio de redução de amplitude dado pela não linearidade.

FIGURA 19. Ilustração de como um período do sinal $v$ passa através da não linearidade saturação dando um período do sinal $u$.

FIGURA 20. Relações entre os parâmetros PID e o ponto crítico ................................................ 46

FIGURA 21. Relações entre os parâmetros PI e o ponto crítico. ........................................... 47

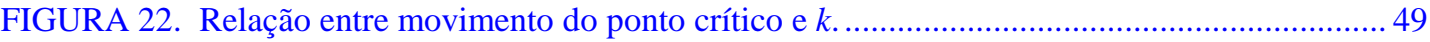

FIGURA 23 Característica de ângulo de fase para o termo $e^{-L s} \quad 51$

FIGURA 24. Diagrama de Bode da função de transferência de primeira ordem mais tempo morto para os valores $\mathrm{L}=0.5 \mathrm{e} \mathrm{T}=1$.

FIGURA 25. Diagrama de Nyquist da função de transferência (2.48a) para $L=0.5$ e $T=1.2 .52$

FIGURA 26. Frontal do controlador industrial utilizado na implementação dos algoritmos de controle PID e sintonia automática.

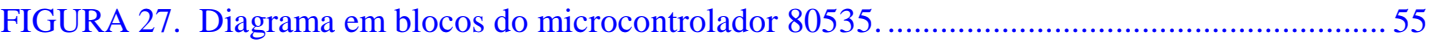

FIGURA 28. (a) Ajuste de tensões internas a faixas de tensões externas das entrada analógicas; (b) Operação do conversor A/D interno para conversão resultante de 10 bits. ..........................56

FIGURA 29. Sensores PT100 e Termopar tipo J, da esquerda para a direita................................57

FIGURA 30. (a) Saída do PWM; (b) $C_{T}$ com valor correto; (c) $C_{T}$ com valor muito elevado............. 58

FIGURA 31. Processo industrial exemplo: mini-forno.

FIGURA 32: Diagrama em bloco do sistema de controle a malha fechada.....................................6 60

FIGURA 33. Funções de transferência aproximadas para o mini-forno. ...................................... 61

FIGURA 34. Resposta temporal a entrada tipo degrau dos processos: (a) I e II; (b) III e (c ) IV...... 62 
FIGURA 35. Ciclos limites alcançados para os processos por oscilação a relê: (a) I: $d=5, a_{0}=0,48$ e $\mathrm{t}_{\mathrm{o}}=0,38 \mathrm{~s}$; (b) II: $\mathrm{d}=1, \mathrm{a}_{0}=0,63$ e $\mathrm{t}_{\mathrm{o}}=2,98 \mathrm{~s}$; (c ) III: $\mathrm{d}=1, \mathrm{a}_{\mathrm{o}}=1,0$ e $\mathrm{t}_{\mathrm{o}}=174,0 \mathrm{~s}$ e (d) IV: $\mathrm{d}=$

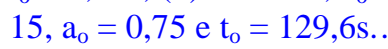

FIGURA 36. Ciclos limites alcançados pelos quatro processos pelo método de Friman (referência = 1): (a) I : $K_{c}=4, T_{i}=0,05$; (b) II $: K_{c}=5, T_{i}=3$; (c ) III : $K_{c}=5, T_{i}=100$ e (d) IV: $K_{c}=50, T_{i}=$ 100.

FIGURA 37. Resposta ao degrau unitário com os controladores obtidos pelos 5 métodos.............. 65

FIGURA 38. Resposta ao degrau unitário com os controladores obtidos pelos 5 métodos.............. 66

FIGURA 39. Resposta ao degrau unitário com o controlador obtido por 3 dos 5 métodos.............. 67

FIGURA 40. Resposta ao degrau unitário com os controladores obtidos pelos 5 métodos................68

FIGURA 41. Diagrama utilizado para geração do ciclo limite dos processos I, II, III e IV..............71

FIGURA 42 . Malha fechada com controlador PID para obtenção da resposta ao degrau..................72

FIGURA 43. Diagrama de simulação contendo todos os elementos presentes na malha para realização: (a) do experimento a relê; (b) do controle a malha fechada com controlador PID. .................. 73

FIGURA 44. Exemplo de ganho proporcional do controlador PID apresentado como uma banda..... 76

FIGURA 45. Exemplo da ação de reset do controlador PI.

FIGURA 46. Ilustração da banda derivativa do controlador PD

FIGURA 47. Correção de distúrbio de carga durante o procedimento de sintonia automática para o processo $e^{-2 s} /(10 \mathrm{~s}+1)$; (a) Sem a perturbação o relê é chaveado em 0 , (b) Uma perturbação de $3^{\circ} \mathrm{C}$ é aplicada, (c) Correção: um bias de $-3^{\circ} \mathrm{C}$ é aplicado na saída do relê.

FIGURA 48 Efeito do chaveamento do PWM na forma de onda da saída do processo para

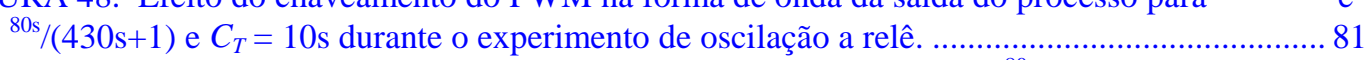

FIGURA 49. Efeito do PWM na forma de onda da saída do processo para $\mathrm{e}^{-80 \mathrm{~s}} /(430 \mathrm{~s}+1)$, controlador PID com $K_{c}=2,4 T_{i}=446, T_{d}=35$ e Ref $=50^{\circ} \mathrm{C}:$ (a) $C_{T}=10 \mathrm{~s} ;$ (b) $C_{T}=100 \mathrm{~s}$

FIGURA 50: Sintonia automática do mini-forno (teste 5 da Tabela 10); de 0 a 1050s fase de estimação dos parâmetros do modelo de primeira ordem mais tempo morto, de 1050 s a 1755 s fase de sintonia automática dos parâmetros do controlador PID.

FIGURA 51: Diagrama de Nyquist do controlador $K_{c}=13,8, T_{i}=829,5 \mathrm{~s}, T_{d}=27 \mathrm{~s}$ e processo com variação nos parâmetros; (a) Pior caso: $L=41 \mathrm{~s}, T=207,7 \mathrm{~s}, K_{p}=0,74, A_{m}=2,0$ e $\phi_{m}=79,6^{\circ}$; (b) Nominal: $L=34 \mathrm{~s}, T=247,1 \mathrm{~s}, K_{p}=0,69, A_{m}=2,7$ e $\phi_{m}=84,9^{\circ}$; (c) Melhor caso: $L=25 \mathrm{~s}, T$ $=265,7 \mathrm{~s}, K_{p}=0,63, A_{m}=3,3$ e $\phi_{m}=89,0^{\circ}$

FIGURA 52: Resposta ao degrau simulada (referência $=50^{\circ} \mathrm{C}$ ) com o controlador $K_{c}=13,8, T_{i}=$ $829,5 \mathrm{~s}, T_{d}=27 \mathrm{~s}$; (a) Pior caso; (b) Nominal; (c) Melhor caso. ......................................... 89

FIGURA 53: Mudança da referência ( para $15^{\circ} \mathrm{C}$ ) em $3000 \mathrm{~s}$ com controlador para o mesmo caso da Figura 52.....

FIGURA 54: Resposta do mini-forno com mudança da referência (de $75,0^{\circ} \mathrm{C}$ para $40,0^{\circ} \mathrm{C}$ ) com controlador PID do teste 5 programado no controlador de temperatura industrial................... 90

FIGURA A1. Curvas de amplitude em função da frequencia para oscilações naturais para o sistema dado por (A1)...

FIGURA A2. (a) Característica de entrada-saída para não-linearidade tipo liga-desliga; (b) formas de pnda de entrada e saída. ....................................................................................... 104

FIGURA A3. Função descritiva da não-linearidade tipo liga-desliga. ...................................... 104

FIGURA A4. (a) Curva entrada-saída para não-linearidade tipo liga-desliga com histerese; (b) formas de onda de entrada e saída

FIGURA A5. Função descritiva da não-linearidade tipo liga-desliga com histerese, (a) Fase, em graus

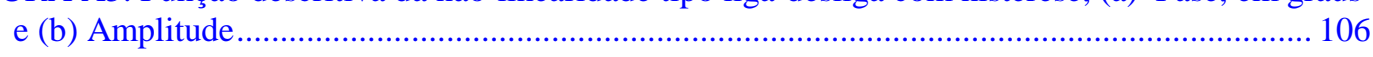

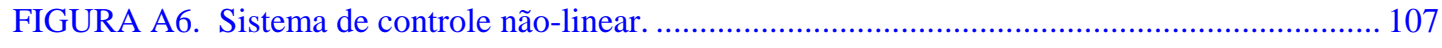

FIGURA A7. Análise da estabilidade de operações de ciclo limite para sistemas não-lineraes....... 108 FIGURA B1. Ambiente de simulação com diversas janelas ativas. 


\section{LISTA DE TABELAS}

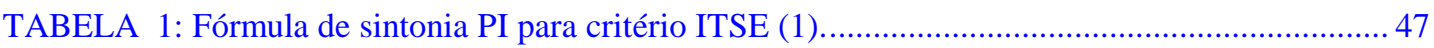

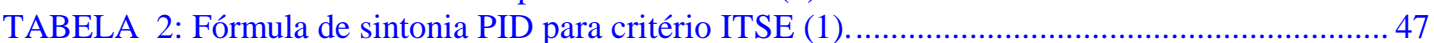

TABELA 3: Fórmula de sintonia PI para critério ITSE (2) .................................................. 48

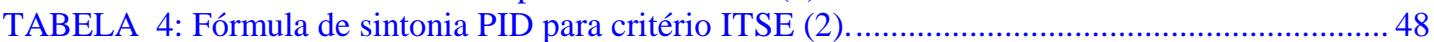

TABELA 5: Valores dos parâmetros do controlador e margens de ganho e fase para o processo I.... 65

TABELA 6: Valores dos parâmetros do controlador e margens de ganho e fase para o processo II...66 6

TABELA 7: Valores dos parâmetros do controlador e margens de ganho e fase para o processo III. 67

TABELA 8: Valores dos parâmetros do controlador e margens de ganho e fase para o processo IV. 68

TABELA 9: Características das rotinas implementadas. ........................................................ 85

TABELA 10: Resultados experimentais para estimativas de $L, T, \mathrm{~K}_{\mathrm{P}}$, parâmetros críticos $\left(\mathrm{a}_{\mathrm{o}}\right.$ e $\left.\mathrm{t}_{\mathrm{o}}\right)$ e espectivos parâmetros do controlador PID calculados para o mini-forno. 


\section{LISTA DE SÍMBOLOS}

$a$ : valor medido para a saída do processo para experimento a relê em malha fechada.

$a_{o}$ : valor exato da saída do processo para experimento a relê em malha fechada.

$a_{R E F}$ : valor desejado para a saída do processo durante o experimento a relê.

$a_{P O S}$ : valor do semi-ciclo positivo da oscilação assimétrica durante o experimento a relê.

$a_{N E G}$ : valor do semi-ciclo negativo da oscilação assimétrica durante o experimento a relê.

$a_{V}$ : amplitude da saída do controlador PI durante o experimento controlador PI saturado.

$a_{Y}$ : amplitude da oscilação de saída do processo durante o experimento controlador PI saturado.

A/D: conversor analógico/digital.

$A_{m}$ : margem de ganho.

BD: banda derivativa.

BI: banda integral.

bias: valor do "bias" do relê.

BP: banda proporcional.

$C_{T}$ : tempo de ciclo da saída (período do PWM).

d: amplitude do relê.

D: operador derivada $\left(\frac{d}{d t}\right)$.

EPROM: memória somente de leitura programável e apagável.

EEPROM: memória somente de leitura programável e apagável eletricamente.

$f_{l}$ : função auxiliar para o calculo de $\mathrm{Np}$.

$G(s)$ : função de transferência do processo de $1^{\mathrm{a}}$. ordem mais tempo morto.

$G_{q}(s)$ : função de transferência do processo de $1^{\mathrm{a}}$. ordem mais integrador.

$G_{p i}(s)$ : função de transferência do controlador PI.

$j$ : unidade imaginária $(\mathrm{j}=\sqrt{-1})$

$k$ : valor calculado para o ganho do processo normalizado.

$k_{o}$ : valor exato do ganho do processo normalizado.

$K_{C R}$ : valor calculado para o ganho crítico.

$K_{o}$ : valor exato do ganho crítico.

$K_{c}$ : ganho do controlador proporcional.

$K_{q}$ : ganho integrativo do processo. 
$K_{p}$ : ganho estático do processo (processos com auto-regulação).

$K_{P I}$ : contribuição de ganho do controlador PI.

$K_{v}$ : ganho do processo para sistemas sem auto-regulação.

$L$ : tempo morto.

$M_{g}$ : magnitude da malha aberta no ponto de tangência.

$M(w)$ : magnitude da malha fechada na frequiência $\underline{w}$.

MSB: byte mais significativo.

$N$ : constante de limitação para o ganho derivativo em altas freqüências.

$N(a)$ : ganho da não linearidade saturação ideal.

$N_{p}$ : ganho da não linearidade saturação ideal à entrada senoidal com "offset".

PID: proporcional - integral - derivativo.

PWM: modulação por largura de pulso.

RAM: memória de acesso randômico.

$r_{P}$ : ganho do processo na freqüência de identificação.

$r_{S}$ : valor mínimo para a margem de ganho.

$t_{C R}:$ valor calculado para o período crítico.

$t_{o}$ : valor exato do período crítico.

$t_{K}$ : instante de tempo da amostra $\mathrm{k}$

$t_{s}$ : valor do tempo de amostragem.

$t_{p}$ : valor de tempo em que a saída permanece ligada.

$T$ : constante de tempo de processos com auto-regulação.

$T_{d}$ : tempo derivativo.

$T_{i}$ : tempo integral.

$T_{o}$ : constante de tempo aproximada do processo integrativo.

$T_{q}$ : constante de tempo do processo integrativo.

$T_{v}$ : constante de tempo de processos sem auto-regulação.

$u_{M A X}$ : nível máximo de saturação para o experimento controlador PI saturado.

$u_{M I N}$ : nível mínimo de saturação para o experimento controlador PI saturado.

$u_{o}$ : média aritmética dos níveis de saturação para o experimento controlador PI saturado.

$v_{M A X}$ : valor máximo da saída do controlador PI durante o experimento controlador PI saturado.

$v_{M I N}$ : valor mínimo da saída do controlador PI durante o experimento controlador PI saturado. 
$v_{o}$ : metade do valor pico-a-pico da saída do controlador PI durante o experimento controlador PI saturado.

$w_{C R}$ : valor calculado para a freqüência angular crítica.

$w_{o}$ : valor exato para a freqüência angular crítica.

$\alpha$ : fator de correção para cálculo do tempo integral.

$\beta$ : fator de ponderação do sinal de referência.

$\varnothing_{1}$ : tempo morto normalizado.

$\varnothing_{m}$ : margem de ganho.

$\varnothing_{g}$ : fase da malha aberta no ponto de tangência.

$\varnothing_{p}$ : ângulo de identificação.

$\varnothing_{P I}$ : contribuição de fase do controlador PI.

$\varnothing_{s}$ : valor mínimo para a margem de fase.

$\lambda$ : fator de correção de ganho do controlador PI.

$\mu$ : taxa de modificação do tempo integral.

$\rho$ : argumento da função $f_{1}$.

$\Psi$ : índice de desempenho. 


\section{Resumo}

O presente trabalho tem por objetivo a implementação de algoritmos de controle do tipo PID com sintonia automática de seus parâmetros para controle de processos térmicos de primeira ordem mais tempo morto. Existe um grande número de métodos para a sintonia automática, os quais requerem informações variadas sobre o processo. A sintonia automática dos parâmetros do controlador escolhida para implementação é baseada no método da realimentação a relê que utiliza o ganho estático e o período e amplitude críticos do processo e pode ser facilmente adotada na indústria. Este método foi implementado em um controlador industrial microprocessado que utiliza um microcontrolador da família 8051. A correta identificação dos parâmetros críticos do processo presume a geração de oscilações simétricas durante a realimentação a relê. O algoritmo de sintonia automática desenvolvido inclui correção em tempo real da amplitude do relê para evitar identificação falsa de um ciclo da oscilação e da assimetria na saída do processo durante a realimentação a relê. A implementação do algoritmo é simples e direta em termos de programação no ambiente de microcontroladores mesmo em linguagem de baixo nível (assembly). São apresentados resultados de simulação e os resultados experimentais realizados em um aparelho industrial comercial.

Palavras Chave: Controladores PID industriais, sintonia automática, método a relê, oscilações simétricas, controle de temperatura 


\section{Abstract}

The objective of this work is the implementation of a PID control algorithm with autotuning for a thermal first order process plus dead-time. There is a number of methods for the auto-tuning of PID controllers which require different information on the process. The auto-tuning algorithm is implemented in a industrial controller based on the 8051 microcontroller family. The auto-tuning method considered for implementation is based on the relay feedback procedure which require the process steady state gain and the ultimate point on the Nyquist plot and can be easily adopted by industry. The method is also suited for pre-tuning adaptive controllers. The auto-tuning method used assume symmetrical oscillations during the relay feedback experiment to render the correct ultimate point on the Nyquist plot The proposed auto-tuning algorithm includes on-line correction for asymmetry oscillation and relay amplitude to avoid false capture of the limit cycle. The symmetrical oscillations are ensured by a DC bias signal added to the relay output. The algorithm is simply and straight to be written in a microcontroller programming language. Experimental results accomplished in a industrial PID auto-tuner are presented.

Key Words: Industrial PID control, auto-tuning, relay method, symmetrical oscillations. 


\section{Introdução}

Temperatura, sem dúvida alguma, é uma das grandezas físicas mais medidas e controladas em todo o mundo, seja em ambiente industrial (fornos, estufas, reatores químicos, etc) ou na climatização de ambientes (residenciais, shopping-centers, hospitais, etc.). Seu valor muitas vezes determina a qualidade de um produto, a eficiência de um processo ou o bem estar de um ambiente.

Em um mercado cada vez mais exigente, tendo à disposição um leque de ofertas muito diversificado, que busca por produtos de maior qualidade e confiabilidade, está claro que qualidade é fator de sucesso e de sobrevivência de uma empresa.

É neste cenário que a série de normas sobre sistemas de qualidade denominada ISO 9000 têm conduzido as ações industriais mundiais para melhoria e garantia da qualidade. Esta série, composta por cinco normas numeradas de 9000 a 9004, apresenta condições bastante exigentes que permitem à indústria apresentar produtos e serviços competitivos em nível internacional, trazendo ao ambiente industrial a necessidade de um controle quase que total sobre máquinas e processos. Isto dá a engenharia de controle a obrigação de fornecer soluções teóricas e práticas para atender as exigências das normas industriais nacionais e internacionais.

Desta forma o processo de automação industrial aumentou vertiginosamente na última década visando obter produtos e serviços com menor tempo de produção, menor consumo de energia, maior precisão de ajuste e medidas, graças a maior eficiência nos processos de produção industrial.

É neste contexto que os controladores industriais microprocessados tornaram-se peças fundamentais à produção industrial. Maior eficiência, maior confiabilidade e menor número de trabalhadores necessários na atuação e supervisão de processos são as principais características trazidas com o uso destes controladores microprocessados na indústria.

No panorama internacional, estes aparelhos surgiram para atender a demanda industrial a partir de meados dos anos 1980. Estes apresentavam esquemas de controle variados: controlador PID e auto-ajuste de parâmetros (self-tuning), controlador adaptativo de uso geral, controlador PID adaptativo, controlador PID e auto-sintonia (auto-tuning) e vários outros; hoje um só aparelho reuni todas estas características (controle PID, autosintonia e auto-ajuste) e outras indicações de interesse industrial como indicação da potência de saída, saídas para alarme, tipo de entrada (sensor) configurável por software, etc. 
No panorama nacional infelizmente não há aparelhos equivalentes a estes, os dispositivos nacionais são limitados ao controle tipo on-off e somente poucas empresas têm atuado no sentido de buscarem para seus produtos características semelhantes ao produtos estrangeiros. Por exemplo somente em 1993, a Smar Equipamentos Industriais Ltda colocou no mercado equipamentos dotados de algoritmo de controle PID e em 1996 a possibilidade de auto-ajuste da variável de processo; a empresa Novus Ltda. somente a partir de 1996 colocou no mercado nacional um aparelho capaz de realizar a sintonia automática de parâmetros. Desta forma a sintonia de parâmetros dos processos industriais é ainda feita na maioria das vezes manualmente ou por meio de gráficos. A saída frente a necessidade imediata de um aparelho mais completo é, portanto, recorrer a importação dos produtos estrangeiros que hoje apresenta o inconveniente das altas taxas de importação. Desta forma a necessidade do desenvolvimento de aparelhos nacionais microprocessados para a indústria, similares aos importados, é altamente conveniente e desejável.

Portanto na indústria brasileira há uma demanda reprimida por aparelhos microprocessados de menor custo que apresentem características de controle estáveis, confiáveis, eficientes e com uma interface amigável para os operadores. De modo que estes não necessitem ter conhecimentos mais profundos sobre a teoria aplicada e na programação do dispositivo. Isto ainda contribui para eliminar a figura do operador especializado que é o único a conseguir acertar a sintonia manual dos parâmetros de controle para os processos industriais.

Atualmente outras formas de controle de processos estão surgindo com a utilização de lógica difusa (controle fuzzy) e redes neurais, contudo estes trabalhos situam-se ainda no plano acadêmico e sua implementação efetiva em larga escala no ambiente industrial ainda são tímidas ou praticamente inexistentes e vão levar tempo para surgirem como uma opção concreta a mais de utilização.

A concorrência mais forte com os aparelhos microprocessados é o controle por microcomputador devido a elevada velocidade e poder de processamento dos microcomputadores que tornam possível a implementação de esquemas de controle mais sofisticados, em tempo real e com opção para monitoração gráfica dos processos. No entanto com o aparecimento de microcontroladores cada vez mais velozes, mais poderosos (16 e 32 bits), com conversores A/D e D/A e PWM integrados na mesma pastilha a disputa fica equilibrada e com espaço no meio industrial para ambas as opções.

Da experiência acumulada e aplicações industriais já realizadas e bem sucedidas fica claro que nenhum método utilizado irá resolver sozinho todos os problemas encontrados na 
indústria. Há limitações em todos eles e seu uso só será definido após extensiva análise do problema e parâmetros considerados relevantes; há muitos casos em que é mais conveniente o uso de mais de um esquema de controle que são combinados de maneira a produzirem o resultado desejado. Um exemplo desta interação são os algoritmos destinados à supressão de sobre-sinal que utilizam a lógica fuzzy e que atuam em conjunto com os controladores PID, em YASUDA \& CROTTY (1990) um destes algoritmos pode ser encontrado.

O presente trabalho está organizado como segue. No Capítulo 2 é apresentada a ação de controle do tipo PID nas formas contínua e discreta com detalhes sobre questões práticas de implementação das ações derivativa e integral. No Capítulo 3 são apresentados os algoritmos mais conhecidos na literatura para sintonia dos parâmetros PID que utilizam diferentes informações e aproximações do processo. Em seguida, no Capítulo 4, é feita a caracterização no tempo e na frequiência dos processos térmicos industriais para a aplicação dos métodos de sintonia apresentados no Capítulo 3. O hardware que compõe o controlador industrial e a planta térmica utilizada é descrito no Capítulo 5. No Capítulo 6 resultados de simulações para os métodos de sintonia automática tratados são apresentados e comparados em termos do comportamento transitório resultante e das margens de fase e ganho obtidas. Neste capítulo também é apresentada a resposta experimental de um processo industrial exemplo, um mini-forno. A implementação da técnica de sintonia automática adotada é apresentada no Capítulo 7. No Capítulo 8 os resultados de vários experimentos realizados com o processo industrial exemplo são apresentados juntamente com a avaliação da estabilidade dos controladores sintonizados. No Capítulo 9 são apresentadas conclusões acerca dos métodos de sintonia automática de parâmetros bem como a indicação do método mais adequado para uso industrial para a classe de processos considerada. 


\section{Controladores Industriais}

A evolução dos controladores microprocessados industrias permite hoje em pouco tempo obter automaticamente os parâmetros do controlador necessário para manter o processo com um mínimo de erro em relação a um sinal de referência desejado. Podem ser também dotados com a possibilidade de ajuste contínuo dos parâmetros (auto-ajuste) frente a variações devido a mudanças da planta ou perturbações externas.

A forma mais simples de controle de processo utilizada na indústria é o controlador on-off que para um sinal de realimentação acima do sinal de referência desejado mantém o sinal atuante em um valor mínimo (ou zero) e consequentemente com nenhuma potência aplicada à planta e para um nível de realimentação abaixo do sinal de referência a potência é totalmente aplicada. Este controlador é ilustrado na Figura 1 onde uma resposta típica é também apresentada. Sua principal desvantagem é a variação permanente da saída controlada em torno do sinal de referência desejado.

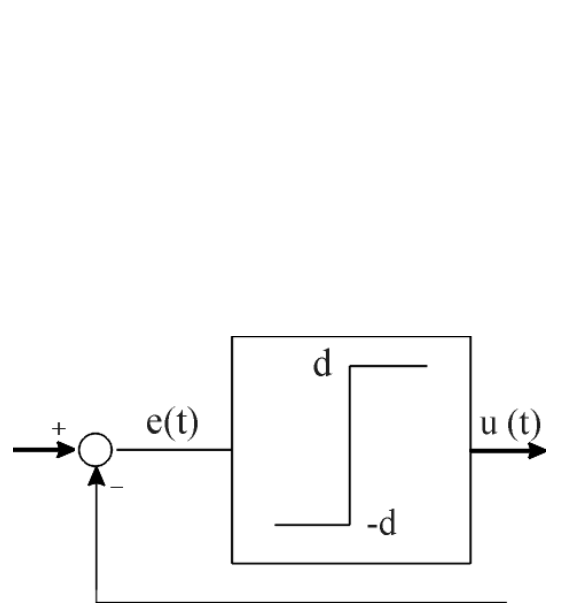

(a)

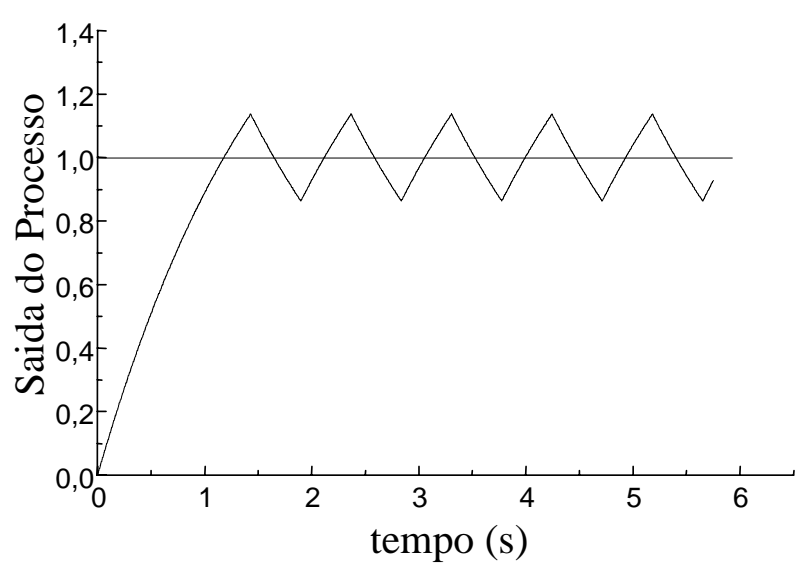

(b)

FIGURA 01. (a) Diagrama de bloco do controlador on-off; (b) forma de onda típica da saída.

$$
u(t)=\left\{\begin{aligned}
d & \text { para } \mathrm{e}(\mathrm{t})>0 \\
-d & \text { para } \mathrm{e}(\mathrm{t})<0
\end{aligned}\right.
$$

Para diminuir a freqüência desta oscilação é acrescentado ao sistema de controle um parâmetro denominado histerese que corresponde a uma região simétrica ao valor da referência desejada e cria assim uma região na qual a saída do controlador $u(t)$ mantenha seu valor presente até que o sinal de erro atuante tenha sido movido além do valor desta faixa. $\mathrm{O}$ 
novo comportamento da saída é mostrado na Figura 2. Com isto consegue-se uma diminuição na freqüência de oscilação da saída, porém se a histerese for definida com um valor muito elevado a variação na amplitude da saída será muito grande e um novo problema surge. Assim o valor da histerese será um compromisso entre precisão desejada e a durabilidade do elemento atuador.

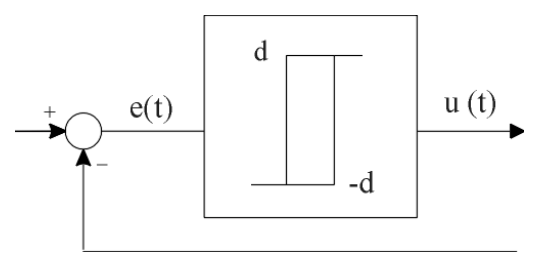

(a)

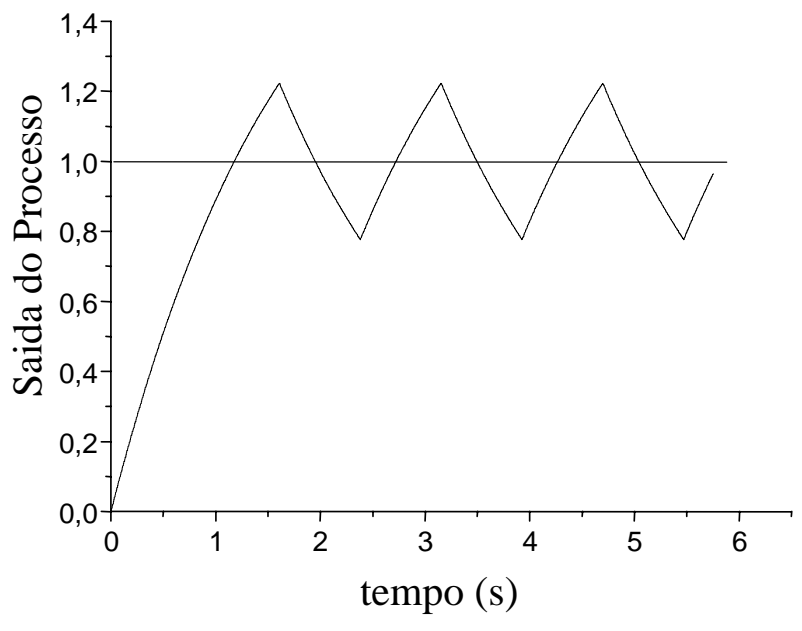

(b)

FIGURA 02. (a) Diagrama em bloco do controlador on-off com histerese; (b) forma de onda típica da saída.

Os esquemas de controle on-off e on-off com histerese podem ser implementados na forma analogica ou digital.

Depois do controlador on-off em termos de simplicidade temos o controle de processos por controladores proporcionais (um ganho) que já permitem algumas melhoras na resposta da saída controlada como redução da sensibilidade do sistema a variações de parâmetros internos e perturbações externas mas também a possibilidade de instabilidade. Seu diagrama de blocos é mostrado na Figura 3 e sua saída corresponde ao sinal de erro multiplicado pelo valor de sua constante de proporcionalidade (o ganho proporcional).

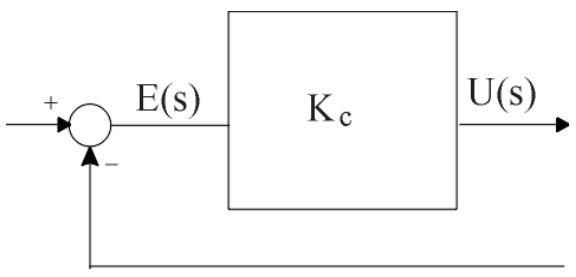

FIGURA 03. Diagrama em bloco do controlador proporcional.

A função de transferência deste controlador é 


$$
\frac{U(s)}{E(s)}=K_{c}
$$

O próximo controlador de processos a ser considerado é o PID, que soma à ação proporcional as ações integral e derivativa. A ação integral elimina erro em regime estacionário pois o sinal de controle apresenta um valor não nulo quando o erro for nulo; a ação integral entretanto pode introduzir oscilação na resposta pelo aumento da ordem do sistema. A ação derivativa antecipa o erro atuante e produz a ação corretiva mais cedo (pois responde a taxa de variação do erro atual). O diagrama está ilustrado na Figura 4.

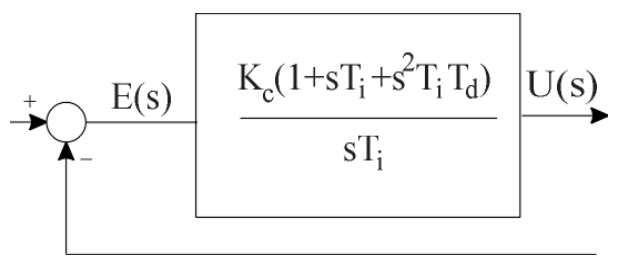

FIGURA 04. Diagrama em bloco do controlador PID.

A função de transferência do controlador PID é

$$
\frac{U(s)}{E(s)}=K_{c}\left(1+\frac{1}{T_{i} s}+T_{d} s\right)
$$

No momento da aplicação prática deste controlador alguns cuidados devem ser tomados para que se obtenha o desempenho adequado do sistema controlado sem os quais o efeito final do controlador pode ser degradado ou mesmo inadequado. Os principais efeitos a serem considerados são a saturação do sinal atuante, a limitação do ganho do termo derivativo em altas freqüências e a ponderação do sinal de referência por um fator adequado.

\subsection{Efeito Reset - Windup}

A ação temporal do controlador PID é dada por:

$$
u(t)=K_{c}\left[e(t)+\frac{1}{T_{i}} \int_{0}^{t} e(t) d t+T_{d} \frac{d e(t)}{d t}\right]
$$


Da equação do controlador PID (2.2) observa-se que quando o sinal de erro for muito grande a saída $u(t)$ do controlador também será podendo ocasionar uma saturação dos atuadores, fonte de potência ou do próprio processo. Este sinal demasiado pode provocar um retardo para que a saída alcance o valor desejado da referência, mantendo o sinal do erro ainda positivo, e aumentando a ação de controle, devido ao efeito da integração do controlador PID. Quando a saída atingir o valor desejado, a inversão de sinal do erro $e(t)$ poderá demorar a ter efeito sobre a ação de controle $u(t)$ devido ao grande valor alcançado pelo termo integral. Este efeito é denominado reset-windup.

Para evitar este fenômeno utiliza-se um esquema denominado anti-reset-windup que pode ser implementado de diversas maneiras, entre as quais as sugeridas por ISERMANN (1989) :

- Cancelamento da integração: neste caso faz-se, $\Delta u_{I}(k)=0$ quando $u(k) \geq u_{\max }$

- Integração condicional: aqui faz-se, $\Delta u_{I}(k)=0$ se $|e(k)| \geq e_{\max }$

onde $u_{I}(k)$ é a contribuição da ação de controle integral na saída do controlador PID discreto.

No segundo caso o valor de $e_{\max }$ pode ser determinado por experimentos ou simulação a partir da função de transferência do processo.

\subsection{Filtragem (atraso) no termo derivativo}

A aplicação de um filtro no termo de ação derivativa é necessária para atenuar o ganho de malha em altas frequiências que pode levar o sistema à instabilidade, devido ao ganho crescente que a ação derivativa introduz nesta região de freqüência. Este atraso (polo) permite ainda que a função de transferência do controlador PID seja realizável.

Da função de transferência do controlador PD observamos que este é um controlador de avanço de fase com polo localizado no infinito. Da sua resposta em freqüência temos que sua característica é somar ângulo de fase positivo a resposta em frequiência do sistema como também melhorar a estabilidade, aumentar a largura de banda e a velocidade de resposta, sendo que seus efeitos são sentidos em altas freqüências. Desta forma quando o controlador PID estiver na malha de controle o ganho do controlador continua a aumentar indefinidamente conforme a freqüência aumenta (pelo menos analiticamente). Assim o 
ganho de malha (controlador mais processo) se aproximará do infinito para altas frequiências o que poderá levar o sistema para a instabilidade ou prejudicar o desempenho do sistema pela amplificação de ruídos que causam variação na saída do controlador, sendo este efeito denominado quick derivate. Para evitar este problema, um polo (pelo menos) deve ser adicionado ao termo derivativo resultando na seguinte função de transferencia para este termo:

$$
D=\frac{K_{c} T_{d} s}{1+\frac{T_{d}}{N} s}
$$

com o valor de $N$ situado entre $3 \leq N \leq 20$ e usualmente utiliza-se $N=10$, sem perda de generalidade. Com isto o ganho em baixas freqüências é praticamente mantido mas em altas freqüências é limitado a $K_{C} N$.

\subsection{Ponderação da referência no termo proporcional}

A principal modificação aplicada à ação PID de controle que traz resultados significativos é a ponderação do sinal de referência na ação proporcional de controle.

Esta modificação na ação de controle PID é proposta por HANG;ASTROM;HO (1991), mostrando-se ser uma prática de relevante aplicação nos sistemas de controle. Neste caso o controlador PID é implementado como :

$$
\begin{aligned}
& u_{c}(t)=K_{c}\left(e(t)+\frac{1}{T_{i}} \int e(t) d t-T_{d} \frac{d y_{f}(t)}{d t}\right) \\
& e(t)=y_{r}-y(t) \quad y_{f}(t)=L\left[\frac{1}{1+\frac{s T_{d}}{N}}\right]^{-1} y(t)
\end{aligned}
$$

onde $y_{r}$ é a referência, $y(t)$ a saída, $\mathrm{L}[]^{-1}$ a transformada inversa de Laplace e $N=10$.

Quando a fórmula de sintonia de ZIEGLER\&NICHOLS (1942) é usada para obtenção dos parâmetros PID muitos sistemas resultam em sobre-sinal excessivo, HANG; ASTROM;HO (1991). Assim a modificação proposta é a introdução de um fator de ponderação $\beta$ sobre a referência desejada no termo proporcional, 


$$
u_{c}(t)=K_{c}\left(\left(\beta y_{r}-y(t)\right)+\frac{1}{T i} \int e(t) d t-T_{d} \frac{d y_{f}(t)}{d t}\right), \quad 0<\beta \leq 1
$$

Esta solução é melhor do que a remoção total da referência no termo proporcional como proposto por alguns autores que pode tornar a resposta do sistema muito lenta, e tem sua eficiência confirmada por um extenso trabalho de simulações, e como pode ser vista pela resposta mostrada na Figura 5.

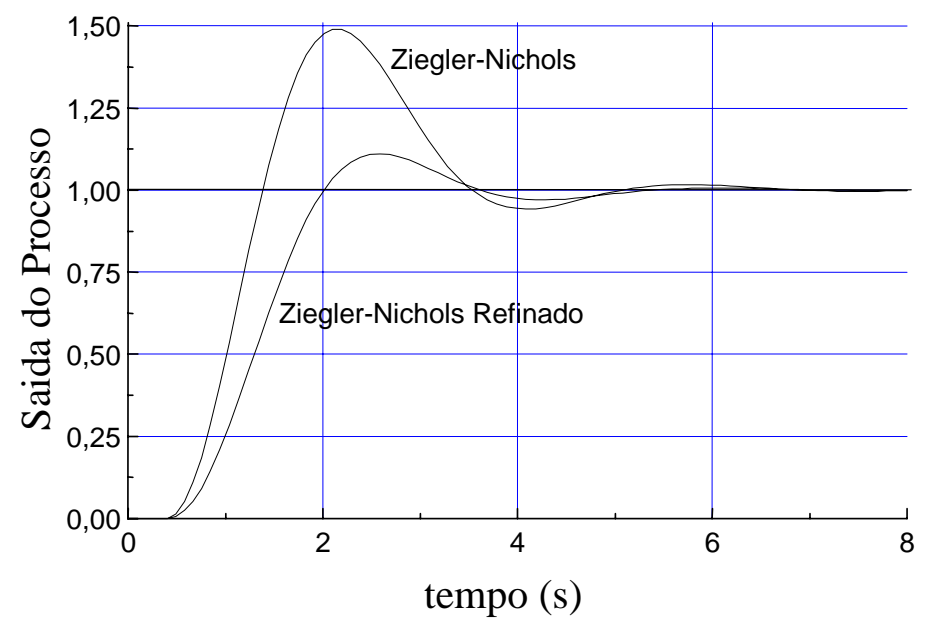

FIGURA 05. Sobre-sinal excessivo na resposta ao degrau para controle PID por Ziegler-Nichols, e redução do mesmo pela aplicação do fator de ponderação $\beta=0.45$ para $e^{-0.4 s} /(1+s)^{2}$.

A introdução do fator de ponderação $\beta$ proporciona um meio de ajustar os zeros da função de transferência de malha fechada que afetam o valor do sobre-sinal na saída do sistema. Os resultados alcançados mostram que a redução do sobre-sinal conseguida é bastante acentuada tornando-se assim uma prática quase obrigatória nos sistemas de controle.

O ganho do processo normalizado é definido como o produto do ganho crítico e do ganho estático do processo (vide Cap. 4). Então,

$$
k=k_{C R} \cdot K_{p}
$$

A porcentagem de sobre-sinal e a porcentagem de sub-sinal estão relacionadas com o ganho normalizado do processo como mostrado na Figura 6. Para valores de $k>4$ o sobresinal é excessivo e para $k<2$ o sub-sinal ultrapassa o sobre-sinal. 


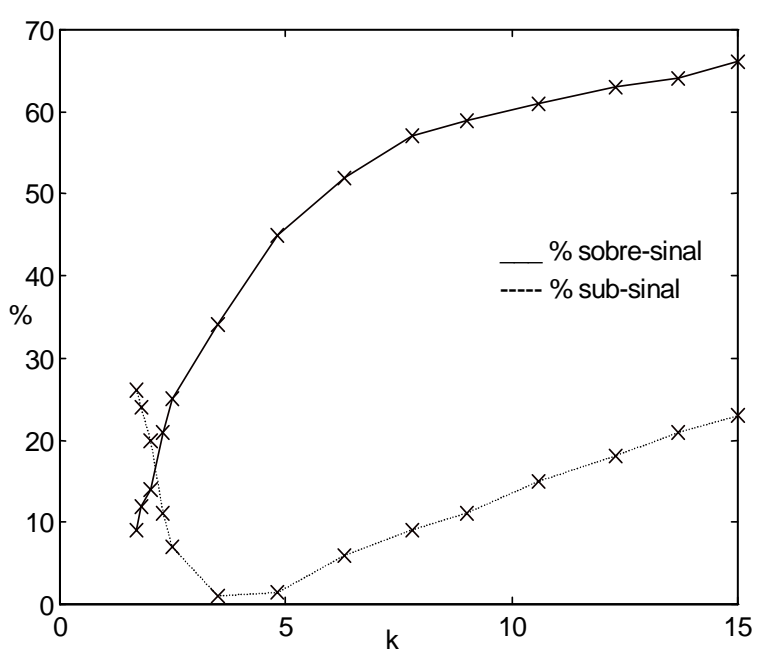

FIGURA 06. Porcentagem de sobre-sinal e sub-sinal para controle PID por Ziegler-Nichols.

Esta relação entre sobre-sinal e sub-sinal com o ganho normalizado sugere que a formula de sintonia de Ziegler-Nichols pode ser refinada em termos deste ganho normalizado. Baseado em observações empíricas o seguinte critério heurístico para refinar a fórmula de sintonia PID de Ziegler-Nichols é recomendado: quando $k>2.25$ manter as fórmulas de Ziegler-Nichols e aplicar o fator $\beta$ de ponderação no termo proporcional; quando $k<2.25$ modificar as fórmulas de Ziegler-Nichols por uma conveniente redução do tempo integral para melhorar a resposta ao degrau. Os valores do fator $\beta$ são determinados como mostrado abaixo.

\section{Ganho do processo normalizado elevado $(2.25<k<15)$}

Dependendo da aplicação $10 \%$ ou $20 \%$ de sobre-sinal são admissíveis sobre a variável de processo. Um extenso trabalho de simulação mostra que a relação entre o sobre-sinal e o ganho do processo normalizado para a faixa $2.25<k<15$ é a apresentada na Figura 7. Os valores fornecidos pelas expressões (2.7) e (2.8) estão plotados em linha sólida. 


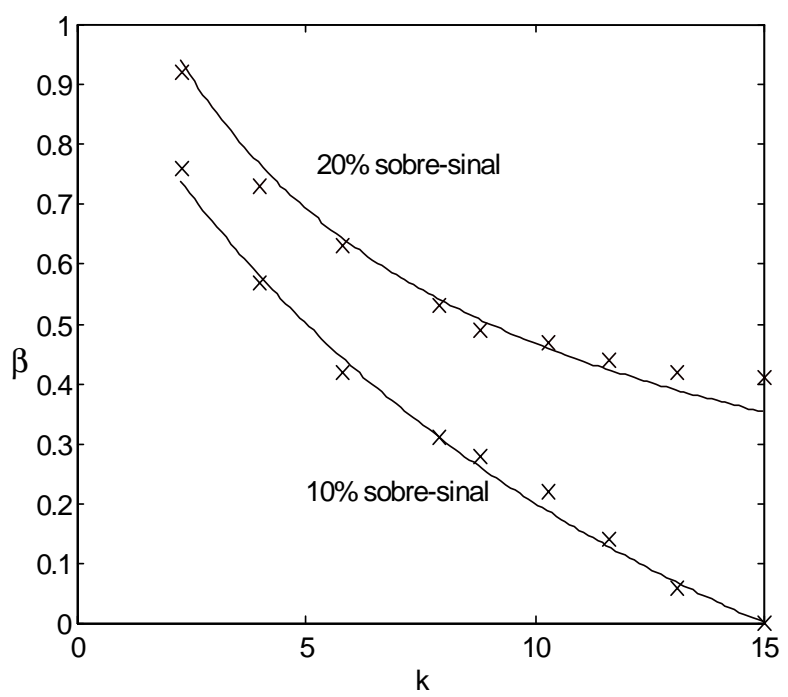

FIGURA 07. Fator de ponderação para controle PID.

As expressões empíricas para o fator de ponderação são então dadas por,

$$
\begin{aligned}
& \beta=\frac{15-k}{15+k} \\
& \beta=\frac{36}{27+5 \cdot k}
\end{aligned}
$$

para $10 \%$ e $20 \%$ de sobre-sinal, respectivamente.

Ganho do processo normalizado pequeno $(1.5<k<2.25)$

Como visto na Figura 6 para a faixa $1.5<k<2.25$ o sub-sinal é elevado e as simulações mostraram que um conveniente tempo integral pode ser determinado sem mudanças no ganho proporcional e tempo derivativo para reduzir o sub-sinal. Esta melhora é, no entanto, acompanhada de um aumento no sobre-sinal e então a ponderação do sinal de referência fazse necessária.

As expressões empíricas para a ponderação do sinal de referência no termo proporcional são apresentadas nas equações (2.9).

$$
\begin{aligned}
\mu & =\frac{4}{9} k \\
\boldsymbol{T}_{i} & =0,5 \cdot \mu \cdot t_{C R}
\end{aligned}
$$




$$
\beta=\frac{8}{17}\left(\frac{4}{9} k+1\right)
$$

para $20 \%$ de sobre-sinal.

O novo tempo integral é dado por (2.9b) onde $\mu$ é definido como a taxa de modificação do tempo integral para o método de Ziegler-Nichols e $t_{C R}$ é o período crítico. A Figura 8 mostra as relações entre $\mu, \beta$ e o ganho do processo normalizado, sendo que para o valor de ponderação foi considerado um sobre-sinal de $20 \%$.
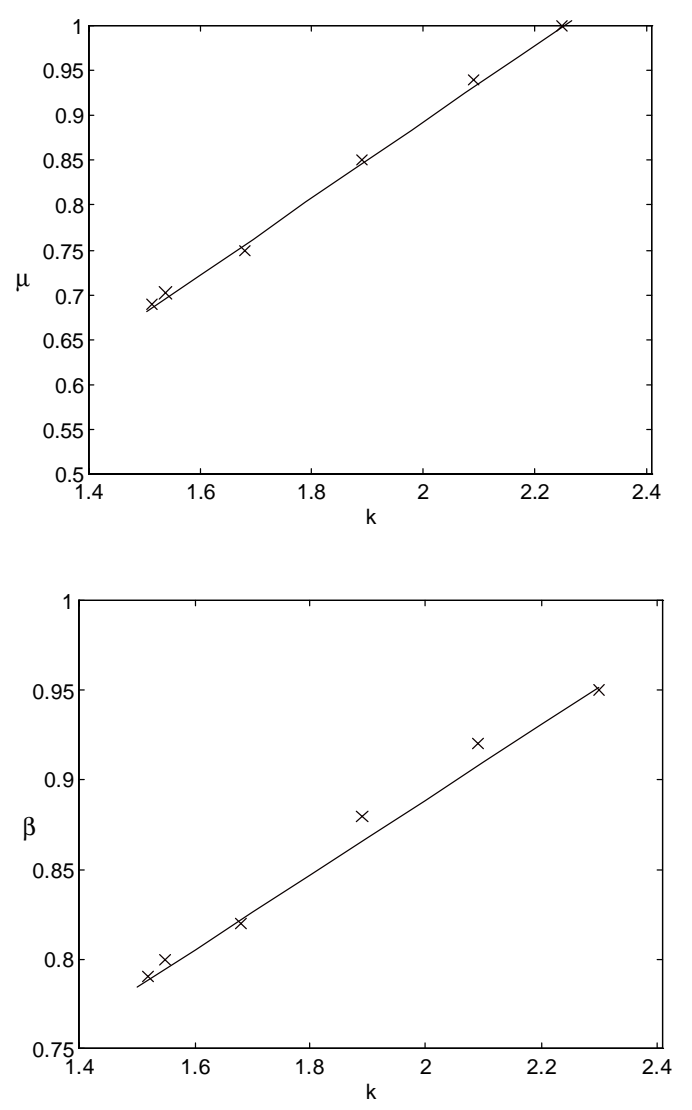

FIGURA 08. Fator de ponderação e taxa de modificação do tempo integral para controle PID.

As linha sólidas na Figura 8 correspondem aos valores fornecidos pelas equações (2.9).

\subsection{Implementação Digital}

\section{Discretização}


Para implementação da lei de controle contínua do controlador PID na forma digital é necessário adotar aproximações para os termos integral e derivativo e alguns métodos bastante conhecidos serão apresentados. As formas digitais dos termos proporcional, integral e derivativo são então apresentadas abaixo.

\section{Ação proporcional}

O termo proporcional é implementado simplesmente trocando-se as variáveis contínuas pelas amostradas, desde que trata-se de um termo puramente estático. Então,

$$
P(k)=K_{\mathrm{c}}[\beta r(k)-y(k)]
$$

\section{Ação integral}

O termo integral é dado por

$$
I(t)=\frac{K_{c}}{T_{i}} \int_{0}^{t} e(s) d s
$$

E podemos re-escrever,

$$
\frac{d I}{d t}=\frac{K_{c}}{T_{i}} e
$$

Aproximando o termo derivativo por uma diferença,

$$
\frac{I(k+1)-I(k)}{t_{S}}=\frac{K_{c}}{T_{i}} e(k)
$$

que dá a seguinte equação recursiva para o termo integral

$$
I(k+1)=I(k)+\frac{K_{c} t_{S}}{T_{i}} e(k)
$$

\section{Ação derivativa}


Como apresentado em ASTROM \& HAGGLUND (1995) o termo derivativo como dado em (2.3) pode ser re-arranjado para

$$
\frac{T_{d}}{N} \frac{d D}{d t}+D=-K_{c} T_{d} \frac{d y}{d t}
$$

Há muitas maneiras de discretizar esta igualdade como as apresentadas a seguir.

Diferença posterior. Por esta aproximação temos

$$
\frac{T_{d}}{N} \frac{D(k+1)-D(k)}{t_{S}}+D(k)=-K_{c} T_{d} \frac{y(k+1)-y(k)}{t_{S}}
$$

a qual re-escrevendo dá

$$
D(k+1)=\left(1-\frac{t_{S} N}{T_{d}}\right) D(k)-K_{c} N[y(k+1)-y(k)]
$$

Diferença anterior. Com esta aproximação temos

$$
\frac{T_{d}}{N} \frac{D(k)-D(k-1)}{t_{S}}+D(k)=-K_{c} T_{d} \frac{y(k)-y(k-1)}{t_{S}}
$$

Re-escrevendo chega-se a

$$
D(k)=\frac{T_{d}}{T_{d}+N t_{S}} D(k-1)-\frac{K c T_{d} N}{T_{d}+N t_{S}}[y(k)-y(k-1)]
$$

Aproximação de Tustin. A aproximação proposta por Tustin é

$$
D(k)=\frac{2 T_{d}-t_{S} N}{2 T_{d}+t_{S} N} D(k-1)-\frac{2 K_{c} T_{d} N}{2 T_{d}+t_{S} N}[y(k)-y(k-1)]
$$


Observe que todas as aproximações têm a mesma forma, isto é,

$$
D(k)=a_{i} D(k-1)+b_{i}[y(k)-y(k-1)]
$$

que diferem nos valores dos coeficientes $a_{i}$ e $b_{i}$.

As aproximações do termo derivativo discretizado são estáveis apenas quando $\left|a_{i}\right|<$ 1. Na aproximação (2.17) para valores pequenos de $T_{d}$ teremos instabilidade, pois ela requer $T_{d}>N t_{S} / 2$. As aproximações de Tustin e por diferença posterior resultarão em valores negativos para $a_{i}$ se $T_{d}$ for pequeno e a aproximação exibirá ringing. Assim apenas a aproximação por diferença anterior dará bons resultados para quaisquer valores de $T_{d}$.

Caso um gráfico de fase das aproximações apresentadas acima e da equação (2.3) seja plotado veremos que a aproximação que mais assemelha-se ao caso contínuo é a aproximação de Tustin.

\section{Forma incremental}

O algoritmo PID até agora descrito é denominado algoritmo posicional porque obtém-se a saída do controlador diretamente. Em certos casos é mais desejada uma forma incremental da saída. Nesta forma apenas uma mudança $\Delta u(k)$ da saída é calculada em cada instante de amostragem e somada a saída anterior, $u(k-1)$, e neste caso o algoritmo é denominado algoritmo de velocidade.

$$
\Delta u(k)=u(k)-u(k-1)=\Delta P(k)+\Delta I(k)+\Delta D(k)
$$

O incremento das partes proporcional e integral são obtidos de (2.10) e (2.14) e resultam,

$$
\begin{gathered}
\Delta P(k)=P(k)-P(k-1)=\mathrm{K}_{c}[\beta r(k)-y(k)-\beta r(k-1)+y(k-1)] \\
\Delta I(k)=I(k)-I(k-1)=\frac{K_{c} t_{S}}{T_{i}} e(k-1)
\end{gathered}
$$

Para o termo derivativo tomando-se a equação geral (2.18) temos,

$$
\Delta D(k)=D(k)-D(k-1) \frac{b_{i}}{1-a_{i}}[y(k)-2 y(k-1)+y(k-2)]
$$




\section{Sintonia de Controladores PID}

O principal problema com os controladores PID na indústria é a sintonia adequada dos seus parâmetros, necessária para produzir respostas suficientemente rápidas porém sem sobresinal. Inicialmente esta sintonia era feita manualmente utilizando-se gráficos como proposto por Ziegler-Nichols, o que produz variação de valores de operador para operador, em seguida os valores conseguidos eram introduzidos nos aparelhos e feita um acerto final por tentativa e erro. Outra maneira muito utilizada era ligar o aparelho em modo manual de controle sem nenhum parâmetro inserido e ir ajustando cada parâmetro a medida que a saída do processo fosse aproximando-se da referência desejada. No entanto este método é demorado e não é simples de ser realizado pois depende muito da experiência e conhecimento do operador, chegando-se ao ponto de apenas certos operadores mais experientes conseguirem realizar uma boa sintonia e mesmo assim sintonias feitas por operadores diferentes resultam em valores diferentes para os parâmetros do controlador para o mesmo processo. Vários métodos então são disponíveis para se conseguir sintonizar os parâmetros operando-se diretamente o aparelho e em ISA (1989) pode ser encontrado exemplos de alguns deles.

Assim mostra-se muito útil a utilização de métodos de sintonia automática dos parâmetros de controladores, pois esta será feita em um tempo muito menor que a manual e com uma repetibilidade dos parâmetros garantida.

Nos últimos anos, várias técnicas de auto-sintonia para reguladores clássicos e simples como os PID's, têm sido apresentadas na literatura especializada. Este grande esforço é motivado por duas razões principais: primeiro, um regulador simples é rápido, fácil de implementar e, usualmente, fácil de sintonizar; segundo, este regulador clássico é bem conhecido e aceito no ambiente industrial, LEVA (1993). Como resultado temos que estes trabalhos têm encontrado aplicação industrial imediata.

Para a auto-sintonia dos parâmetros de controladores (em sua maioria do tipo PID) vários autores propõem métodos distintos e que requerem informações variadas sobre características de projeto, como margem de ganho e fase, e sobre os parâmetros da planta a ser controlada. As informações utilizadas por cada método são variadas: conhecimento preciso de estrutura da planta, característica da resposta ao degrau unitário de malha aberta, conhecimento de pontos da curva de Nyquist, constante de tempo da malha fechada e outros. Estes métodos derivam leis de sintonia simples para reguladores PID e muitos auto- 
sintonizadores comerciais baseados nestes métodos de sintonia têm estado disponíveis desde 1981.

Em NISHIKAWA et al. (1984), o conceito de áreas características da malha fechada é utilizado para identificação de processos de primeira ordem mais tempo morto, e os parâmetros PID ótimos são obtidos com o critério integral ISE, sendo resolvido com o uso do determinante de Hurwitz. Em LEVA (1993) um procedimento de sintonia baseado no método de realimentação a relê com a inclusão de dinâmicas de primeira ordem (filtros) na entrada e saída do processo é usado na obtenção do controlador PID, com estas dinâmicas extras a duração da auto-sintonia é bastante prolongada. WANG; BARNES; CLUETT (1995) obtêm um controlador PID a partir de dois pontos da resposta em frequiência em malha fechada do processo e da resposta desejada para o sinal de controle através de uma função de ponderação complexa para o sinal de controle aplicado. Com VODA \& LANDAU (1995) a auto-sintonia dos controladores PID é feita combinando-se o experimento a relê com regras de sintonia baseadas no princípio da simetria ótima de KRESSLER (1958), no entanto o tempo de acomodação alcançado é o mais conservador de todos os métodos analisados. Em KHAN \& LEHMAN (1996) é apresentado um método de auto-sintonia que seleciona os ganhos de um controlador PI, que utiliza cancelamento polozero, a partir da análise do feito do controle proporcional sobre o sobre-sinal e tempo de subida; este método resulta em um bom tempo de subida para tempos de atraso menores ou iguais a 10 segundos ( $\mathrm{L} \leq 10 \mathrm{~s}$.). Com POULIN et al. (1996) a sintonia automática é baseada na minimização do critério ITAE aproximada para controladores PI , a ausência de sobresinal é alcançada a custa de um tempo de acomodação muito elevado. FUNG; WANG; LEE (1998) apresentam um método gráfico para obter a sintonia de controladores PI a partir das especificações de margem de ganho e fase que são desdobradas em duas funções complexas. O ponto de interseção destas duas funções fornecem os parâmetros procurados. Embora o método forneça bons resultados ele não é prático de implementar. Em SUNG; LEE; LEE (1998), é utilizado um procedimento de identificação dos parâmetros do processo que envolve o calculo de derivadas de alta ordem e os parâmetros do controlador PID são obtidos com o método IMC (controle por modelo interno). O esforço computacional do procedimento de estimação do modelo do processo inviabiliza sua implementação em microcontroladores de baixo custo.

Todos os métodos anteriores são contínuos no tempo e para a realização do controlador um método de discretização deve ser adotado. Outra possibilidade é utilizar um modelo de processo discreto e sintonizar um controlador discreto no tempo diretamente. 
Com a escolha de um modelo de processo e um controlador discretos, o problema de encontrar um método de discretização apropriado de um controlador continuo no tempo é evitado. A estrutura discreta do controlador permite também a compensação de tempos mortos elevados de forma mais direta através de técnicas de predição, ISERMANN (1989).

Cinco métodos contínuos no tempo foram selecionados e serão apresentados: o método proposto por ASTROM \& HAGGLUND (1984) que consiste na presença de elementos não lineares (um relê) na função de transferência de malha para provocar a sintonia dos parâmetros desejados; o método proposto por HO; HANG; CAO (1995) que utiliza um procedimento analítico para desenvolver a sintonia dos parâmetros de um controlador PI; o método de LORON (1997) que é elaborado para sintonia de controladores PI e PID e apresenta uma resposta comparável aos demais (mas com a presença de sobresinal) e que baseia-se num desenvolvimento analítico também; o método apresentado por FRIMAN (1997) também realiza a sintonia para controladores PI, com um controlador PI inicial atuando durante o procedimento de auto-sintonia, e o método apresentado por ZHUANG \& ATHERTON (1993) que obtém os parâmetros do controlador a partir do experimento a relê e otimização de um critério de desempenho.

\subsection{Sintonia Automática pelo Método de Astrom-Hagglund}

O diagrama em blocos do sistema de controle com auto-sintonia é o mostrado na Figura 9. O método de Astrom-Hagglund baseia-se na idéia de Ziegler-Nichols que observaram que os parâmetros de um controlador podem ser determinados pelo conhecimento de um ponto da curva de Nyquist do sistema a malha aberta. Este ponto, a intersecção da curva de Nyquist com o eixo real negativo, é dado em termos do ganho crítico, $k_{C R}$, e do período crítico, $t_{C R}$.

Ziegler-Nichols obtiveram $k_{C R}$ e $t_{C R}$ como segue: um controlador proporcional é colocado no sistema e seu ganho é aumentado gradualmente até conseguir-se uma oscilação periódica e de amplitude constante. Quando este ponto é atingido o ganho utilizado é o ganho crítico e o período da oscilação é o período crítico. 


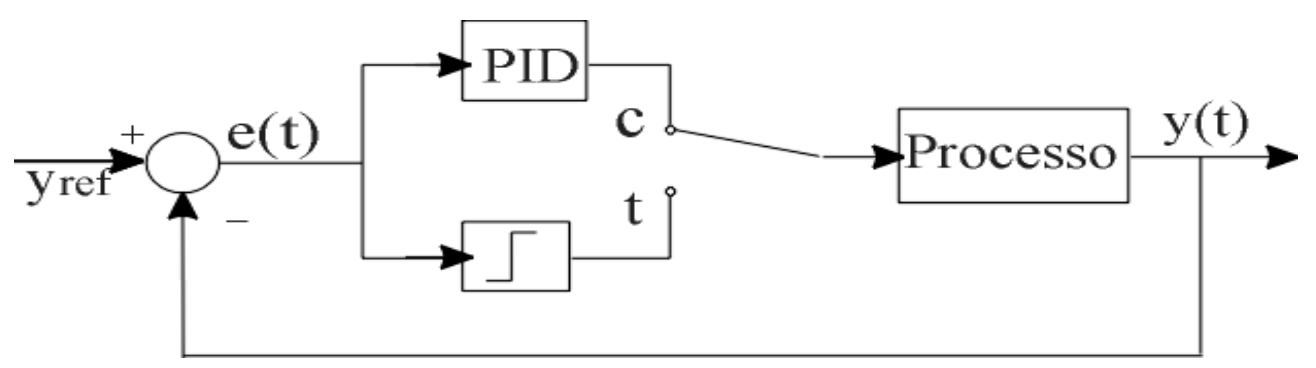

FIGURA 09. Diagrama em bloco da auto-sintonia. O sistema opera com um controlador a relê no modo sintonia (t) e como controlador PID no modo (c).

No método baseado no controle a relê observa-se que o sistema com um atraso de fase de pelo menos $\pi \mathrm{em}$ altas freqüências pode oscilar com período $t_{C R}$. O sinal de erro é então um sinal periódico com período $t_{C R}$ e se $d$ é a amplitude do relê, da expansão em série de Fourier tem-se que o primeiro harmônico da saída do relê tem amplitude $4 d / \pi$. Com a amplitude da saída do processo sendo $a_{2}$ o ganho crítico é dado por

$$
k_{C R}=\frac{4 d}{\pi \mathrm{a}}
$$

Assim obtêm-se uma maneira automatizada de calcular o ganho e o período críticos; os valores da frequiência e da amplitude de oscilação podem ser facilmente determinado pela contagem de tempo entre passagens por zero e pela medida de valores pico a pico da saída.

Pode-se então agora obter os parâmetros de um controlador satisfazendo-se algum critério de desempenho em função destes valores de $k_{C R}$ e $t_{C R}$.

\section{Sintonia pela especificação da margem de ganho}

Quando o ponto crítico é conhecido é imediata a escolha de um controlador que apresente a margem de ganho, $A_{m}$, desejada; uma maneira simples é escolher um controlador proporcional com ganho dado por

$$
K_{C}=\frac{k_{C R}}{A_{m}}
$$

Considerando a resposta em frequiência de um controlador PID dada por 


$$
G_{p i d}(j w)=K_{C}\left(1+\frac{1}{j w T_{i}}\left(1-w^{2} T_{i} T_{d}\right)\right)
$$

com o ganho dado por (3.2) e com a relação entre $T_{d}$ e $T_{i}$ sendo tomada como

$$
T_{d}=\frac{1}{w_{C R}^{2} T_{i}}
$$

ter-se-á também a margem de ganho desejada. O tempo integral pode ser escolhido arbitrariamente e o tempo derivativo será dado por (3.4). As equações para sintonia dos parâmetros são dadas então por (3.2) e (3.4).

\section{Sintonia pela especificação da margem de fase}

A partir de um ponto da curva de Nyquist do sistema em malha aberta conhecido, com controladores PI, PD ou PID é possível mover este ponto da curva de Nyquist para uma posição arbitrária do plano complexo como indicado na Figura 10.

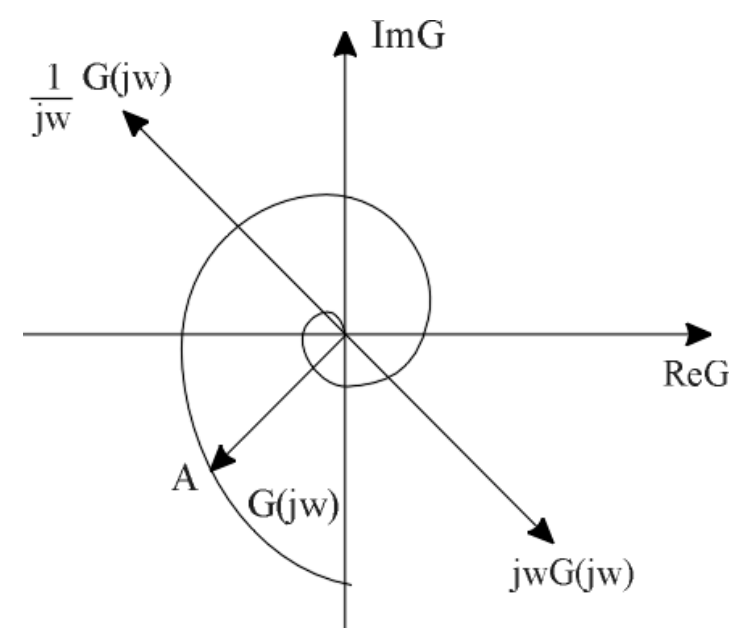

FIGURA 10. O ponto dado pode ser movido para uma posição arbitrária no plano- $G$ pelos controladores PI, PD ou PID. O ponto $\underline{\mathrm{A}}$ pode ser movido nas direções $G(j w), G(j w) / j w$ e $j w G(j w)$ pela variação dos ganhos proporcional, integral e derivativo, respectivamente.

O ponto $A$ pode ser movido na direção de $G(j w)$ pela mudança do ganho proporcional e nas direções ortogonais pela mudança dos ganhos integral e derivativo. Então valores de margem de fase preestabelecidos são conseguidos movendo-se $\underline{A}$ para um ponto do círculo unitário. 
A função de transferência de malha com controlador PID é

$$
K_{C}\left(1+s T_{d}+\frac{1}{s T_{i}}\right) G(s)
$$

Assumimos que o ponto de cruzamento da curva de Nyquist de $G(s)$ com o eixo real negativo é conhecido e é dado por $w=w_{C R}$; temos então que

$$
\underline{G_{p i d}\left(i w_{C R}\right) G\left(i w_{C R}\right)}=\phi_{m}-\pi
$$

que fornece a relação

$$
w_{C R} T_{d}-\frac{1}{w_{C R} T_{i}}=\tan \phi_{m}
$$

Existem muitos $T_{d}$ 's e $T_{i}$ 's que satisfazem esta relação. Uma possibilidade de escolha para $T_{d}$ e $T_{i}$ é

$$
T_{i}=\alpha T_{d}
$$

Substituindo (3.7) em (3.6) e resolvendo para $T_{d}$ obtêm-se

$$
T_{d}=\frac{\tan \phi_{m}+\sqrt{\frac{4}{\alpha}+\tan ^{2} \phi_{m}}}{2 w_{C R}}
$$

A função de transferência de malha terá ganho unitário em $w_{C R}$ se o ganho do controlador for escolhido como

$$
K_{C}=\frac{\cos \phi_{m}}{\left|G\left(i w_{C R}\right)\right|}=k_{C R} \cos \phi_{m}
$$

As equações para sintonia dos parâmetros são dadas então por (3.7), (3.8) e (3.9). 


\subsection{Sintonia pelo Método de W. Khuen Ho, C. Chieh Hang, L. S. Cao}

Normalmente a solução para o projeto de controladores satisfazendo critérios de margem de fase e ganho são obtidas por métodos numéricos ou graficamente por tentativa e erro usando o diagrama de Bode. Estas aproximações certamente não são convenientes para uso em controle adaptativo e auto-sintonia.

Neste método propõe-se algumas aproximações, que são apresentadas no desenvolvimento das equações, de forma que nem métodos numéricos nem métodos gráficos têm de ser usados. Bastante precisa as fórmulas analíticas são obtidas para sintonia e projeto de controladores PI e PID com as desejadas especificações de margem de fase e ganho para processos de primeira e segunda ordens mais tempo morto. As fórmulas são particularmente usuais no contexto de controle adaptativo e auto-sintonia, onde os parâmetros do controlador têm de ser calculados em tempo real. É mostrado também que os métodos por especificação de margem de fase e ganho podem dar combinações dos valores de margem de ganho e fase que não são convenientes.

\section{Fórmula para sintonia PI}

Com as funções de transferência do processo e do controlador dadas por $G_{p}(s)$ e $G_{c}(s)$ e as especificações de margem de ganho e fase por $A_{m}$ e $\phi_{m}$, respectivamente, das definições de margem de ganho e fase, o seguinte conjunto de equações são obtidos,

$$
\begin{aligned}
& \arg \left[G_{c}\left(j w_{p}\right) G_{p}\left(j w_{p}\right)\right]=-\pi \\
& A_{m}=\frac{1}{\left|G_{c}\left(j w_{p}\right) G_{p}\left(j w_{p}\right)\right|} \\
& \left|G_{c}\left(j w_{g}\right) G_{p}\left(j w_{g}\right)\right|=1 \\
& \phi_{m}=\arg \left[G_{c}\left(j w_{g}\right) G_{p}\left(j w_{g}\right)\right]+\pi
\end{aligned}
$$

onde a margem de ganho é dada por (3.10) e (3.11) e a margem de fase por (3.12) e (3.13). A freqüência $w_{p}$, na qual a curva de Nyquist da planta tem fase $-\pi$, é conhecida como 
freqüência de cruzamento de fase e a frequiência $w_{g}$, onde a curva de Nyquist tem amplitude 1, como freqüência de cruzamento de ganho.

O controlador PI é dado por

$$
G_{C}(s)=K_{C}\left(1+\frac{1}{s T_{i}}\right)
$$

e o processo por

$$
G_{P}(s)=\frac{K_{P}}{1+T . s} e^{-s L}
$$

Das equações (3.14) e (3.15) a função de transferência de malha é

$$
G_{C}(s) G_{P}(s)=\frac{K_{C} K_{P}\left(1+s T_{i}\right)}{s T_{i}(1+T . s)} e^{-s L}
$$

Substituindo a equação (3.16) nas equações de (3.10) a (3.13) obtém-se

$$
\begin{aligned}
& \frac{1}{2} \pi+\arctan \left(w_{p} T_{i}\right)-\arctan \left(w_{p} T\right)-w_{p} L=0 \\
& \mathrm{~A}_{\mathrm{m}} \mathrm{K}_{\mathrm{C}} \mathrm{K}_{\mathrm{P}}=w_{p} T i \sqrt{\frac{w_{p}^{2} T^{2}+1}{w_{p}^{2} T_{i}^{2}+1}} \\
& K_{C} K_{P}=w_{g} T_{i} \sqrt{\frac{w_{g}^{2} T^{2}+1}{w_{g}^{2} T_{i}^{2}+1}} \\
& \phi_{m}=\frac{1}{2} \pi+\arctan \left(w_{g} T_{i}\right)-\arctan \left(w_{g} T\right)-w_{g} L
\end{aligned}
$$

Para um dado processo $\left(K_{p}, T, L\right)$ e especificações $\left(A_{m}, \phi_{m}\right)$, as equações (3.17) a (3.20) podem ser resolvidas para os parâmetros do controlador PI $\left(K_{c}, T i\right)$ e as frequiências de cruzamento $\left(w_{p}, w_{g}\right)$ numericamente mas não analiticamente devido a presença da função arco-tangente. Entretanto uma solução analítica aproximada pode ser obtida se a seguinte aproximação da função arco-tangente for usada: 


$$
\arctan x \approx\left\{\begin{array}{cc}
\frac{1}{4} \pi x & |x| \leq 1 \\
\frac{1}{2} \pi-\frac{\pi}{4 x} & |x|>1
\end{array}\right.
$$

como mostrado na Figura 11. A identidade

$$
\arctan x=\frac{1}{2} \pi-\arctan \frac{1}{x} \quad|x|>1
$$

é usada na expressão (3.18) quando $|x|>1$.

A solução numérica das equações (3.17) a (3.20) mostram que para $L / T>0,3, T i \approx T$ e para $L / T<0,3, x>>1$, onde $x$ é cada um dos argumentos $w_{p} T_{i}, w_{p} T, w_{g} T_{i}$ e $w_{g} T$. A aproximação dada por (3.21) para o caso $|x|>1$ é melhor que o caso $|x|<1$. Isto ajuda a aproximar (3.18) e (3.19) como

$$
\begin{aligned}
& A_{m} K_{C} K_{P}=w_{p} T \\
& K_{C} K_{P}=w_{g} T
\end{aligned}
$$

respectivamente.

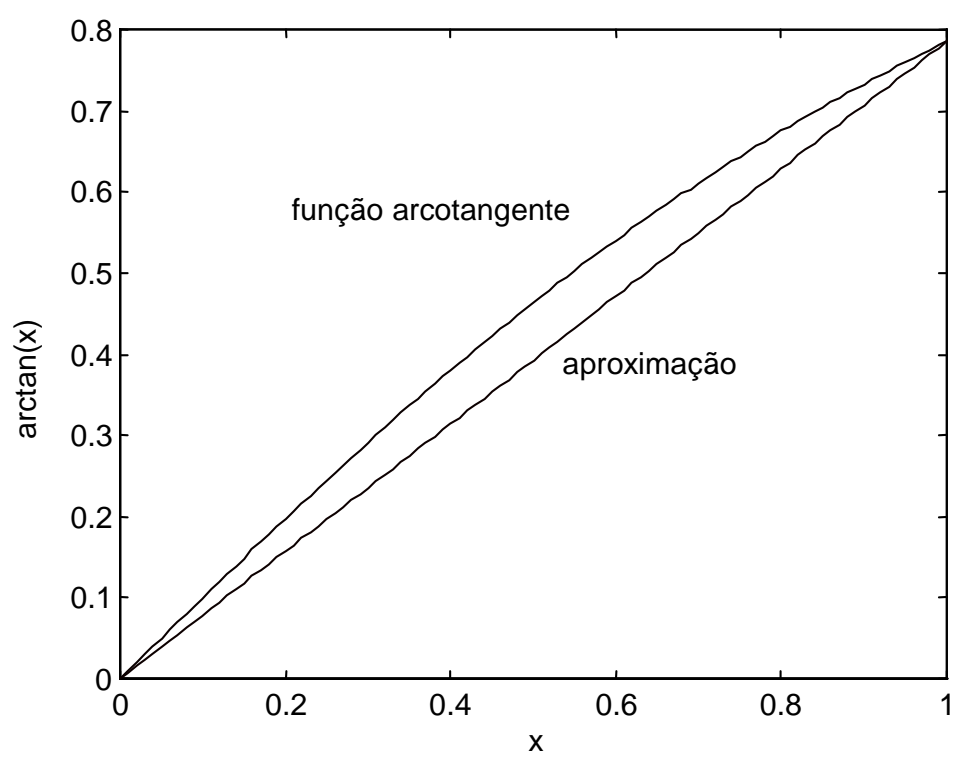

FIGURA 11. Aproximação da função arco-tangente. 
A quantidade $L / T$ é definida como tempo morto normalizado. Usando a aproximação em (3.21) para a função arco-tangente as equações (3.17) e (3.20) são aproximadas como

$$
\begin{aligned}
& \frac{1}{2} \pi-\frac{\pi}{4 w_{p} T_{i}}+\frac{\pi}{4 w_{p} T}-w_{p} L=0 \\
& \phi_{m}=\frac{1}{2} \pi-\frac{\pi}{4 w_{g} T_{i}}+\frac{\pi}{4 w_{g} T}-w_{g} L
\end{aligned}
$$

respectivamente.

Finalmente resolvendo para $K_{C}$ e $T_{i}$ as equações (3.23) a (3.26) tem-se

$$
\begin{gathered}
K_{C}=\frac{w_{p} T}{A_{m} K_{p}} \\
T_{i}=\left(2 w_{p}-\frac{4 w_{p}^{2} L}{\pi}+\frac{1}{T}\right)^{-1} \\
\text { onde } w_{p}=\frac{A_{m} \phi_{m}+\frac{1}{2} \pi A_{m}\left(A_{m}-1\right)}{\left(A_{m}{ }^{2}-1\right) L}
\end{gathered}
$$

Portanto as equações de sintonia dos parâmetros do controlador PI são (3.27) e (3.28).

Na escolha dos pares $\left(A_{m}, \phi_{m}\right)$ há algumas restrições. Uma usual é que os parâmetros do controlador obtido sejam positivos, $K c>0$ e $T i>0$. Da equação (3.27) esta restrição leva a fronteira $\mathrm{AB}$ na Figura 12. Esta fronteira é função de $L / T$ e na Figura 12 é mostrado o caso $L / T=0,5$. A solução numérica mostra que a equação (3.27) torna-se menos precisa fora da região $\mathrm{CD}$. Portanto as especificações válidas dos pares $\left(A_{m}, \phi_{m}\right)$ para a auto-sintonia dos parâmetros é dada pela região hachuriada da Figura 12, sendo que ela mantêm-se satisfatoriamente para $L / T \leq 1$. Uma regra geral é utilizar $A_{m}=4$ e $\phi_{m}=60^{\circ}$. 


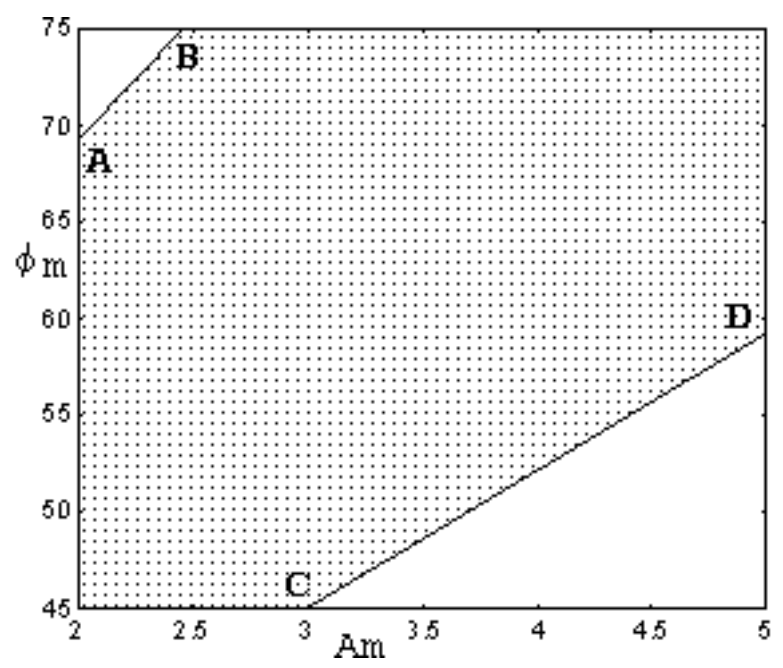

FIGURA 12. Região de especificação para margem de fase e ganho

\section{Fórmula para sintonia PID}

É sugerido por ASTROM \& HAGGLUND (1995) que o controlador de ação PI é suficiente quando a dinâmica do processo é essencialmente de primeira ordem. Este método também mostra que para processos de primeira ordem mais tempo morto, os desempenhos de controladores PI e PID são aproximadamente os mesmos. Assim a fórmula de sintonia para controladores PID será desenvolvida para processos de segunda ordem mais tempo morto.

O controlador PID é dado por

$$
G_{C}(s)=\frac{K_{C}\left(1+s T_{i}\right)\left(1+s T_{d}\right)}{s T_{i}}
$$

e o processo por

$$
G_{P}(s)=\frac{K_{P}}{(1+s T)\left(1+s T^{\prime}\right)} e^{-s L}, \mathrm{~T} \geq T^{\prime}
$$

Destas equações a função de transferência de malha é

$$
G_{m a}(s)=\frac{K_{C} K_{P}\left(1+s T_{i}\right)\left(1+s T_{d}\right)}{s T_{i}(1+s T)\left(1+s T^{\prime}\right)} e^{-s L}
$$


Para simplificar a equação (3.31), escolhe-se $T d=T^{\prime}$ para cancelar o menor pólo do processo. Então a equação (3.31) fica

$$
G_{m a}(s)=\frac{K_{C} K_{P}\left(1+s T_{i}\right)}{s T_{i}(1+s T)} e^{-s L}
$$

Note que a equação (3.32) é idêntica a equação (3.16). Desta maneira as soluções para $K_{c}$ e $T_{i}$ são as dadas pela equação (3.27). A fórmula de sintonia para o controlador com ação PID é então dada por

$$
\begin{gathered}
K_{C}=\frac{w_{p} T}{A_{m} K_{P}} \\
T_{i}=\left(2 w_{p}-\frac{4 w_{p}^{2} L}{\pi}+\frac{1}{T}\right)^{-1}, \quad T_{d}=T^{\prime}
\end{gathered}
$$

onde $w_{p}$ é dado por (3.28). Portanto as equações para sintonia dos parâmetros do controlador PID são (3.28) e (3.33).

\subsection{Sintonia pelo Método Ótimo Não-Simétrico}

O método ótimo não simétrico (NSOM) é uma aproximação analítica para a sintonia de controladores PI baseada no método ótimo simétrico (SOM) de Kessler, KRESSLER (1958). Estes métodos utilizam a especificação do pico ressonante da malha fechada para a otimização do desempenho da malha fechada, para processos integrativos de primeira ordem. Uma aproximação garante a aplicação do método em processos de primeira ordem mais tempo morto. A sintonia resulta em um ganho de malha aberta maximizado, portanto a ação da malha fechada é melhorada e a largura de banda é aumentada. A seguir o método ótimo não-simétrico proposto por LORON (1997) é apresentado.

\section{Modelo da planta}

Tanto o método SOM quanto o método NSOM são baseados em um modelo de processo consistindo de um integrador e um sistema de primeira ordem: 


$$
G_{q}(s)=\frac{K_{q}}{s\left(1+T_{q} s\right)}
$$

Embora este modelo simples seja usado para a sintonia automática do controlador, a função de transferência real do processo pode ter uma estrutura mais complexa, incluindo múltiplas constantes de tempo, zeros e tempos mortos introduzidos, por exemplo, por atuadores e sensores. O modelo real pode então ser determinado analiticamente pela aproximação de um modelo de ordem mais elevada.

Considerando a função de transferência real do processo por $G_{p}(s)$, em geral, tem-se

$$
\begin{gathered}
G_{P}(s)=K_{P} \frac{N(s)}{D(s)} e^{-L s} \\
\operatorname{com} N(s)=\prod_{i}\left(T_{n 1, i} s+1\right) \prod_{i}\left(T_{n 2, i}^{2} s^{2}+2 z_{n, i} T_{n 2, i} s+1\right) \quad \mathrm{e} \\
D(s)=s^{N} \prod_{i}\left(T_{d 1, i} s+1\right) \prod_{i}\left(T_{d 2, i}^{2} s^{2}+2 z_{d, i} T_{d 2, i} s+1\right) .
\end{gathered}
$$

Cada coeficiente $T_{x l, i}$ corresponde a um pólo real ou zero de um sistema de primeira ordem, e cada coeficiente $T_{x 2, i}$ corresponde a um par de pólos complexo conjugado ou zeros de um sistema de segunda ordem sub-amortecido. Ambos os métodos assumem sistema tipo $1(N=1)$. Pode-se aplicar uma aproximação para sistemas tipo zero $(N=0)$ com um pólo real dominante pela aproximação da constante de tempo $T_{o}$ pela integração:

$$
G_{p}(s)=\frac{K_{P}}{1+T_{o} s} \frac{N(s)}{D^{\prime}(s)} e^{-L s} \approx \frac{K_{q}}{s} \frac{N(s)}{D^{\prime}(s)} e^{-L s}
$$

onde $K_{q}$ é a constante de velocidade,

$$
K_{q}=\frac{K_{P}}{T_{o}}
$$

Os demais termos (pólos rápidos, zeros e tempos mortos) podem ser agrupados em uma constante de tempo equivalente pela expansão em série do modelo real: 
$G_{p}^{\prime}(s)=\frac{N(s)}{D^{\prime}(s)} e^{-L s} \approx \frac{1}{\left(T_{q} s+1\right)}$

onde

$T_{q}=\left(\sum_{i} T_{d 1, i}+2 \sum_{i} z_{d, i} T_{d 2, i}\right)-\left(\sum_{i} T_{n 1, i}+2 \sum_{i} z_{n, i} T_{n 2, i}\right)+L$

\section{Método ótimo simétrico}

O método SOM é aplicado ao sistema em malha aberta formado pelo processo integrativo de primeira ordem (1) e controlador PI definido como

$$
G_{p i}(s)=K_{C}\left(1+\frac{1}{T_{i} s}\right)
$$

O método de Kressler pode ser re-escrito com respeito a margem de fase $\phi_{m}$. Então, os parâmetros do controlador PI são obtidos das seguintes equações:

$$
\begin{aligned}
& \rho=\left(\frac{1+\operatorname{sen}\left(\phi_{m}\right)}{\cos \left(\phi_{m}\right)}\right)^{2} \\
& w_{g}=\frac{1}{\sqrt{\rho} T_{q}} \\
& T_{i}=\rho T_{q} \\
& K_{C}=\frac{w_{g}}{K_{q}}
\end{aligned}
$$

onde $w_{g}$ é a freqüência de cruzamento de ganho. 


\section{Otimização do ganho e ponto ótimo de tangência}

Para auxiliar na motivação da necessidade de aumentar-se o ganho de malha aberta vamos observar a Figura 13 onde o método SOM foi aplicado a um sistema com $K_{q}=1 s^{-1}, w_{q}=1$ $\operatorname{rad} s^{-1}$ e $\phi_{m}=50^{\circ}$. O gráfico resultante, como esperado, é simétrico com respeito à frequiência de cruzamento de ganho $\left(w_{g}=0.36 \mathrm{rad} s^{-1}\right)$ e a margem de fase desejada é alcançada. A figura mostra também que o controlador será melhor sintonizado se o avanço de fase máximo ocorrer em um ganho maior. Pelo aumento lento do ganho do controlador, o desempenho dinâmico e a estabilidade da malha fechada são melhorados devido ao aumento da largura de banda do sistema e da freqüência do pico de ressonância. O ganho ótimo é obtido quando o pico de ressonância é mínimo. Próprio da sua forma simétrica, o gráfico de Nichols deve ser tangente ao M-locus no ponto de freqüência $w_{g}$, onde este tem direção vertical.

Portanto, para aplicar o método NSOM a magnitude máxima da malha fechada é usada para determinação da posição $\left(\phi_{g}, M_{g}\right)$ do ponto de tangência, no gráfico de malha aberta (onde $\phi_{g}=\phi\left(w_{g}\right)$ e $M_{g}=M\left(w_{g}\right)$ ). Então o método SOM é aplicado para determinar o controlador PI que satisfaça a margem de fase $\phi_{m}=\pi-\phi_{g}$. Por fim, o ganho do controlador é multiplicado por $M_{g}$.

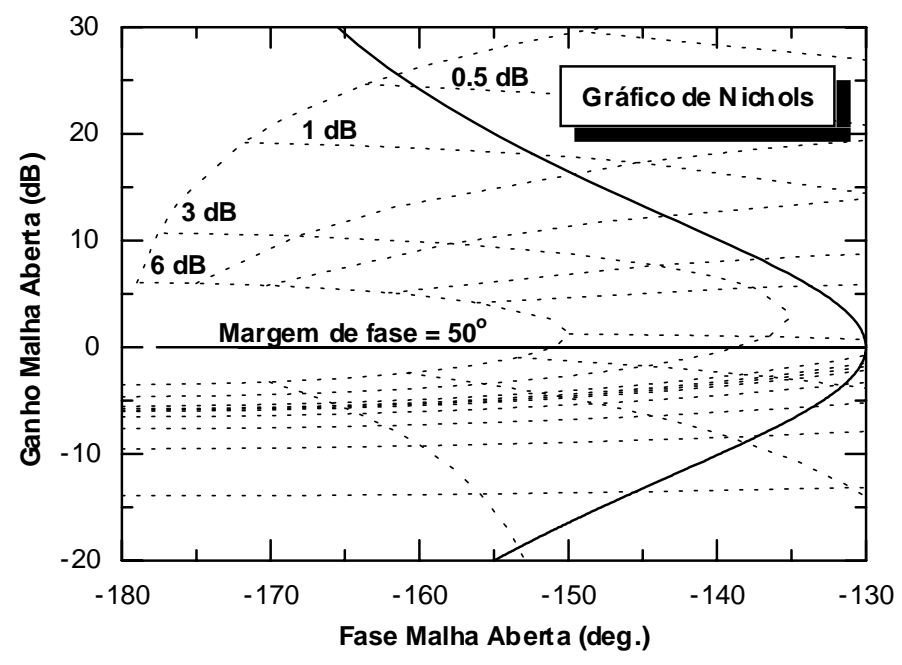

(a) 


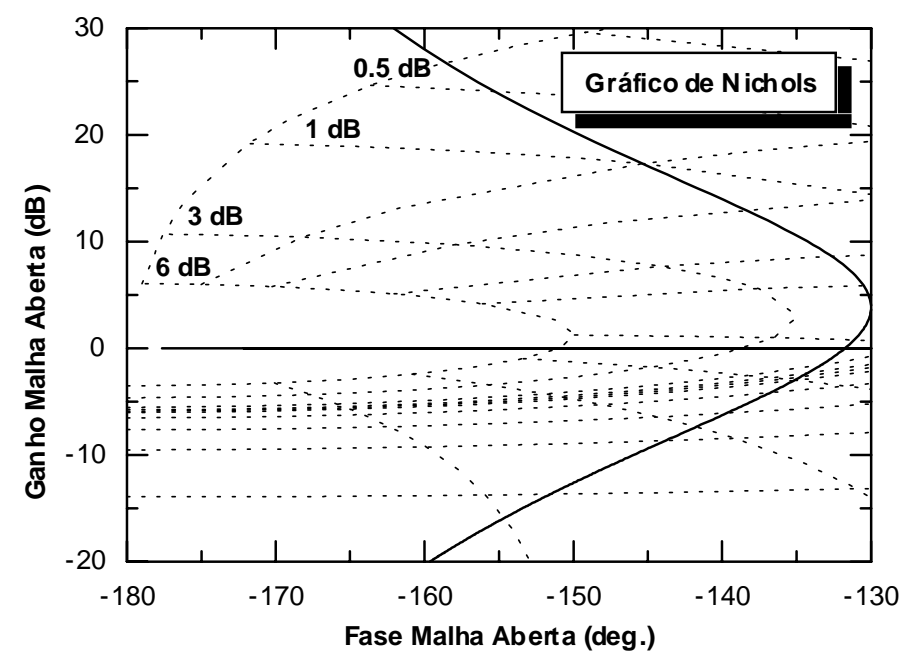

(b)

FIGURA 13. (a) Sintonia pelo Método Ótimo Simétrico; (b) Sintonia pelo Método Ótimo Não Simétrico;

Ponto de Tangência Ótimo: Os pontos do M-locus onde o ponto de tangência é vertical devem ser determinados. A função de transferência da malha fechada e sua magnitude são $\left(M(w)=\left|G_{m f}(w)\right|\right)$ :

$$
\begin{aligned}
& G_{m f}(j w):=\frac{G(j w)}{1+G(j w)}=\frac{M(w) e^{j \phi(w)}}{1+M(w) e^{j \phi(w)}} \\
& M_{m f}^{2}(w):=\frac{M^{2}(w)}{1+2 M^{2}(w) \cos [\phi \quad(w)]+M^{2}(w)}
\end{aligned}
$$

Re-ordenando os termos obtém-se a equação do M-locus:

$$
1+2 M(w) \cos [\phi(w)]+M^{2}(w)-\frac{M^{2}(w)}{M_{m f}^{2}(w)}=0
$$

Pela diferenciação desta equação no ponto $w_{g}$ e igualando a derivada primeira a zero obtém-se a posição do ponto de tangência procurado:

$$
\cos \left[\phi\left(w_{g}\right)\right]=-\sqrt{\frac{M_{m f}^{2}-1}{M_{m f}^{2}}}
$$




$$
M\left(w_{g}\right)=-\frac{1}{\cos \left[\phi\left(w_{g}\right)\right]}
$$

O atraso de fase $\phi_{m}=\pi-\phi_{g}$, que é o critério de sintonia para o método SOM, é dado então por

$$
\cos \left(\phi_{m}\right)=-\cos \left[\phi\left(w_{g}\right)\right]=\sqrt{\frac{M_{m f}^{2}-1}{M_{m f}^{2}}}
$$

Finalmente, o fator de correção do ganho do controlador é:

$$
\lambda=M\left(w_{g}\right)=\frac{1}{\cos \left(\phi_{m}\right)}
$$

Dessa forma, os passos para a aplicação do método NSOM são:

(a) obter o fator de correção do ganho do controlador a partir da margem de fase desejada através de (3.53),

(b) o controlador PI é sintonizado pelo método SOM para a margem de fase $\phi_{m}$,

$$
\begin{aligned}
& \rho=\left(\frac{1+\operatorname{sen}\left(\phi_{m}\right)}{\cos \left(\phi_{m}\right)}\right)^{2} \\
& w_{g}=\frac{1}{\sqrt{\rho} T_{q}} \\
& T_{i}=\rho T_{q} \\
& K_{c}{ }^{\prime}=\frac{w_{g}}{K_{q}}
\end{aligned}
$$

(c) o ganho do controlador é corrigido pelo fator $\lambda$,

$$
K_{c}=\lambda K_{c}^{\prime}
$$

Assim, as expressões para sintonia automática dos parâmetros do controlador PI são as dadas em (3.53) a (3.58). 
Através de uma simples aproximação é possível obter também a sintonia de controladores PID. Das fórmulas de sintonia (3.53) a (3.58) segue que os índices de desempenho dados pelo ganho do controlador e largura de banda são inversamente proporcionais ao dado pela constante de tempo $T_{q}$.

$$
\Psi=\frac{K_{C}(P I D)}{K_{C}(P I)}=\frac{w_{B P}(P I D)}{w_{B P}(P I)}=\frac{T_{q}(P I)}{T_{q}(P I D)}
$$

Um controlador PID pode ser expresso como um controlador PI mais um compensador avanço-atraso:

$$
G_{P I D}(s)=K_{C}\left(1+\frac{1}{T_{i} s}\right) \frac{1+T_{d} s}{1+T_{F} s}
$$

As constantes de tempo $T_{d}$ e $T_{F}$ devem ser escolhidas considerando-se a relação entre desempenho (valor alto para $T_{d} / T_{F}$ ) e sensibilidade a ruídos de alta-freqüência (valor baixo para $\left.T_{d} / T_{F}\right)$. A função de transferência de malha aberta fica,

$$
G_{m a}(s)=K_{C}\left(1+\frac{1}{T_{i} s}\right) \frac{1+T_{d} s}{1+T_{F} s} \frac{K_{q}}{s\left(1+T_{q} s\right)}
$$

Tomando-se as constantes de tempo $T_{d}$ e $T_{F}$ da mesma ordem de magnitude de $T_{q}$, estas constantes de tempo podem ser incluídas numa nova constante de tempo equivalente:

$$
T_{q 1}=T_{q}-T_{d}+T_{F}
$$

Então o índice de desempenho relativo fica,

$$
\Psi=\frac{T_{q}}{T_{q}-T_{d}+T_{F}}>1
$$


À primeira vista pode-se tentar reduzir significativamente a constante de tempo equivalente, escolhendo $T_{d}=T_{q}$ e $T_{F} \ll T_{q}$, mas esta não é uma boa escolha. Esta sintonia aumentaria a frequiência de ressonância excessivamente e também a constante de tempo equivalente não é precisa em altas frequiências. Uma sugestão para projeto é não reduzir a constante de tempo equivalente por mais que um fator de dois a cinco, isto significa que o ganho máximo do desempenho dado pelo compensador avanço-atraso é também de dois a cinco.

Desta forma, as expressões para sintonia automática dos parâmetros do controlador PID são as dadas em (3.53) a (3.58) e (3.63).

\subsection{Re-sintonia Automática de Controladores PI em Malhas de Controle Oscilantes}

Neste método o procedimento de auto-sintonia é realizado em malha fechada. Uma malha de controle PI é inicializada de forma a tornar o sistema marginalmente estável através do ajuste do controlador PI por parâmetros "agressivos". As oscilações obtidas são então usadas para a sintonia do controlador PI com especificações dadas pelas margens de fase e ganho. As oscilações são limitadas pela conveniente escolha dos níveis de saturação adequados na variável de controle e o sistema não precisa ser levado a um ponto de operação antes dos procedimentos de sintonia propriamente ditos.

\section{Identificação do Sistema}

Considere a malha de controle da Figura 14 que consiste de um controlador PI convencional com níveis de saturação sobre a saída do controlador. Os níveis de saturação estão presentes em todos os processos reais em conjunto com seus atuadores mas estes níveis também podem ser programados pelo usuário. 


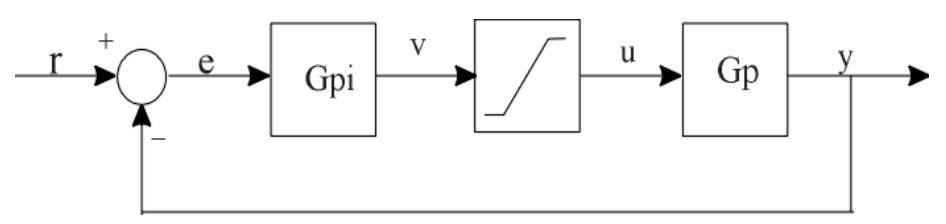

FIGURA 14. Arranjo do experimento "controlador PI saturado", consistindo de um controlador PI convencional e níveis de saturação sobre a entrada do processo e o processo.

Na análise das oscilações considera-se a situação onde a malha de controle é ajustada para tornar o sistema instável. Esta situação é mostrada na Figura 15 juntamente com os parâmetros do controlador.
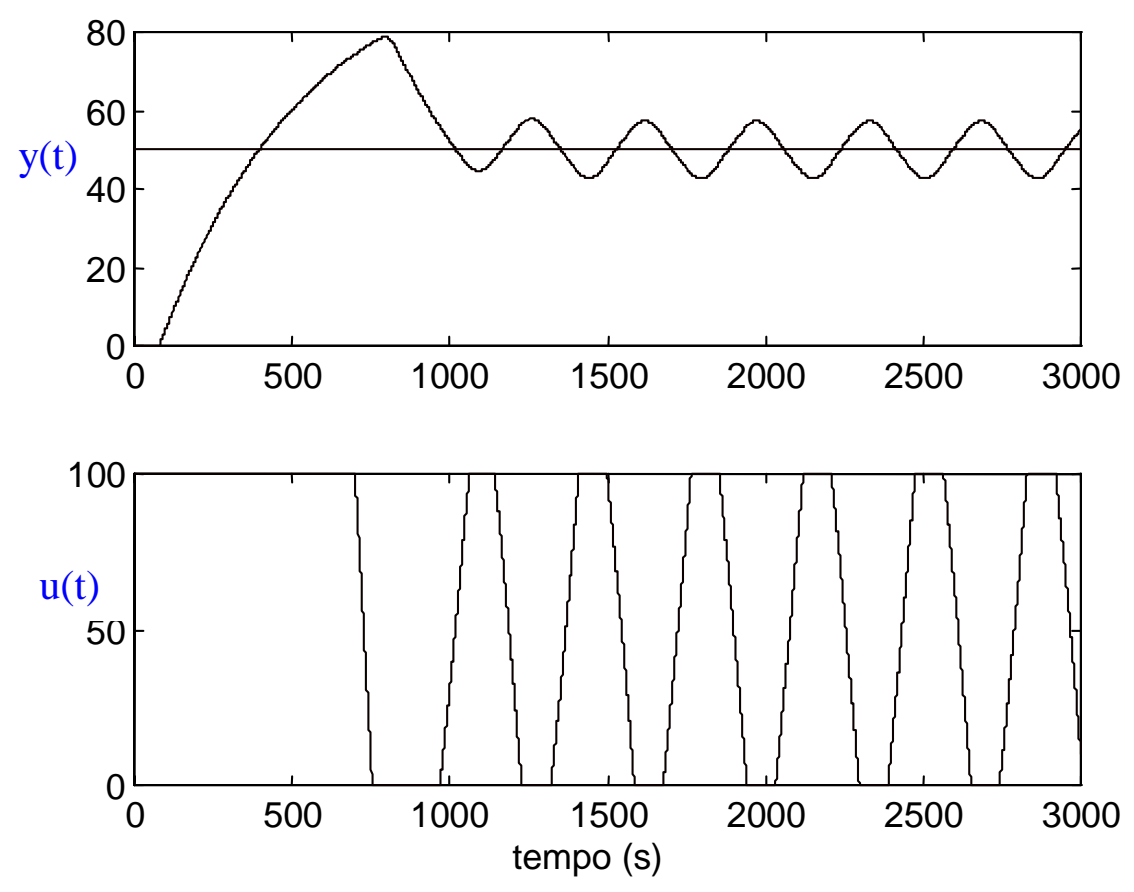

FIGURA 15. Sinais de entrada $(u)$ do processo e saída $(y)$ durante o experimento de identificação. O processo é $\exp (-80 s) /(455 s+1)$ com referência $r=50$, níveis de saturação 0 e 100 e controlador PI dado por $K_{c}=10$ e $T_{i}=200$.

\section{Análise das oscilações}

A idéia do arranjo dado na Figura 14 é gerar uma malha de controle instável (mas com oscilações limitadas) e utilizar estas oscilações para identificar um ponto sobre a curva de Nyquist, e com este ponto sintonizar um controlador PI. Sabemos pela análise da função descritiva (Apêndice A) que se um sistema não linear realimentado negativamente está oscilando com frequiência $\underline{w}$ a seguinte condição é válida: 


$$
G(j w)=-\frac{1}{N(a)}
$$

Segue de (3.64) para o arranjo na Figura 14 as seguintes informações sobre a malha fechada,

- Existe um atraso de fase de $180^{\circ}$ na malha. Então,

$$
\arg \left(G_{P I}(j w)\right)+\arg (N(a))+\arg \left(G_{p}(j w)\right)=-180^{\circ}
$$

- Na frequiência observada a amplificação total dos elementos na malha é igual a unidade,

$$
\left|G_{P I}(j w)\right| .|N(a)| .\left|G_{p}(j w)\right|=1
$$

A não-linearidade da Figura 14 é denominada saturação ideal, sua função descritiva é dada abaixo e sua relação entrada-saída é mostrada na Figura 16.

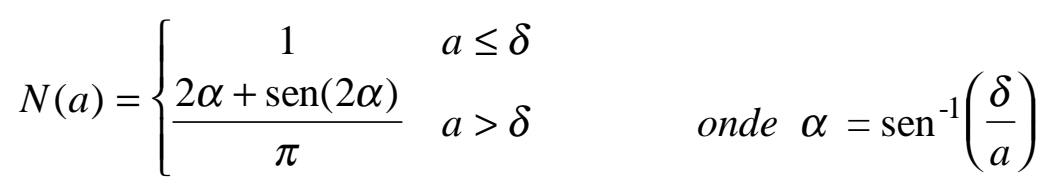

Notemos que $N(a)$ é real e portanto não contribui com atraso de fase na malha $(\arg (N(a))=0)$.

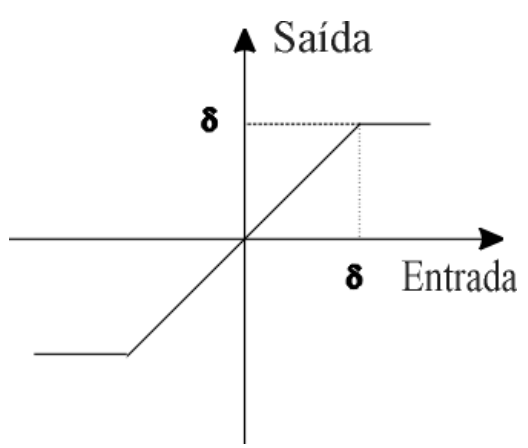

FIGURA 16. Não linearidade saturação ideal.

Da função de transferência do controlador PI tem-se que sua contribuição de fase, $\phi_{P I}$, na malha é, 


$$
\phi_{P I}=-\arg \left(1+\frac{1}{T_{i} j w}\right)=\tan ^{-1}\left(\frac{1}{T_{i} w}\right)-\frac{\pi}{2}
$$

Das equações (3.65) e (3.68) observa-se que a identificação sobre a curva de Nyquist ocorre no terceiro quadrante. Um novo parâmetro é agora introduzido e chamado "ângulo de identificação" que é definido como o ângulo formado entre o eixo real negativo e a linha da origem até o ponto de identificação sobre a curva de Nyquist, como dado na Figura 17.

$$
\phi_{P}=\tan ^{-1}\left(\frac{1}{T_{i} w}\right)
$$

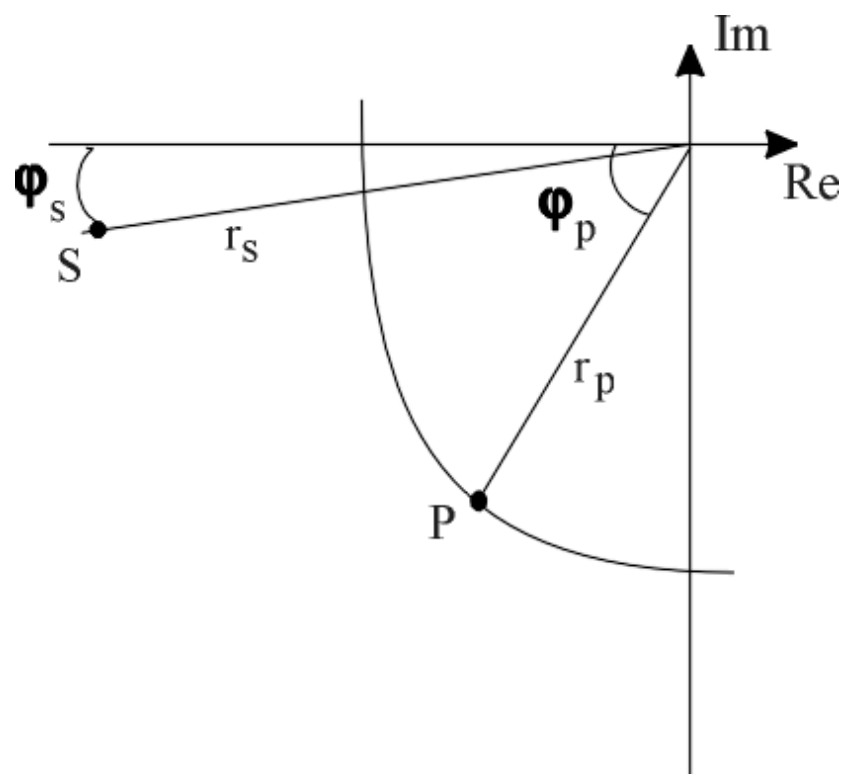

FIGURA 17. O ponto $\underline{\mathrm{P}}$ sobre a curva de Nyquist é identificado no terceiro quadrante pelo ângulo de identificação $\phi_{P}$. Com um controlador PI este ponto pode ser movido para o ponto $\underline{\mathrm{S}}$ que é especificado pelo ângulo $\phi_{S}$ e magnitude $r_{S}$.

A contribuição de ganho do controlador PI na malha é,

$$
k_{p i}=\left|G_{p i}(j w)\right|=K_{c} \sqrt{1+\frac{1}{\left(T_{i} w\right)^{2}}}
$$

A equação (3.66) da o ganho do processo na frequiência identificada, 


$$
r_{p}=\left|G_{p}(w i)\right|=\frac{1}{\left|G_{p i}(j w)\right|\left|N\left(a_{v}\right)\right|}=\frac{1}{k_{p i} N\left(k_{p i} a_{y}\right)}
$$

onde $a_{V}$ é a amplitude da saída do controlador e $a_{Y}$ é a amplitude da oscilação de saída.

Tem-se então que se o arranjo da Figura 14 causa oscilações contínuas simétricas pode-se identificar um ponto $\underline{P}$ sobre a curva de Nyquist, especificado por um ganho de identificação dado por (3.71) e um ângulo de identificação dado por (3.69). Como o atraso de fase dado pelo controlador PI está na faixa de $0^{\circ}$ a $90^{\circ}$, o processo é identificado no terceiro quadrante.

\section{Oscilações assimétricas}

A análise por função descritiva (FD) também pode ser aplicada quando oscilações assimétricas ocorrem durante a fase de identificação e esta situação foi tratada por Atherton, em ATHERTON (1982). Com a análise por função descritiva senoidal mais bias (FDSB) é possível estimar um ganho médio de uma não-linearidade devido não apenas a uma entrada senoidal (como na análise por função descritiva convencional), mas também a uma entrada senoidal mais um bias. A diferença entre a FD e a FDSB é ilustrada na Figura 18.
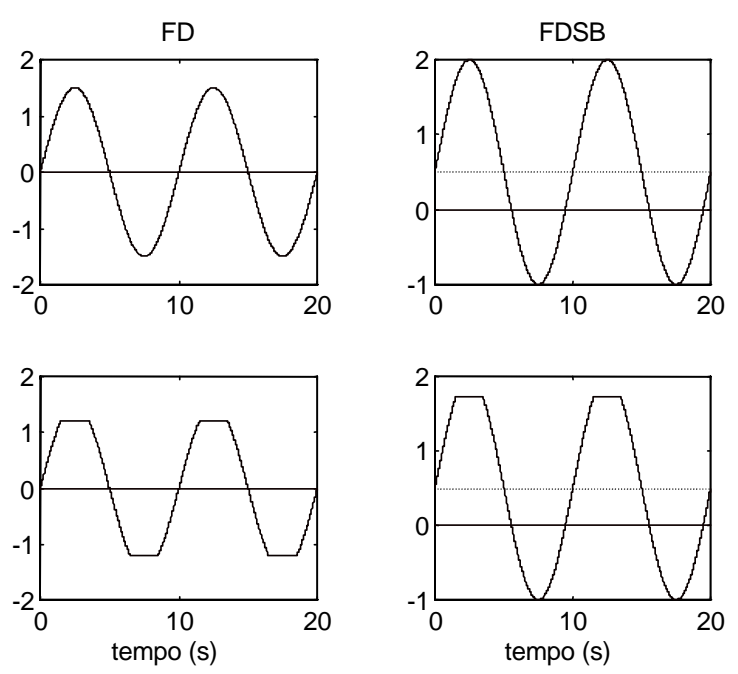

FIGURA 18. A proposta da função descritiva mais bias é estimar um ganho médio de redução de amplitude dado pela não linearidade.

A FDSB para a não linearidade saturação ideal é uma extensão da função descritiva convencional. Na análise por função descritiva convencional, a entrada é assumida ter em 
regime um valor de bias igual a zero. Na análise por FDSB a entrada senoidal possui um bias $\boldsymbol{\gamma}$ como parte do regime. Com estas diferenças pela análise por FDSB o ganho da não linearidade saturação ideal devido a uma entrada senoidal mais bias é dado por (Atherton, 1982, pag. 408) como:

$$
N_{P}=0,5\left(f_{1}\left(\frac{\delta+\gamma}{a_{v}}\right)+f_{1}\left(\frac{\delta-\gamma}{a_{v}}\right)\right)
$$

onde a função $f_{l}$ é dada por

$$
f_{1}(\rho)=\left\{\begin{array}{cc}
\frac{1}{2\left(\operatorname{sen}^{-1}(\rho)+\rho \sqrt{1-\rho^{2}}\right)} & \rho>1 \\
\pi & \rho k 1 \\
-1 & \rho<-1
\end{array}\right.
$$

Assim as relações entre as variáveis $\mathrm{a}_{\mathrm{V}}, \gamma$ e $\delta$ na expressão (3.72), os níveis de saturação $u_{M A X}$ e $u_{M I N}$ e os valores pico-a-pico $v_{M A X}$ e $v_{M I N}$ da entrada são dados pelas relações abaixo e uma figura para melhor compreensão é apresentada.

$$
\begin{gathered}
\gamma=\mathrm{u}_{0}-v_{0} \\
u_{0}=0,5\left(u_{M A X}+u_{M I N}\right) \\
v_{0}=0,5\left(v_{M A X}+v_{M I N}\right) \\
\delta=0,5\left(u_{M A X}-u_{M I N}\right) \\
\mathrm{a}_{\mathrm{v}}=0,5\left(v_{M A X}-v_{M I N}\right)
\end{gathered}
$$




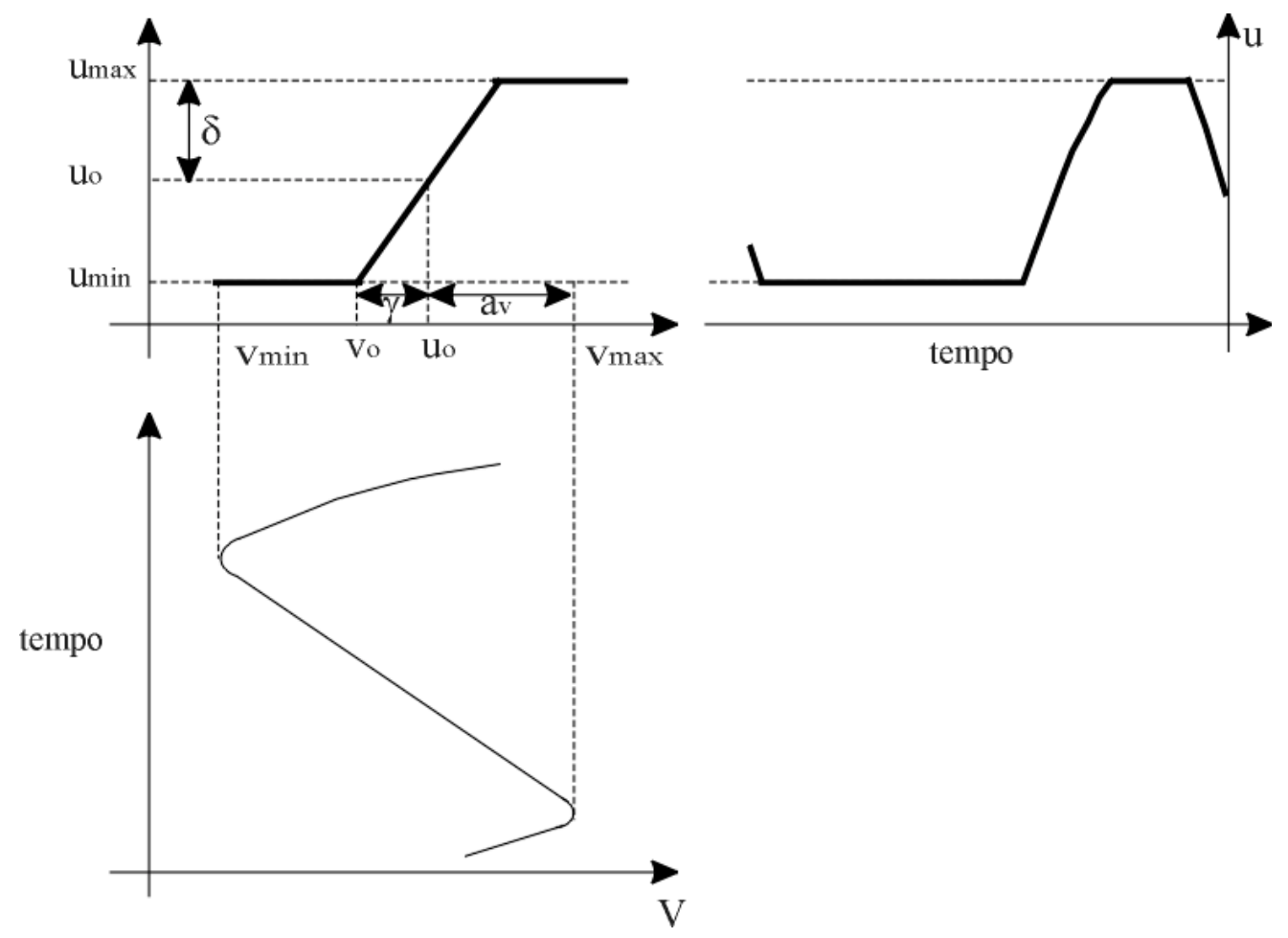

FIGURA 19. Ilustração de como um período do sinal v passa através da não linearidade saturação dando um período do sinal $u$.

Analogamente ao caso da análise de oscilações simétricas (equações 3.68 a 3.71 ), mas agora com a análise por FDSB que incorpora a assimetria nos cálculos, um ponto $\underline{\mathrm{P}}$ sobre a curva de Nyquist pode ser identificado com ângulo de identificação dado por (3.69) e magnitude dada por,

$$
r_{P}=\frac{1}{k_{P I} N_{P}}
$$

\section{Sintonia do controlador PI}

Com o experimento do controlador PI saturado, descrito acima, um ponto sobre a curva de Nyquist em algum lugar do terceiro quadrante é identificado. Este ponto é especificado por três parâmetros, a frequiência da oscilação sustentada $\underline{w}$, o ângulo de identificação $\phi_{P}$ e o ganho de identificação $r_{P}$. Esta informação sobre o processo é a mesma que é obtida pelo experimento de identificação a relê. Como feito por ASTROM \& HAGGLUND (1995) um controlador PID em série com o processo pode mover o ponto identificado para um ponto arbitrário selecionado no plano complexo. Ao restringir-se o controlador a um controlador 
PI, o ponto identificado não poderá ser movido para um ponto arbitrário selecionado no plano complexo, mas apenas no sentido anti-horário (ver Figura 10).

Com o controlador PI em série com o processo o ponto $\underline{\mathrm{P}}$ é movido para um ponto $\underline{\mathrm{S}}$ especificado pela magnitude $r_{S}$ e pelo ângulo $\phi_{S}$. Esta situação pode ser vista na Figura 17. O ponto $\underline{S}$ pode ser interpretado como especificações mínimas das margens de amplitude, $A_{m}$, e fase, $\phi_{m}$, porque assumindo que $\underline{\mathrm{S}}$ é escolhido dentro do círculo unitário no terceiro quadrante, as seguintes relações

$$
\begin{aligned}
& A_{m}>\frac{1}{r_{S}} \\
& \phi_{m}>\phi_{S}
\end{aligned}
$$

mantêm-se para sistemas onde ganho e fase decrescem monotonicamente com o aumento da freqüência.

Quando os pontos $\underline{\mathrm{P}}$ e $\underline{\mathrm{S}}$ são conhecidos a obtenção dos parâmetros do controlador PI é direta. Aström e Hagglund dão as seguintes equações para calcular o controlador,

$$
\begin{aligned}
K_{C} & =\frac{r_{S} \cos \left(\phi_{S}-\phi_{P}\right)}{r_{P}} \\
T_{i} & =\frac{1}{w \tan \left(\phi_{P}-\phi_{S}\right)}
\end{aligned}
$$

Os procedimentos de identificação e sintonia podem então ser sumarizados pelos seguintes passos:

(a) Ajustar os níveis de saturação $u_{M A X}$ e $u_{M I N}$ e selecionar os parâmetros do controlador PI de forma que a malha de controle oscile (torne-se instável).

(b) Medir a frequiência de oscilação $\underline{w}$ e os valores pico-a-pico $v_{M A X}$ e $v_{M I N}$ do sinal de controle.

(c) Identificar a amplificação de processo $r_{P}$ (equação (3.72)) e o ângulo de identificação $\phi_{P}$ (equação (3.69)).

(d) Calcular os parâmetros $K_{c}$ e $T_{i}$ do novo controlador usando a equação (3.77) e as especificações $r_{s}$ e $\phi_{s}$. 


\subsection{Critérios de Otimização Baseados em Índices Quadráticos de Desempenho}

É apresentado a seguir um breve resumo dos conceitos envolvidos na otimização de sistemas lineares baseados em índices quadráticos de desempenho.

\section{Critérios de otimização}

Nos projetos de sistemas de controle, o sistema deve satisfazer as especificações de desempenho dadas. Como os sistemas de controle são sistemas dinâmicos, estas especificações de desempenho podem ser aplicadas em termos do comportamento da resposta transitória a determinadas entradas (como entrada ao degrau, rampa, etc.) ou em termos de índices de desempenho.

Um índice de desempenho é um número que serve como indicativo da qualidade do desempenho do sistema. O sistema de controle é dito ótimo se os parâmetros são escolhidos de forma a minimizar ou maximizar o índice de desempenho escolhido, segundo a situação. O índice de desempenho deve propiciar seletividade, ou seja, um ajuste ótimo dos parâmetros deve ser distinguido claramente de um ajuste não ótimo destes parâmetros. O valor numérico do índice de desempenho deve ser um número positivo ou nulo, apresentando valor nulo somente quando a medida do desvio for nula. $O$ índice de desempenho deve ser uma função dos parâmetros do sistema e deve possuir um máximo ou mínimo e é desejável que seja calculado com facilidade analítica e computacional, o que nem sempre é conseguido.

Há muitos critérios com os quais pode-se obter um sistema ótimo, os mais amplamente usados são os critérios de erro em que o índice de desempenho são integrais de uma função ponderada do desvio da saída do sistema em relação a entrada. Os valores das integrais devem ser obtidos como funções dos parâmetros do sistema, de forma que o sistema ótimo será obtido ajustando-se os parâmetros para fornecer, em geral, o menor valor para a integral.

$\mathrm{Na}$ literatura especializada vários índices de desempenho têm sido propostos. Considerando-se a entrada e saída de um sistema de controle dadas por $y_{r}(t)$ e $y(t)$, respectivamente, o erro é dado como

$$
e(t)=y_{r}(t)-y(t)
$$


Caso a situação

$$
\lim _{t \rightarrow \infty} e(t)=0
$$

não seja verdadeira os índices de desempenho tenderão a infinito. No caso do limite acima não tender a zero podemos definir

$$
e(t)=y(\infty)-y(t)
$$

Com esta definição de erro, os índices de desempenho resultarão em números finitos, se o sistema é estável.

Com a definição de erro colocada como acima estamos prontos para estabelecer os critérios mais conhecidos que são os apresentamos a seguir. Exemplos e mais detalhes podem ser encontrados em OGATA (1993).

Critério da integral do erro quadrático (ISE): neste critério a qualidade do desempenho do sistema é avaliada pela seguinte integral:

$$
\int_{0}^{\infty} e^{2}(t) d t
$$

onde o limite superior da integral pode ser substituído por $t_{l}$, que é escolhido grande o suficiente para que $e(t)$ seja desprezível pata $t_{l}<t$. O sistema ótimo é aquele que minimiza esta integral. Este critério é bastante utilizado por causa da facilidade de se computar a integral, ele proporciona grande peso para erros grandes e pequeno peso para erros pequenos. No entanto ele não é muito seletivo, pois, para variações dos parâmetros do sistema escolhido a variação apresentada pela integral é pequena.

Um sistema projetado utilizando este critério tende a apresentar uma rápida diminuição em um erro inicial grande. Portanto, a resposta é rápida e oscilatória. Desta forma, o sistema tem baixa estabilidade relativa.

Critério da integral do erro quadrático ponderado pelo tempo (ITSE): este critério é dado por :

$$
\int_{0}^{\infty} t e^{2}(t) d t
$$

Com o sistema ótimo sendo aquele que minimiza esta integral. 
Para resposta a degrau unitário do sistema, um erro inicial grande é ponderado com peso baixo, enquanto que erros que ocorrem mais tarde na resposta transitória são bastante penalizados. Este critério apresenta melhor seletividade que o critério ISE.

Critério da integral do erro absoluto (IAE): o índice de desempenho neste caso é:

$$
\int_{0}^{\infty}|e(t)| d t
$$

Se este critério é usado, tanto sistemas altamente subamortecidos como altamente sobreamortecidos não podem ser otimizados, pois, um sistema baseado neste critério apresenta um amortecimento razoável e uma característica de resposta transitória satisfatória. Este índice de desempenho não pode ser computado facilmente por meios analíticos.

Critério da integral do erro absoluto ponderado pelo tempo (ITAE): o sistema ótimo é o que minimiza a integral:

$$
\int_{0}^{\infty} t|e(t)| d t
$$

Como nos critérios precedentes, um erro inicial grande em uma resposta ao degrau unitário é ponderado com pequeno peso, e erros que ocorrem mais tarde na resposta transitória são bastante penalizados. Este critério tem como característica que o sobre-sinal na resposta transitória é pequeno e oscilações são bem amortecidas. Possui boa seletividade e constitui uma melhora sobre o critério IAE.

Vários outros critérios podem ser aplicados, cada um deles difere dos outros pelo grau de seletividade apresentado e pela facilidade ou não de calculo analítico e computacional.

\section{Sintonia de controladores PID ótimos}

Será apresentada a metodologia proposta por ZHUANG \& ATHERTON (1993), que faz uso do critério de desempenho da integral do erro quadrático ponderado pelo tempo (ITSE). Os resultados encontraram uma boa resposta ao degrau com pequeno sobre-sinal e pequeno tempo de acomodação e mostram como o critério será calculado analiticamente. Duas aproximações são adotadas, a primeira produz uma formulação para obter os parâmetros do controlador PID que minimizam o critério ITSE baseado na auto-sintonia dos parâmetros obtida para plantas de primeira ordem mais tempo morto. A segunda aproximação examina onde o ponto crítico da planta ocorre no diagrama de Nyquist da função de transferência de 
malha aberta do sistema compensado para a otimização do critério de desempenho. Destas investigações, é estabelecido um procedimento de projeto pela especificação de margem de fase que requer apenas o ganho estático da planta e os parâmetros obtidos da auto-sintonia a relê.

\section{Critério de desempenho integral utilizado}

O critério da integral do erro quadrático (ISE) (3.85) é um dos mais bem conhecidos pois as integrais podem ser facilmente calculadas analiticamente ou no domínio da frequiência. Soluções analíticas também são disponíveis usando cálculos no domínio da frequiência para critérios integrais ponderados pelo tempo com índices de desempenho mais gerais.

$$
J_{n}(\theta)=\int_{0}^{\infty}\left\{t^{n} e(\theta, t)\right\}^{2} d t
$$

onde $\theta$ denota o parâmetro variável que pode ser escolhido para minimizar (3.85). É analisado os resultados obtidos com $n=1$. Em geral, a escolha de $n=1$ em (3.85), que é conhecido como critério ITSE, dá bons resultados.

\section{Sintonia ótima dos parâmetros usando o ganho e freqüência críticos}

Para desenvolver as fórmulas para sintonia ótima, uma relação entre os parâmetros do controlador PID e ponto crítico da planta deve ser encontrada. O ponto crítico do diagrama de Nyquist é o ponto onde a fase é $180^{\circ}$. A frequiência é dita frequiência crítica e o módulo do ganho é $1 / k_{C R}$ onde $k_{C R}$ é o ganho crítico.

Para um processo de primeira ordem mais tempo morto é fácil mostrar que

$$
\begin{aligned}
& k_{C R}=\frac{\sqrt{\left(1+w_{C R}^{2} T^{2}\right.}}{K_{P}} \\
& w_{C R} L+\tan ^{-1} w_{C R} T=180^{\circ}
\end{aligned}
$$

de onde os valores de $\mathrm{k}_{\mathrm{CR}}$ e $\mathrm{w}_{\mathrm{CR}}$ podem ser calculados. Se o ganho normalizado $k=K_{p} \cdot k_{C R}$ é introduzido, as relações entre $k \times L / T$ e $w_{C R} T \times L / T$ podem ser plotadas. Desde que para os dados parâmetros da planta de primeira ordem mais tempo morto, a planta tem um único 
ponto crítico e único conjunto de parâmetros ótimos de sintonia que satisfazem o critério ITSE, é possível obter-se relações para os parâmetros de sintonia em termos do ponto crítico do diagrama de Nyquist. Estas relações são mostradas na Figura 20. A faixa para a qual os resultados são mostrados é para $L / T$ variando de 0,1 a 2,0, com resultados valendo de 0,1 a 16. As expressões que fornecem valores ótimos dos parâmetros a partir do ajuste dos dados da Figura 20 pelo método dos mínimos quadrados são,

$$
\begin{aligned}
& K_{C}=0,509 k_{C R} \\
& T_{d}=0,125 t_{C R} \\
& T_{i}=\alpha T_{d} \\
& \alpha=0,412(3,302 k+1)
\end{aligned}
$$
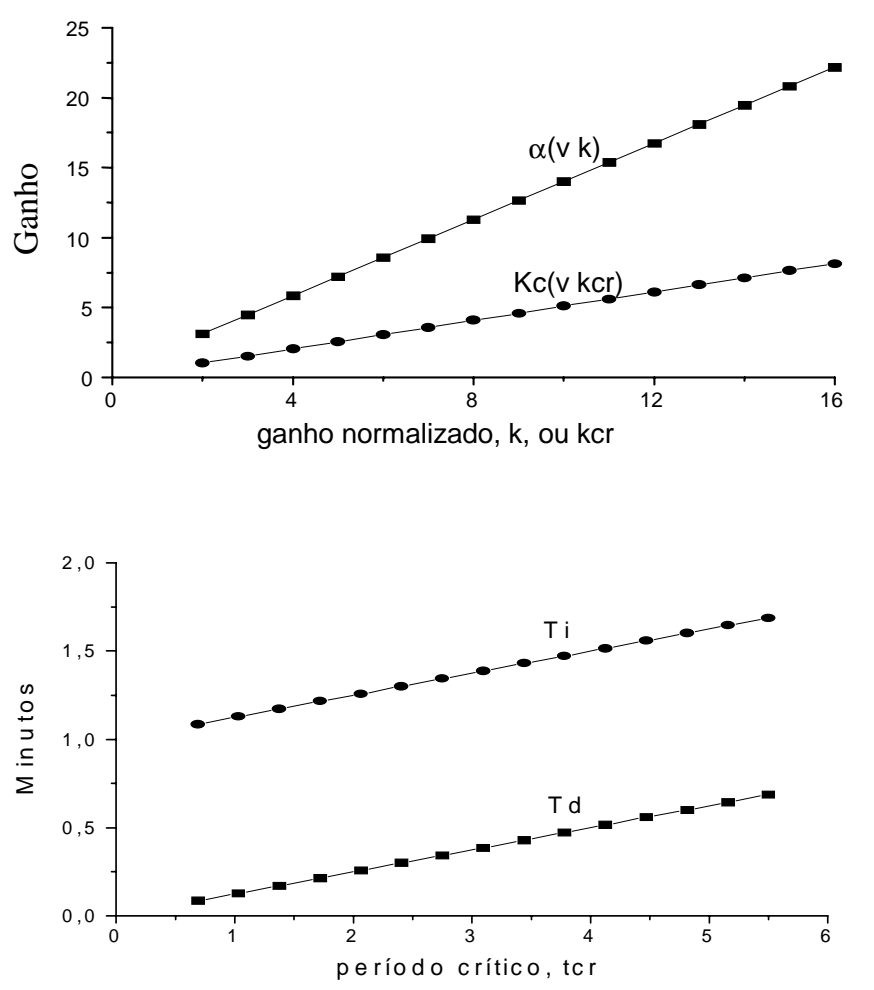

FIGURA 20. Relações entre os parâmetros PID e o ponto crítico.

A Figura 21 mostra as relações para a sintonia ótima dos parâmetros de controladores PI satisfazendo o critério ITSE, e as fórmulas são

$$
\begin{aligned}
& K_{c}=0,361 k_{C R} \\
& T_{i}=0,083(1,935 k+1) t_{C R}
\end{aligned}
$$




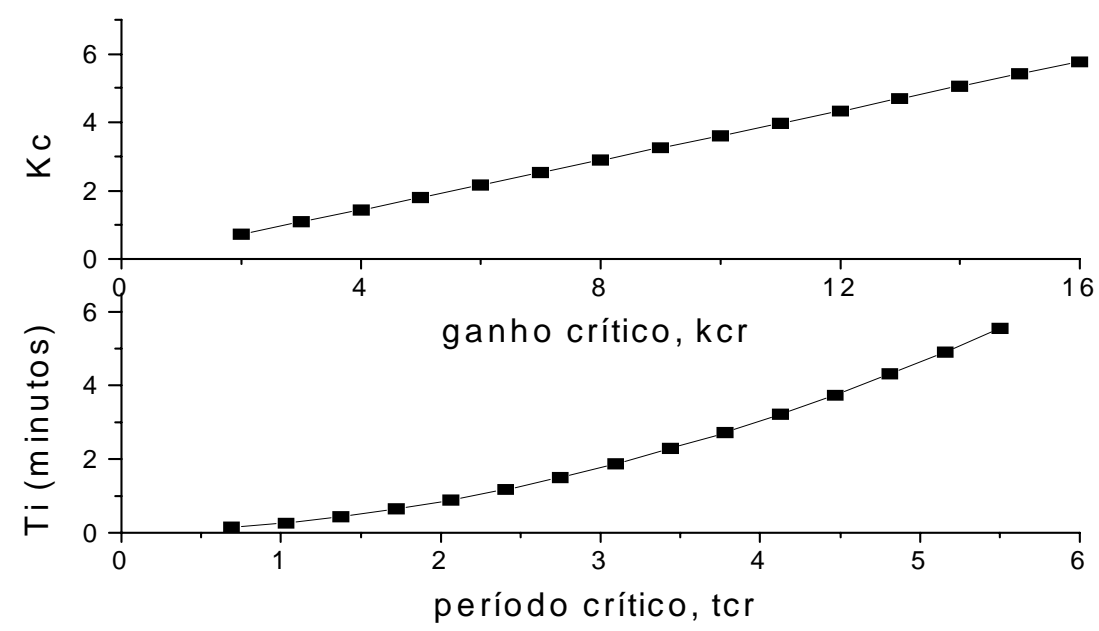

FIGURA 21. Relações entre os parâmetros PI e o ponto crítico.

Os resultados estão sumarizados nas Tabelas 1 e 2 , onde inclui-se também o controlador PID com o termo derivativo aplicado somente na saída do sistema. As tabelas incluem sintonia por mudança de referência e mudança de perturbação.

TABELA 1: Fórmula de sintonia PI para critério ITSE (1).

\begin{tabular}{lll}
\hline & Set point & Perturbação \\
\hline$K_{c}$ & $0,361 k_{C R}$ & $\frac{1,892 k+0,244}{3,249 k+2,097} k_{C R}$ \\
& & $\frac{0,706 k-0,227}{0,7229 k+1,2736} t_{C R}$ \\
\hline
\end{tabular}

TABELA 2: Fórmula de sintonia PID para critério ITSE (1).

\begin{tabular}{llll}
\hline & Set point & Perturbação & Derivada na saída \\
\hline$K_{c}$ & $0,509 k_{C R}$ & $\frac{4,434 k-0,966}{5,12 k+1,734} k_{C R}$ & $\frac{4,437 k-1,587}{8,024 k-1,435} k_{C R}$ \\
& & & \\
$T_{i}$ & $0,051(3,302 \mathrm{k}+1) t_{C R}$ & $\frac{1,751 k-0,612}{3,776 k+1,388} t_{C R}$ & $0,037(5,89 \mathrm{k}+1) t_{C R}$ \\
& & $0,144 t_{C R}$ & $0,112 t_{C R}$ \\
\hline
\end{tabular}

As fórmulas acima foram obtidas com base no valor exato do ponto crítico do diagrama de Nyquist. Quando é utilizada a auto-sintonia a relê, o ponto crítico é obtido aproximadamente da condição de oscilação do ciclo limite, que fornece a frequiência de 
oscilação $w_{o}$ e a saída de amplitude $a_{o}$, que são usados para calcular o ganho crítico aproximado $K_{o}$. Este ganho é dado por $K_{o}=4 h / a_{o} \pi$. É possível obter as fórmulas dadas acima em termos de $K_{o}$ e $w_{o}$. Estas fórmulas são dadas nas Tabelas 3 e 4, onde $k_{o}=K_{p} K_{o}$.

TABELA 3: Fórmula de sintonia PI para critério ITSE (2).

\begin{tabular}{lll}
\hline & Set point & Perturbação \\
\hline$K_{c}$ & $\frac{1,506 k_{o}-0,177}{3,341 k_{o}+0,606} K_{o}$ & $\frac{4,126 k o-2,610}{5,848 k o-1,06} K_{o}$ \\
& $0,055\left(3,616 \mathrm{k}_{\mathrm{o}}+1\right) \mathrm{T}_{\mathrm{o}}$ & $\frac{5,352 k_{o}-2,926}{5,539 k_{o}+5,036} T_{o}$ \\
\hline
\end{tabular}

TABELA 4: Fórmula de sintonia PID para critério ITSE (2).

\begin{tabular}{llll}
\hline & Set point & Perturbação & Derivada na saída \\
\hline$K_{c}$ & $0,604 \mathrm{~K}_{\mathrm{o}}$ & $\frac{6,068 k_{o}-4,273}{5,758 k_{o}-1,058} K_{o}$ & $\frac{2,354 k_{o}-0,696}{3,363 k_{o}+0,517} K_{o}$ \\
& & $\frac{1,1622 k_{o}-0,748}{2,516 k_{o}-0,505} T_{o}$ & $0,271 \mathrm{k}_{\mathrm{o}} \mathrm{T}_{\mathrm{o}}$ \\
$T_{i}$ & $0,04\left(4,972 \mathrm{k}_{\mathrm{o}}+1\right) \mathrm{T}_{\mathrm{o}}$ & \\
& & $0,15 \mathrm{~T}_{\mathrm{o}}$ & $0,116 \mathrm{~T}_{\mathrm{o}}$ \\
\hline
\end{tabular}

Sintonia ótima dos parâmetros pelas margens de fase e ganho (MFG)

Baseia-se na observação do movimento do ponto crítico da resposta em frequiência do sistema compensado para o critério ITSE com $L / T$ entre 0,1 e 2,0. O ponto crítico do sistema compensado foi movido para posições com magnitude entre 0,53 e $0,62 \mathrm{~dB}$ e fase entre $-145^{\circ}$ e $-165^{\circ}$. Tipicamente considera-se valores com margem de ganho 3 e margem de fase $60^{\circ}$.

Examinando o movimento do ponto crítico do sistema compensado com a variação de $k$, temos o comportamento mostrado na Figura 22 , onde $\left|G_{c} G_{p}\left(j w_{C R}\right)\right|$ é a magnitude, $m$, e $180^{\circ}+\phi\left(j w_{C R}\right)$ é a fase. A aproximação para as curvas nos dão:

$$
\begin{aligned}
& \phi_{m}=33,8\left(1-0,97 e^{-0,45 k}\right) \quad, \text { em graus } \\
& m=0,614\left(1-0,233 e^{-0,347 k}\right)
\end{aligned}
$$


Em termos dos dados por auto-sintonia a relê, as expressões acima ficam:

$$
\begin{aligned}
& \phi_{m}=33,2\left(1-1,38 e^{-0,68 k o}\right) \quad, \text { em graus } \\
& m=0,613\left(1-0,262 e^{-0,44 k o}\right)
\end{aligned}
$$

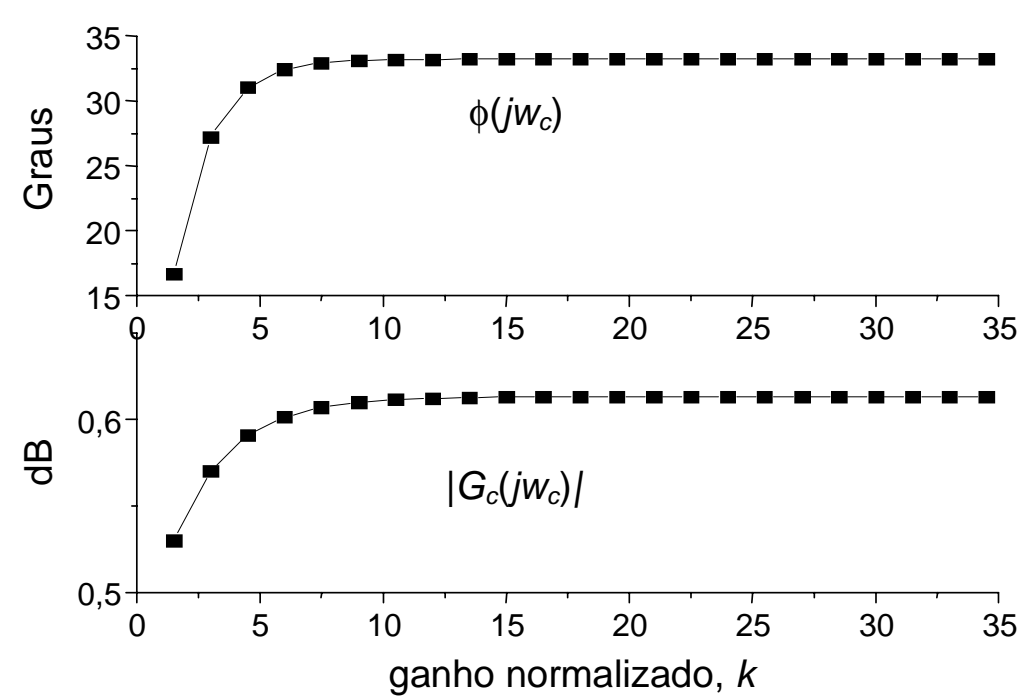

FIGURA 22. Relação entre movimento do ponto crítico e $k$.

Então os parâmetros do controlador PID podem ser obtidos por:

$$
\begin{aligned}
K_{C} & =\frac{m \cdot \cos \phi_{m}}{\left|G\left(j w_{C R}\right)\right|}=m \cdot k_{C R} \cdot \cos \phi_{m} \\
T_{d} & =\frac{\tan \phi_{m}+\sqrt{\left(\frac{4}{\alpha}+\tan ^{2} \phi_{m}\right)}}{2 w_{C R}} \\
T_{i} & =\alpha T_{d}
\end{aligned}
$$

onde $\alpha$ é dado por: $\quad \alpha=0,413(3,302 \mathrm{k}+1) \quad$ ou $\quad \alpha=1,687 \mathrm{k}_{\mathrm{o}}$.

Estes resultados indicam que, se os parâmetros do controlador PID movem o ponto crítico do sistema compensado para o ganho e fase calculados pelas equações (3.89) e (3.90) (ou (3.91) e (3.92)), a resposta é ótima pelo critério ITSE. 


\section{Processos Industriais de Temperatura de $1 \stackrel{\text { a }}{ }$ Ordem com Tempo Morto}

Muitos processos industriais podem ser aproximados por uma função de transferência de primeira ordem mais tempo morto. Suas respostas caracterizam uma resposta temporal monótona ou essencialmente monótona, isto é, monótona exceto para uma pequena parte inicial. Tais processos podem ser divididos em duas amplas classes. A primeira corresponde aos processos estáveis. A dinâmica destes processos é aproximada pela função de transferência dada em (4.1a). Nela $L$ é o tempo morto (ou de atraso), $T$ é a constante de tempo e $K_{P}$ é o ganho estático do processo. Estes parâmetros podem ser obtidos pelo experimento da resposta ao degrau, por exemplo. Estes processos são também denominados processos com auto-regulação. A segunda classe corresponde aos processos com ação integral, e a função de transferência que aproxima esta dinâmica é dada em (4.1b). Tais processos são também denominados processos sem auto-regulação. Processos com pólos ressonantes não apresentam resposta temporal ao degrau essencialmente monótona, por isso não fazem parte desta classificação.

Deve-se notar que da maneira posta a função de transferência apresentada em (4.1a) possui ordem infinita, devido ao termo que modela o atraso de tempo (tempo morto) ser da forma exponencial, no entanto na prática os processos industriais têm ordem finita e uma aproximação deste termo pode ser obtida utilizando-se por exemplo a aproximação de Padé de $2^{\mathrm{a}}$. ordem para o tempo morto, como mostrado em (4.1c).

$$
\begin{aligned}
& G_{P}(s)=\frac{K_{P} e^{-L s}}{T s+1} \\
& G_{q}(s)=\frac{K_{q} e^{-L s}}{s\left(T_{q} s+1\right)} \\
& e^{-L s} \approx \frac{L^{2} s^{2}+6 L s+12}{L^{2} s^{2}-6 L s+12}
\end{aligned}
$$

Com base na função de transferência em (4.1a) alguns números adimensionais são estabelecidos na literatura para completar a caracterização deste tipo de função de transferência, sendo os dois principais o tempo morto normalizado e o ganho do processo normalizado, apresentados abaixo. Segundo KHAN \& LEHMAN (1996), das experiências 
práticas tem-se observado que processos com um valor pequeno para o tempo morto normalizado são "fáceis" de controlar, enquanto que valores grandes do tempo morto indicam processos "difíceis" de controlar.

$\theta_{1}=\frac{L}{T} \quad$, tempo morto normalizado

$k=\frac{G_{P}(0)}{\left|G_{P}\left(j w_{C R}\right)\right|}=K_{P} \cdot k_{C R} \quad$, ganho do processo normalizado

onde $k_{C R}$ é o ganho crítico do processo e $w_{C R}$ é a freqüência crítica $\left(\arg \left[G_{p}\left(j w_{C R}\right)\right]=-\pi\right)$.

Para saber-se como é o comportamento deste tipo de função de transferência em relação à freqüência, é obtida a resposta em freqüência do tempo de atraso.

O módulo do tempo de atraso é igual a unidade para qualquer freqüência,

$\left|e^{L j w}\right|=|\cos (w L)-j \operatorname{sen}(w L)|=1$

Portanto, o log do módulo do tempo de atraso é 0db. O ângulo de fase é

$$
\begin{aligned}
\angle e^{L j w}=-w L & & \text { (radiano) } & \text { ou } \\
=-57,3 w L & & \text { (graus) } &
\end{aligned}
$$

Assim tem-se que o ângulo de fase varia linearmente com a frequiência. Esta característica de freqüência de ângulo de fase do atraso de transporte é mostrada no diagrama de Bode da Figura 23.

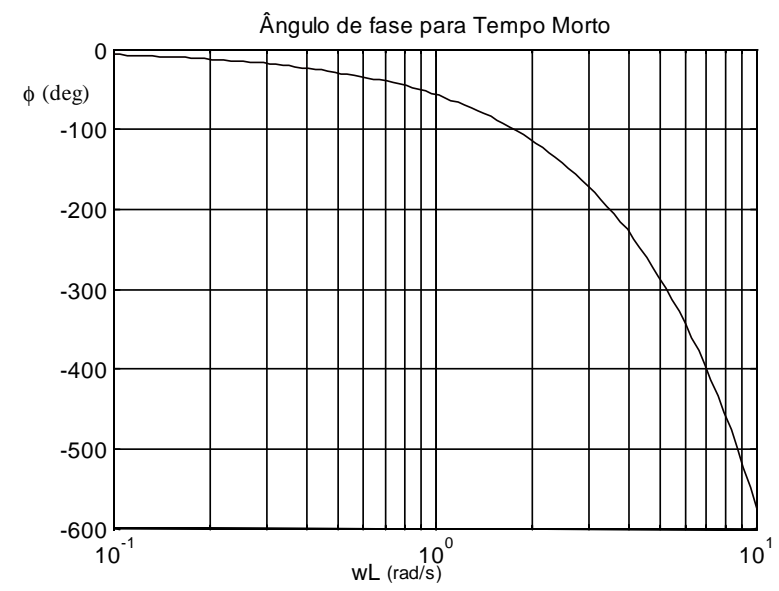

FIGURA 23. Característica de ângulo de fase para o termo $e^{-L s}$. 
Assim a resposta frequencial (Diagrama de Bode) da função de transferência dada em (4.1a) fica:
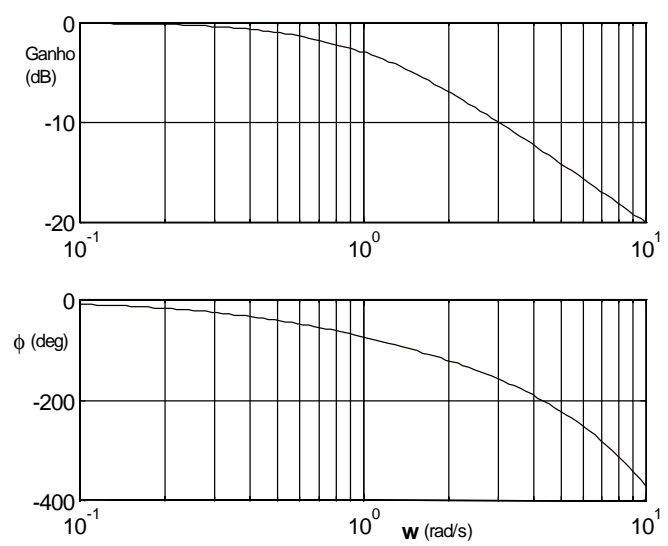

FIGURA 24. Diagrama de Bode da função de transferência de primeira ordem mais tempo morto para os valores $\mathrm{L}=0.5 \mathrm{e} \mathrm{T}=1$.

Para completar a caracterização deste tipo de função de transferência é analisado também o diagrama polar (ou diagrama de Nyquist). O diagrama de Nyquist é o lugar dos vetores $|G(j w)| \angle G(j w)$ conforme $\underline{w}$ (a freqüência angular) varia de zero a infinito. Este tipo de diagrama é importante pois permite obter de maneira rápida a estabilidade absoluta do sistema por inspeção.

O diagrama de Nyquist da função de transferência (4.1a) pode ser então obtido tomando o módulo e ângulo de fase, e resulta na Figura 25 abaixo.

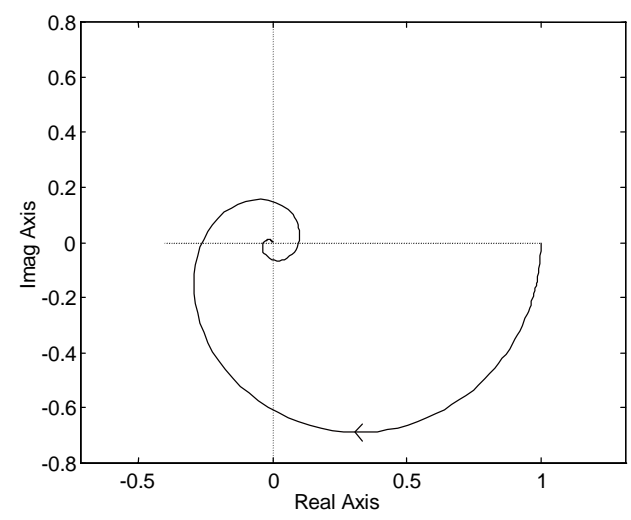

FIGURA 25. Diagrama de Nyquist da função de transferência (2.48a) para $L=0.5$ e $T=1$. 


\section{Processo Industrial Utilizado}

Nesta seção são descritas as diversas partes que compõem o processo em estudo: o controlador microprocessado da família 8051, os sensores de temperatura, o modo de acionamento adotado e a planta térmica utilizada.

\subsection{Controlador Microprocessado}

O controlador industrial microprocessado utilizado para teste possui um entrada analógica para sensor tipo PT100 $\left(0\right.$ a $100,0{ }^{\circ} \mathrm{C}$ ) ou tipo $\mathrm{J}\left(0\right.$ a $700{ }^{\circ} \mathrm{C}$ ), saída de controle a relê, 4 displays de 7 segmentos, 4 teclas multi-funções para entrada dos dados e parâmetros e 3 leds para indicações diversas (saída ligada, alarmes, rompimento de sensor, etc.). Possui as dimensões 96x96x130mm. O frontal do aparelho é mostrado na Figura 26.

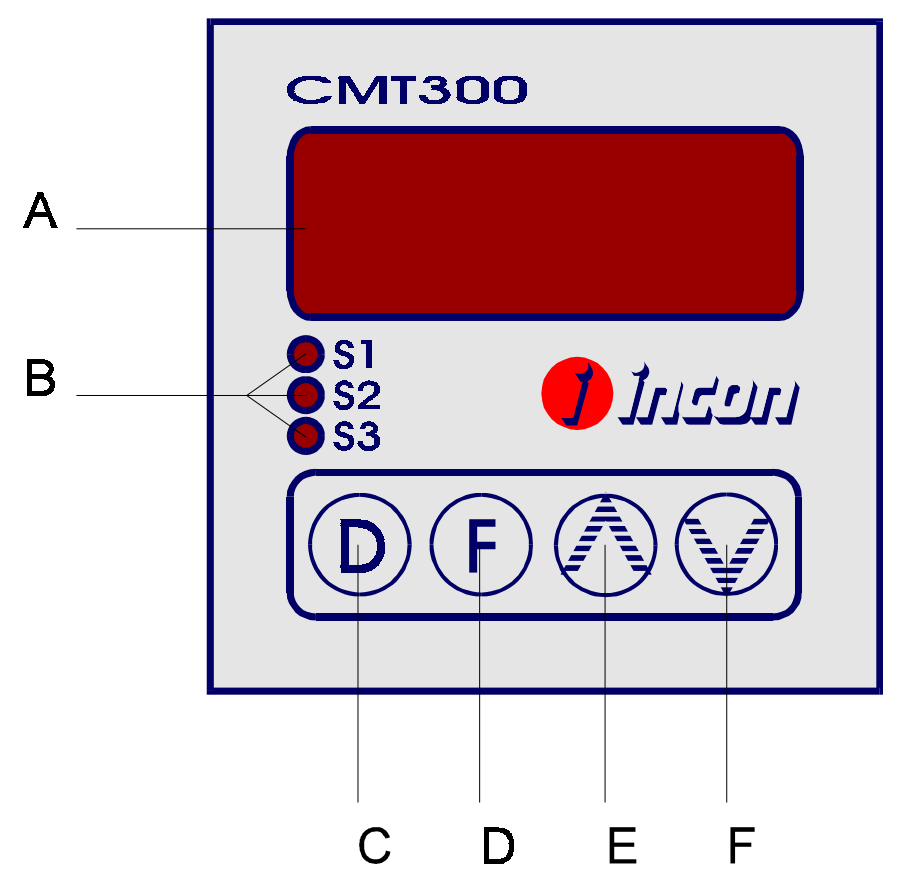

FIGURA 26. Frontal do controlador industrial utilizado na implementação dos algoritmos de controle PID e sintonia automática.

A - Visor para indicação da variável de processo, parâmetros do controlador e do sistema e mensagens ao usuário. 
B - Leds utilizados para indicações diversas como saída (relê) ligada/desligada, alarmes de sobre-sinal, falha no sensor, etc.

C - Tecla para confirmação de entrada de dados.

D - Tecla para seleção de menu.

E - Tecla de incremento.

F - Tecla de decremento.

Este aparelho é dotado do microcontrolador 80C535 da Simens que possui conversor A/D de 8 bits, 256 bytes de memória RAM, 6 portas de 8 bits, 3 timers de 16 bits, porta serial full-duplex, e 12 fontes de interrupção com 4 níveis de prioridade. Este microcontrolador é capaz de endereçar até 64Kbytes de memória de programa e de dados externa, sendo que neste aparelho é possível utilizar uma memória de programa do tipo EEPROM com até 32Kbytes e não é dotado de memória de dados externa.

O conjunto de instruções deste microcontrolador é composto por 30 instruções das quais $44 \%$ possuem um byte, $41 \%$ dois bytes e apenas $15 \%$ são de três bytes. Com um cristal de $12 \mathrm{MHz}, 58 \%$ das instruções são executadas em $1 \mu \mathrm{s}$.

Um diagrama em blocos com as principais partes constituintes do microcontrolador é dado abaixo. 


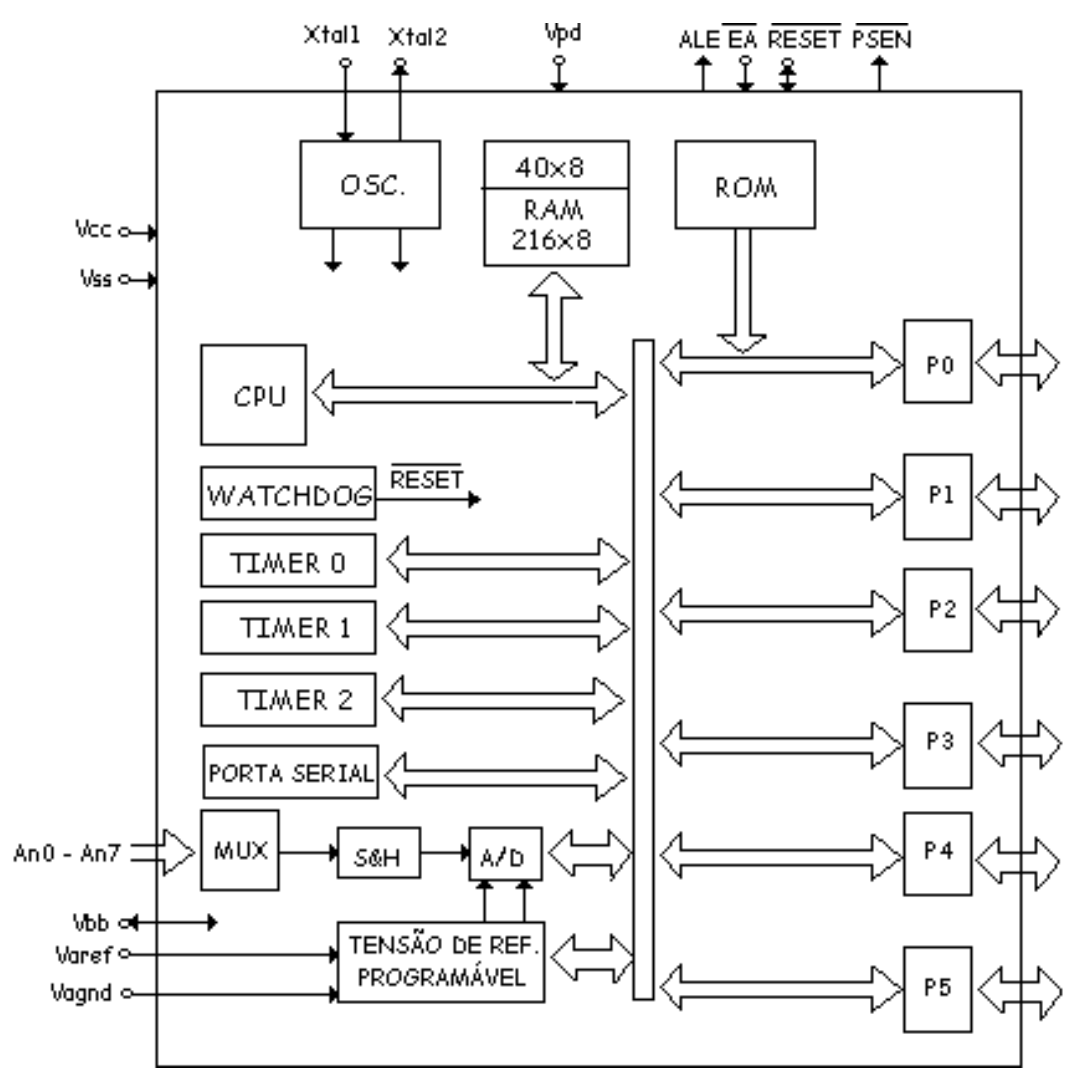

FIGURA 27. Diagrama em blocos do microcontrolador 80535.

Uma característica interessante deste microcontrolador é que devido ao fato do conversor A/D interno (que utiliza a técnica de aproximação sucessiva na conversão) possuir a sua tensão interna de referência programável, pode-se ajustá-la à faixa de tensão externa da entrada analógica (dentro de 0 a $5 \mathrm{~V}$, a faixa de trabalho do conversor) ou pode-se melhorar a resolução da conversão das entradas analógicas para 10 bits fazendo-se uma segunda conversão imediatamente após a anterior com a tensão de referência interna comprimida, bastando selecionar a nova faixa para conversão através dos dois bits MSB da primeira conversão. A primeira situação pode ser aplicada para compensação de temperatura ambiente, por exemplo, em aparelhos dedicados a indicação de temperaturas. A segunda situação é a utilizada neste controlador industrial para conversão das temperaturas obtidas pelo sensor. Portanto, a variável correspondente ao valor da temperatura do processo possui 10 bits.

A ilustração destas duas situações é dada na Figura 28. 


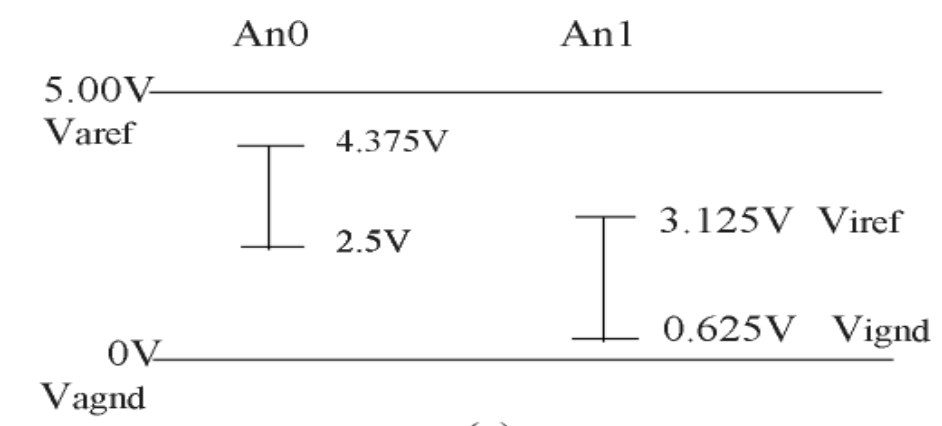

(a)

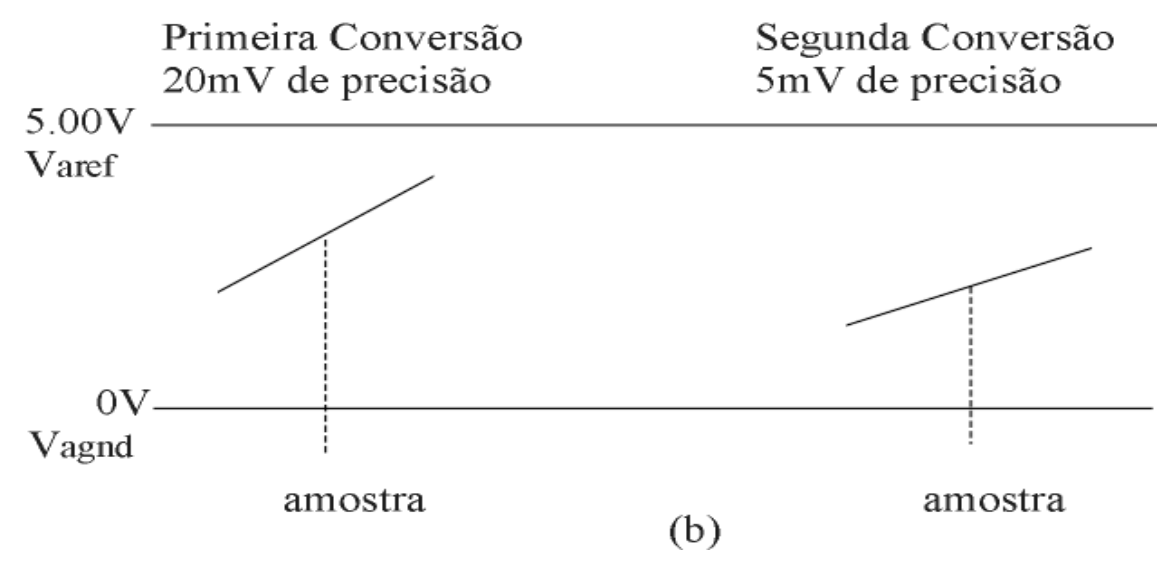

FIGURA 28. (a) Ajuste de tensões internas a faixas de tensões externas das entrada analógicas;

(b) Operação do conversor A/D interno para conversão resultante de 10 bits.

\subsection{Sensores de Temperatura}

O controlador industrial pode ser utilizado com dois tipos de sensores de temperatura, um sensor tipo PT100 (termoresistência) para a faixa de temperatura de 0,0 a $100,0^{\circ} \mathrm{C}$ ou um sensor tipo $\mathrm{J}$ (termopar) para a faixa de temperatura de 0 a $700^{\circ} \mathrm{C}$.

A termoresistência é um componente composto na parte sensível dos bulbos por platina ou níquel e fios internos de prata com isolamento cerâmico. A platina é o material mais adequado devido à precisão conseguida e à estabilidade de suas características ao longo da vida útil do material, porém apresenta um custo superior. O componente feito com platina tem resistência de $100 \mathrm{Ohm}$ a $0^{\circ} \mathrm{C}$ e é denominado no meio industrial PT100. A resposta temperatura-resistência é linear. Esta curva pode ser obtida facilmente por ensaio em bancada ou fornecida pelo fabricante do componente. O componente feito com níquel é mais barato porém apresenta falta de linearidade na sua relação resistência-temperatura. Uma ilustração deste tipo de sensor é mostrada na Figura 29. 
O termopar é um tipo de sensor amplamente utilizado no meio industrial para medida de temperatura. Existem diversos tipos ( $\mathrm{J}$ (Ferro/Constantan), K (Cromo/Alumínio), T (Cobre/Constantan), E (Cromo/Constantan) e R (Ródio/Platina) ) que diferem na composição dos materiais que os formam e, consequentemente, possuem faixas de atuação diferentes sendo indicados para ambientes industrias diferentes. Dois metais dessemelhantes são unidos para compor a "junção quente" (ponto que efetivamente detecta a temperatura), e as pontas livres constituem a "junção fria" ou de referência. O componente mediante um gradiente de temperatura produz uma mili-voltagem nos seus terminais que é utilizada para obtenção do valor da temperatura da junta quente, ou seja, conhecendo a temperatura da junta fria (normalmente a temperatura ambiente) e a força eletromotriz nos terminais calcula-se a temperatura em que a junta quente está. A relação temperatura-milivoltagem pode ser obtida por meio de tabelas de referência encontradas em manuais. No presente caso é implementada uma tabela de 1 Kbytes (conversão em 10 bits). Um sensor deste tipo é mostrado na Figura 29.

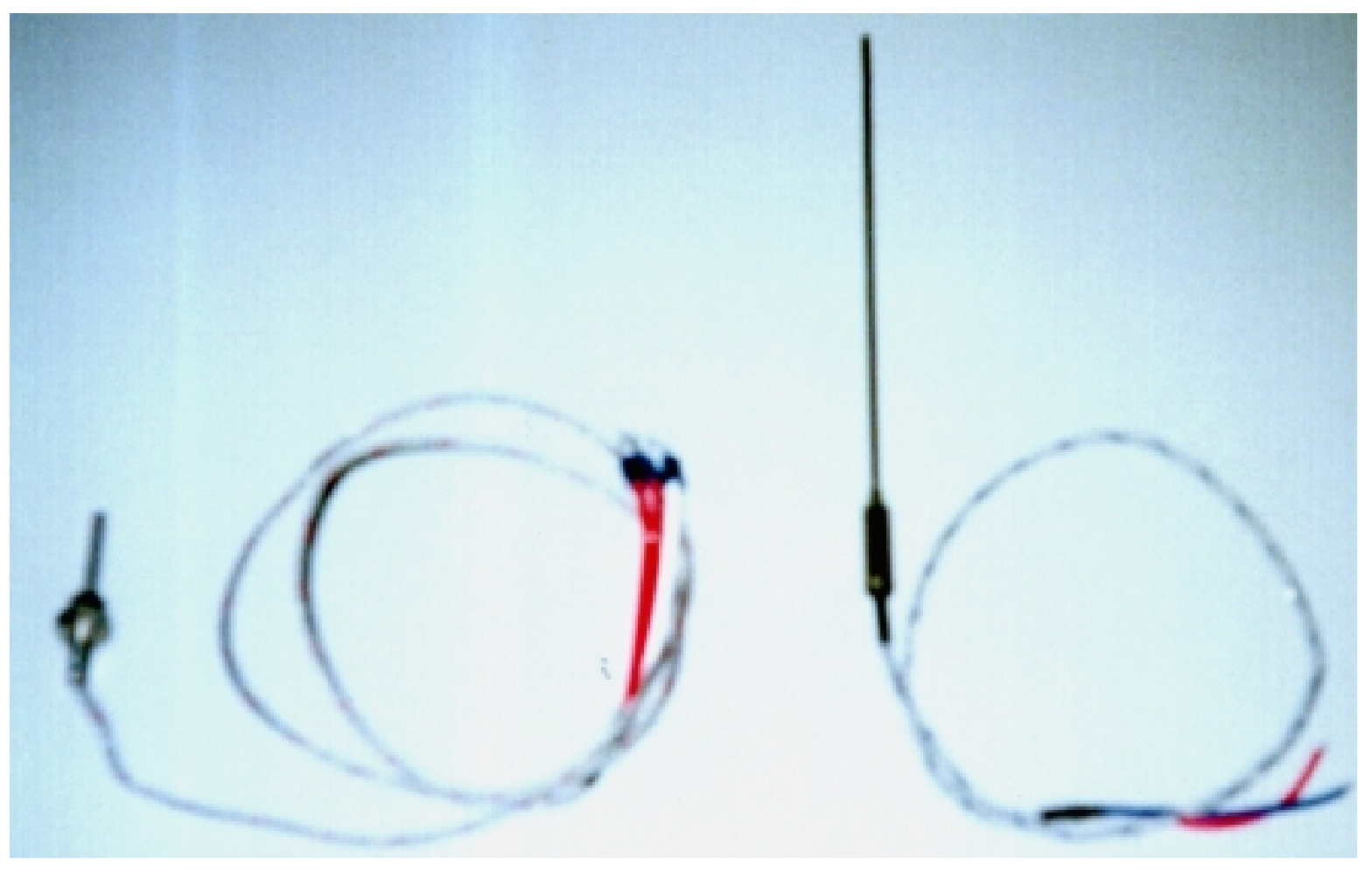

FIGURA 29. Sensores PT100 e Termopar tipo J, da esquerda para a direita. 


\subsection{Acionamento da Planta por PWM}

Como mencionado anteriormente, este controlador industrial possui uma saída a relê para acionamento da planta, o que significa que a atuação na planta dá-se por modulação de largura de pulso (PWM, do inglês). Este é o tipo de saída mais comum encontrado no mercado em controladores de processos industriais, outros tipos de saídas disponíveis são: saída lógica e saída contínua (DC).

A saída lógica pode ser tomada em tensão, $24 \mathrm{~V}$, ou corrente, $20 \mathrm{~mA}$. A saída contínua (DC) permite que a planta seja acionada por um sinal analógico contínuo na faixa de 0 a 20mA, 4 a 20mA ou 0 a 10V (carga de 500 Ohm), gerado por um PWM com período fixo. A saída por modulação de largura de pulso toma o valor selecionado pelo operador para o período desejado, $\mathrm{C}_{\mathrm{T}}$, e mantém a saída acionada por um tempo entre 0 e $100 \%$ do valor deste período e desligada no tempo restante, repetindo esta operação indefinidamente enquanto o aparelho estiver energizado. O valor de tempo em que a saída é mantida ligada, $t_{P}$, é calculado pelo algoritmo de controle com base no erro existente entre o valor da referência programado e o valor atual da variável de processo. A Figura 30 mostra esta forma de operação da saída e a influência do valor de $C_{T}$ no comportamento da variável de processo.

$$
0 \leq t_{p}=f\left(u(k), C_{T}\right) \leq C_{T}
$$

onde $u(k)$ : valor da saída do controlador no instante $k ; C_{T}$ : período do PWM.

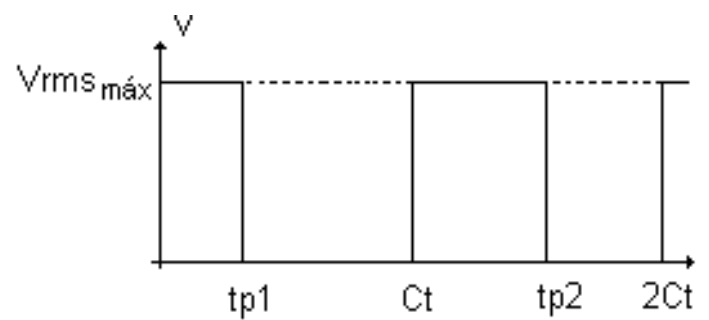

(a)

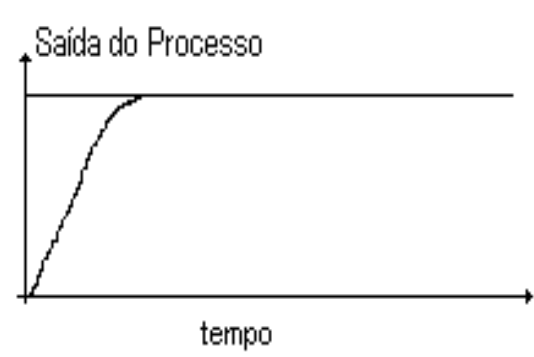

(b)

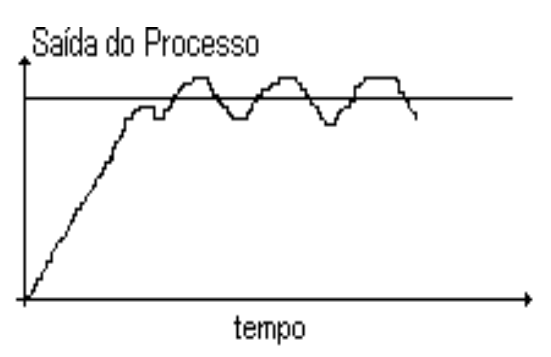

(c)

FIGURA 30. (a) Saída do PWM; (b) $C_{T}$ com valor correto; (c) $C_{T}$ com valor muito elevado. 


\subsection{Planta Térmica para Teste}

Como planta industrial exemplo foi montado um mini-forno composto por uma caixa metálica de dimensões $15 \mathrm{~cm} \times 18 \mathrm{~cm} \times 8 \mathrm{~cm}$ com furos retangulares laterais, na qual foi inserida uma resistência de 74W e um sensor tipo PT100 para a leitura das temperaturas, que é obtida através de um indicador digital. Utilizou-se uma chave estática (SSR - relê de estado sólido) para acionamento.

A Figura 31 mostra esta planta exemplo e a Figura 32 mostra o diagrama em blocos do sistema de controle implementado com os seus componentes.

Este processo foi adotado por ser caracterizado por uma dinâmica de primeira ordem mais tempo morto que representa uma ampla gama de processos encontrados na prática no meio industrial.

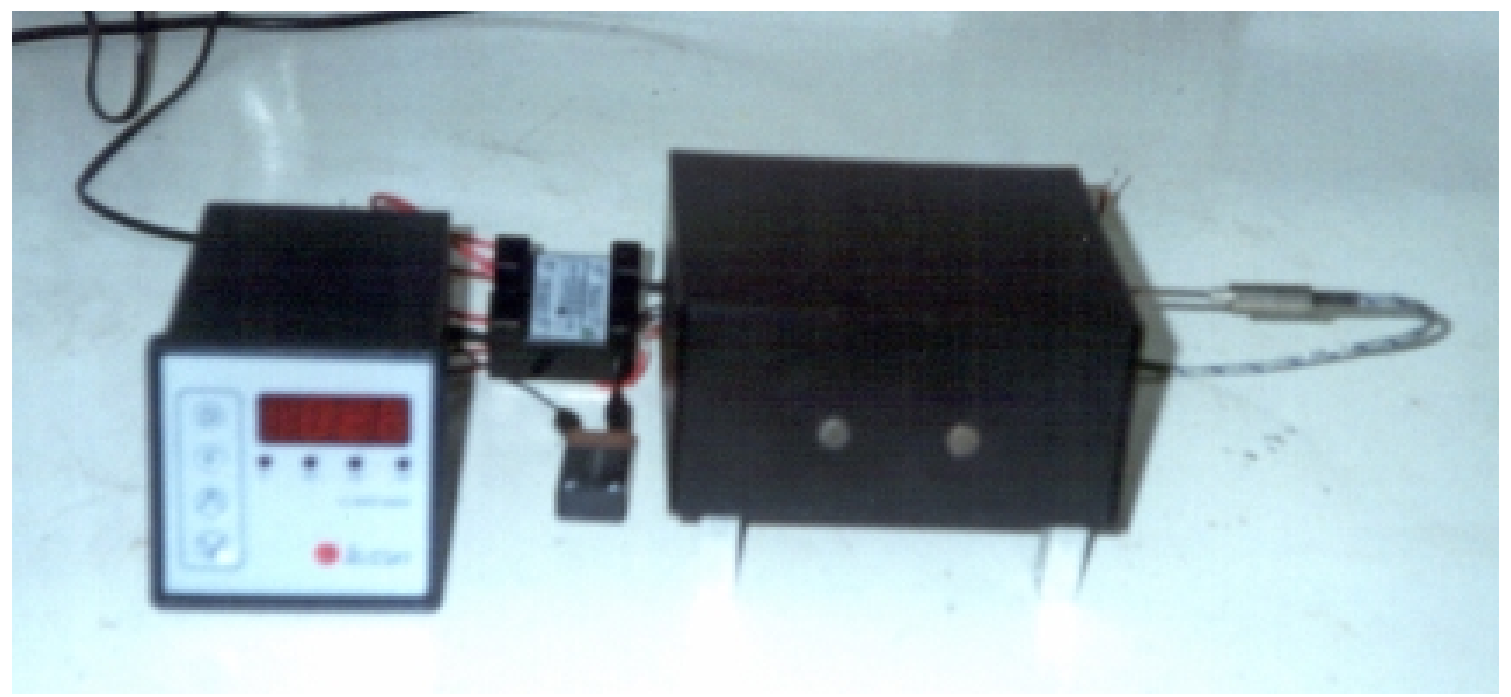

FIGURA 31. Processo industrial exemplo: mini-forno. 


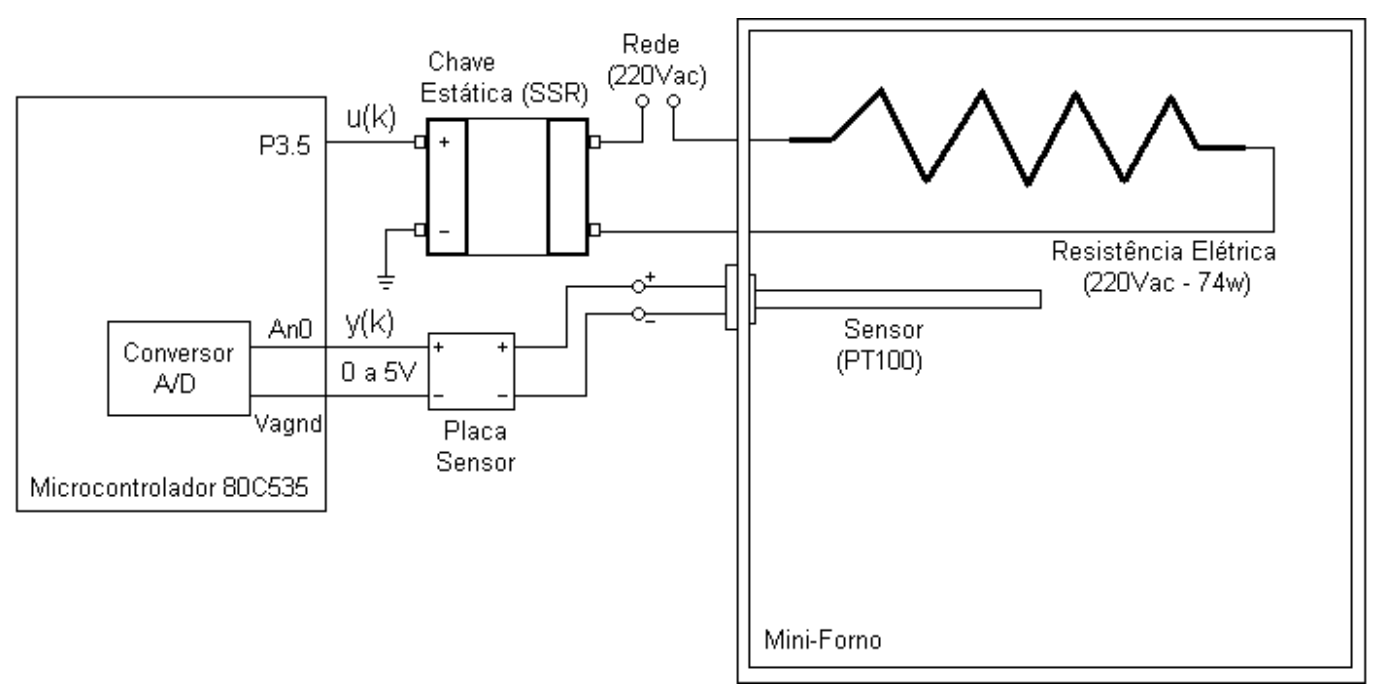

FIGURA 32: Diagrama em bloco do sistema de controle a malha fechada.

Este mini-forno foi ensaiado em bancada pela aplicação de um degrau de potência e a sua curva temperatura-tempo foi levantada.

Aplicando o $1^{\circ}$ método de Ziegler-Nichols para a curva de resposta temporal levantada do mini-forno obtém-se os parâmetros característicos $K_{P}, L$ e $T$, que levam à seguinte função de transferência aproximada:

$$
G(s)=\frac{0,75 e^{-95 s}}{219 s+1}
$$

Os parâmetros característicos do processo também foram obtidos pelo procedimento de estimação implementado juntamente com a sintonia automática do controlador PID (seção 8.1). Os parâmetros resultantes são :

$$
G(s)=\frac{0,77 e^{-33 s}}{484 s+1}
$$

A resposta temporal dada por (5.2), (5.3) e a resposta experimental são dadas na Figura 33 abaixo. 


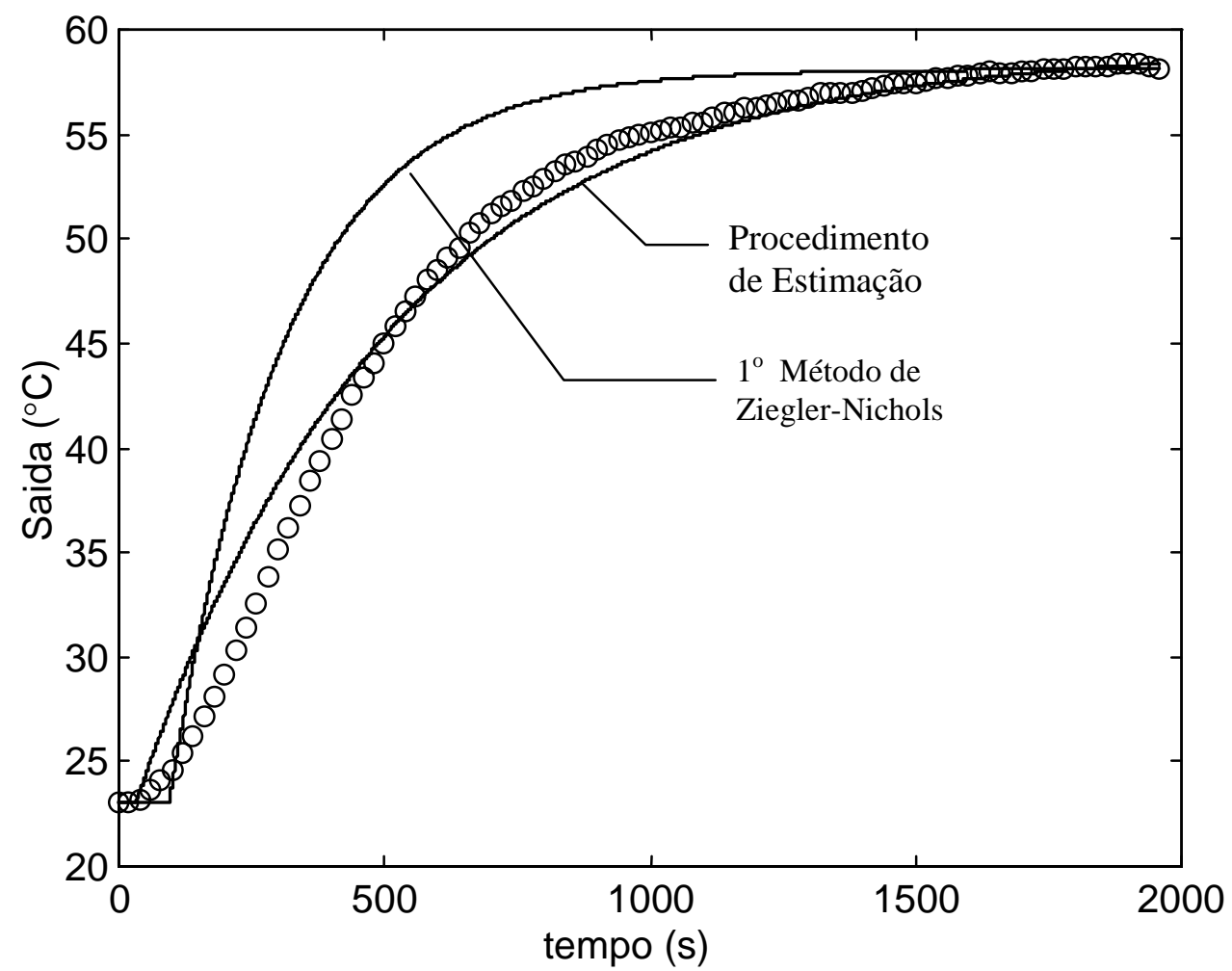

FIGURA 33. Funções de transferência aproximadas para o mini-forno. 


\section{Simulações}

Os cinco algoritmos para sintonia apresentados nas Seções 3.1, 3.2, 3.3, 3.4 e 3.5 foram simulados no programa Matlab (ambiente Simulink) e os resultados obtidos com cada um deles serão apresentados a seguir juntos com uma comparação em termos das margens de fase e ganho apresentadas em cada situação.

\subsection{Processos Utilizados}

Os processos utilizados são de primeira ordem mais tempo morto com o tempo normalizado $L / T$ no intervalo 0,05 a 8,0, como especificado no desenvolvimento de cada método de sintonia apresentado, sendo que três deles são processos fictícios (I, II e III) e um correspondente a curva de resposta do mini-forno utilizado (processo IV).

As funções de transferência são dadas abaixo e as curvas de resposta ao degrau unitário dos quatro processos são mostradas na Figura 34.

Processo I : $\quad G(s)=\frac{e^{-0.1 s}}{s+1} \quad$ Processo III: $G(s)=\frac{e^{-80 s}}{10 s+1}$

Processo II : $\quad G(s)=\frac{e^{-1.0 s}}{s+1} \quad$ Processo IV : $\quad G(s)=\frac{0,77 e^{-33 s}}{484 s+1}$
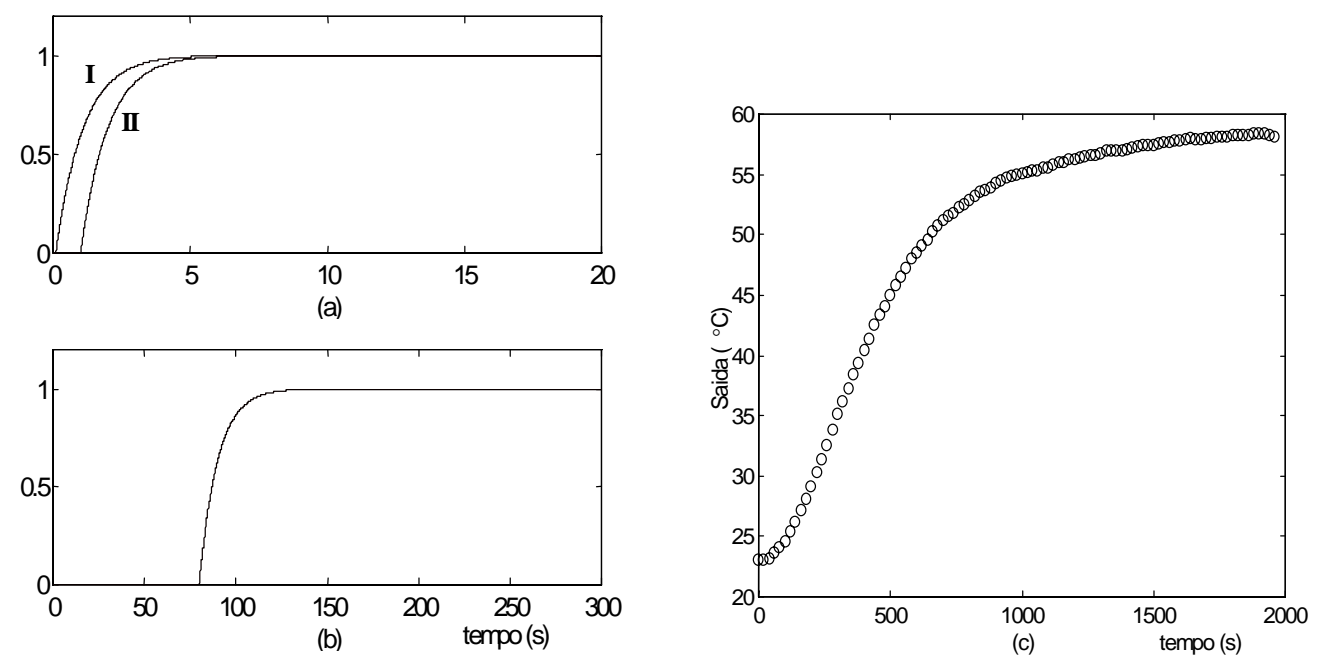

FIGURA 34. Resposta temporal a entrada tipo degrau dos processos: (a) I e II; (b) III e (c ) IV. 


\section{Ciclo Limites e Sintonia Automática}

Com as funções de transferências foi gerado no ambiente Simulink® do Matlab o ciclo limite para estes processos através do inclusão de um elemento não linear na malha fechada como proposto por ASTROM \& HAGGLUND (1984) onde sugere-se a utilização de um relê. O ciclo limite foi alcançado incrementando-se a amplitude $\underline{d}$ do relê a partir de 1 até surgir uma oscilação com período e amplitude constantes. Com estes valores e as equações (3.7) a (3.9), (3.28) e (3.33), (3.53) a (3.58) e (3.63), e (3.84) a (3.86) os valores dos parâmetros de controladores PID foram sintonizados para os processos I, II, III e IV. Para o método proposto por FRIMAN (1997) um controlador PI inicial que cause o ciclo limite é usado para cada processo e as equações (3.69), (3.72) e (3.77) fornecem os parâmetros do controlador PI sintonizado.

Os ciclos limites obtidos com oscilação a relê são mostrados na Figura 35 para os processos I, II, III e IV. Os ciclos limites obtidos pelo método proposto por FRIMAN (1997) são dados na Figura 36. As Tabelas 5, 6, 7 e 8 mostram os valores sintonizados para os parâmetros dos controladores por cada método bem como a margem de ganho e fase atingidas. As respostas em malha fechada com os controladores são mostradas nas Figuras $37,38,39$ e 40 .

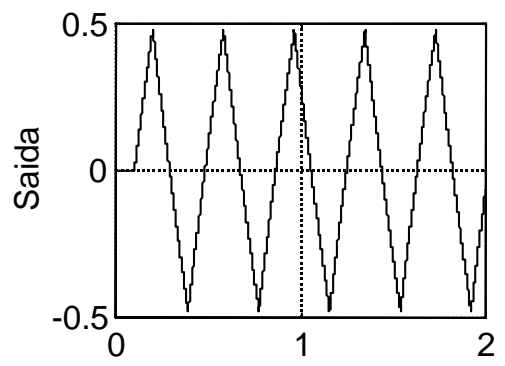

(a)

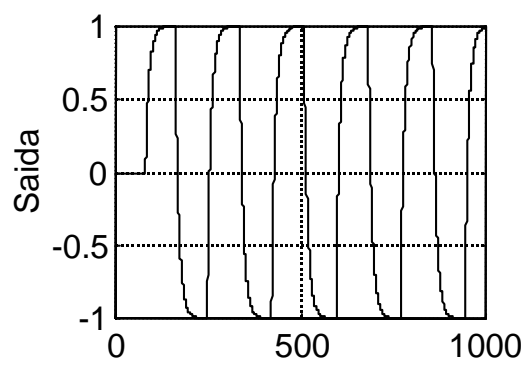

(c) tempo (s)

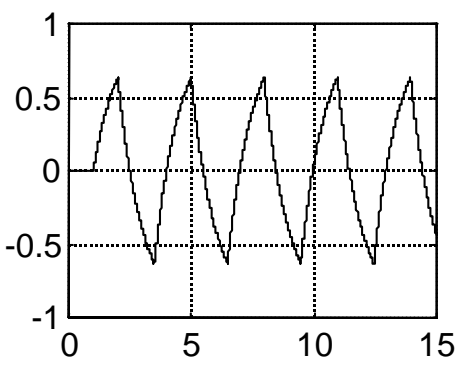

(b)

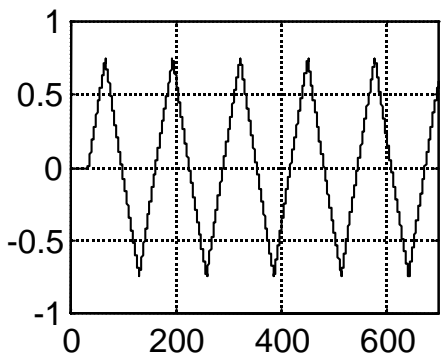

(d) tempo (s)

FIGURA 35. Ciclos limites alcançados para os processos por oscilação a relê: (a) I: $d=5, a_{0}=$ 0,48 e $\mathrm{t}_{\mathrm{o}}=0,38 \mathrm{~s}$; (b) II: $\mathrm{d}=1, \mathrm{a}_{\mathrm{o}}=0,63$ e $\mathrm{t}_{\mathrm{o}}=2,98 \mathrm{~s}$; (c ) III: $\mathrm{d}=1, \mathrm{a}_{\mathrm{o}}=1,0$ e $\mathrm{t}_{\mathrm{o}}=174,0 \mathrm{~s}$ e (d) IV: $\mathrm{d}=15, \mathrm{a}_{\mathrm{o}}=0,75$ e $\mathrm{t}_{\mathrm{o}}=129,6 \mathrm{~s}$. 


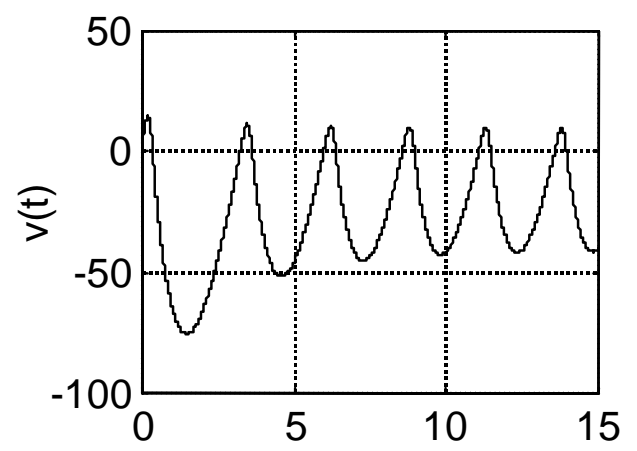

(a)

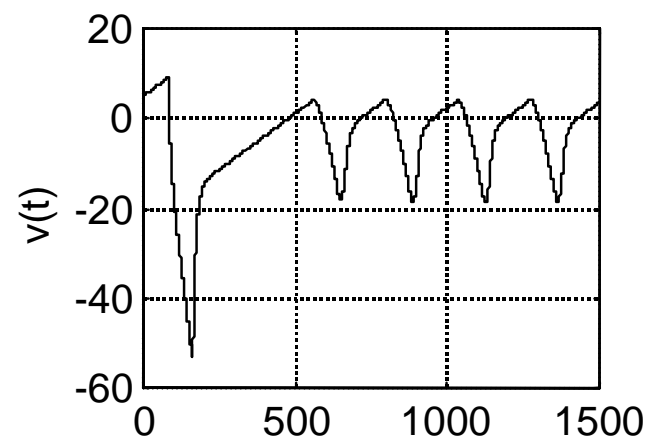

(c) tempo (s)

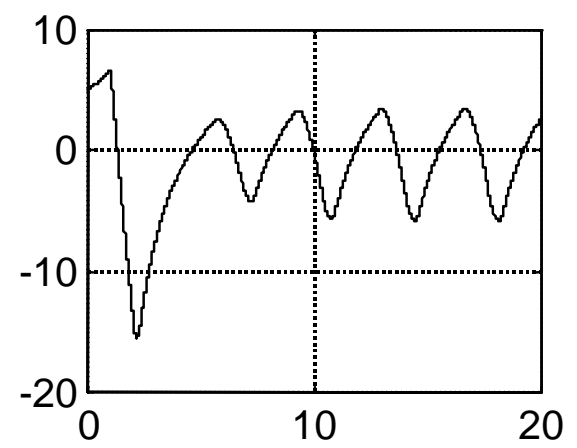

(b)

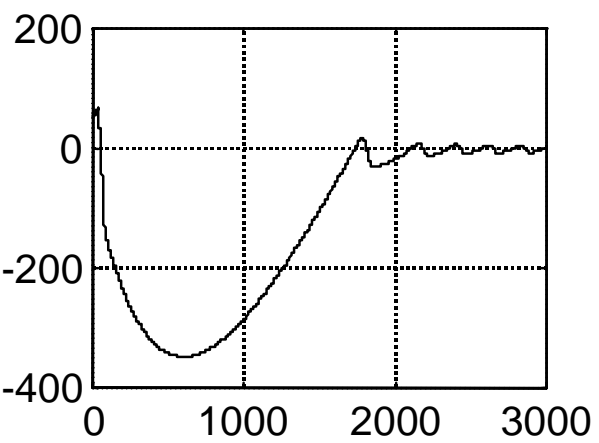

(d) tempo (s)

FIGURA 36. Ciclos limites alcançados pelos quatro processos pelo método de Friman (referência = 1): (a) I : $K_{c}=4, T_{i}=0,05$; (b) II : $K_{c}=5, T_{i}=3$; (c ) III : $K_{c}=5, T_{i}=100$ e (d) IV: $K_{c}=50, T_{i}=100$. 


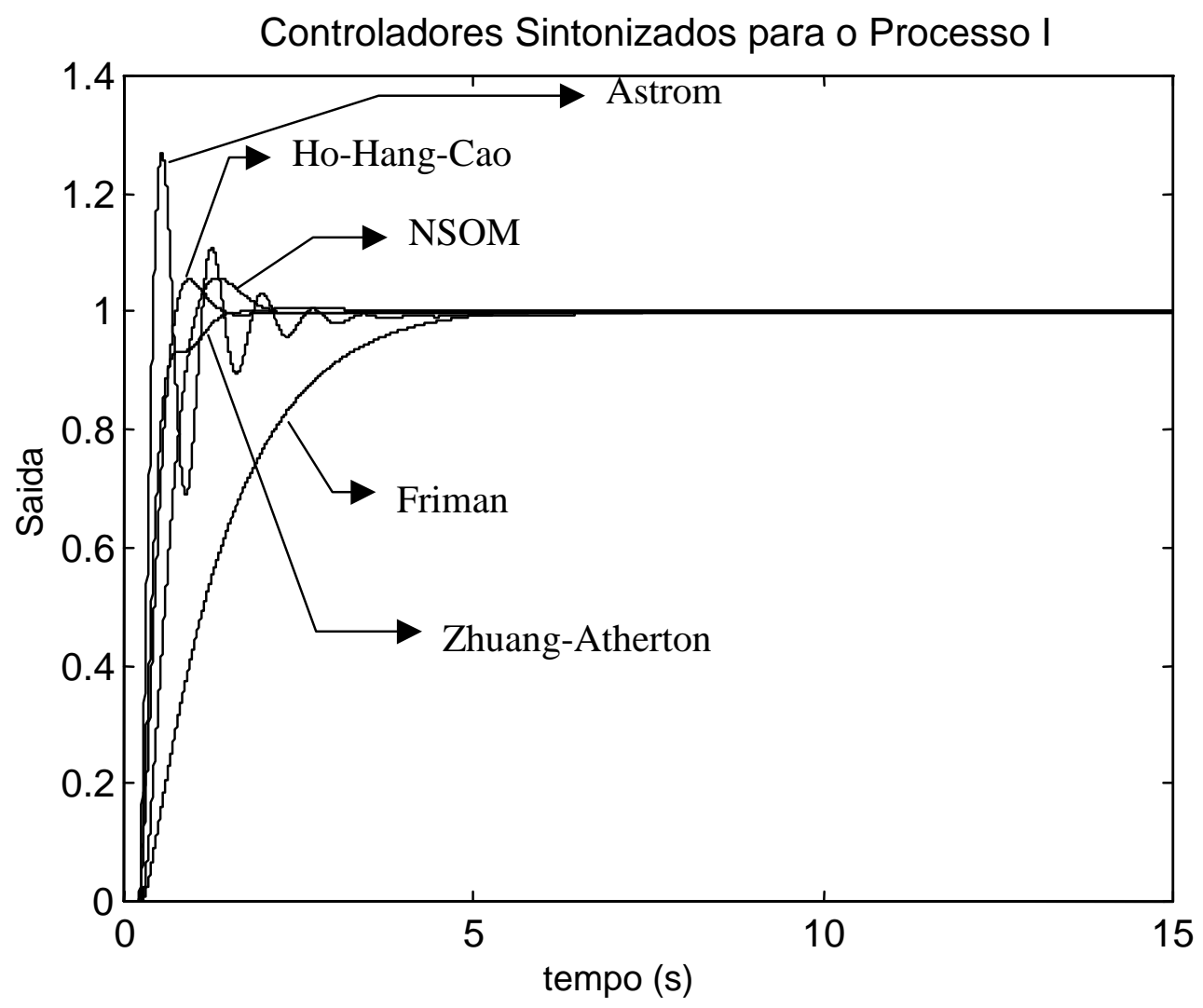

FIGURA 37. Resposta ao degrau unitário com os controladores obtidos pelos 5 métodos.

TABELA 5: Valores dos parâmetros do controlador e margens de ganho e fase para o processo I.

\begin{tabular}{|l|c|c|c|c|c|c|}
\cline { 3 - 6 } \multicolumn{2}{c|}{} & \multicolumn{5}{c|}{ Controlador } \\
\cline { 3 - 7 } \multicolumn{2}{c|}{} & Astrom & $\begin{array}{l}\text { Zhuang - } \\
\text { Atherton }\end{array}$ & $\begin{array}{l}\text { Ho-Hang- } \\
\text { Cao }\end{array}$ & NSOM & Friman \\
\hline \multirow{3}{*}{$\begin{array}{l}\text { Parâmetros do } \\
\text { Controlador }\end{array}$} & $K_{c}$ & 9,3 & 6,7 & 5,2 & 7,1 & 2,0 \\
\cline { 2 - 7 } & $T_{i}(\mathrm{~s})$ & 1,30 & 0,99 & 1,00 & 1,04 & 0,95 \\
\hline \multirow{2}{*}{$\begin{array}{l}\text { Margem de } \\
\text { Fase e Ganho }\end{array}$} & $T_{d}(\mathrm{~s})$ & 0,06 & 0,05 & --- & 0,25 & -- \\
\cline { 2 - 7 } & $A_{m}$ & 1,4 & 2,5 & 3,0 & 2,6 & 7,8 \\
\hline
\end{tabular}




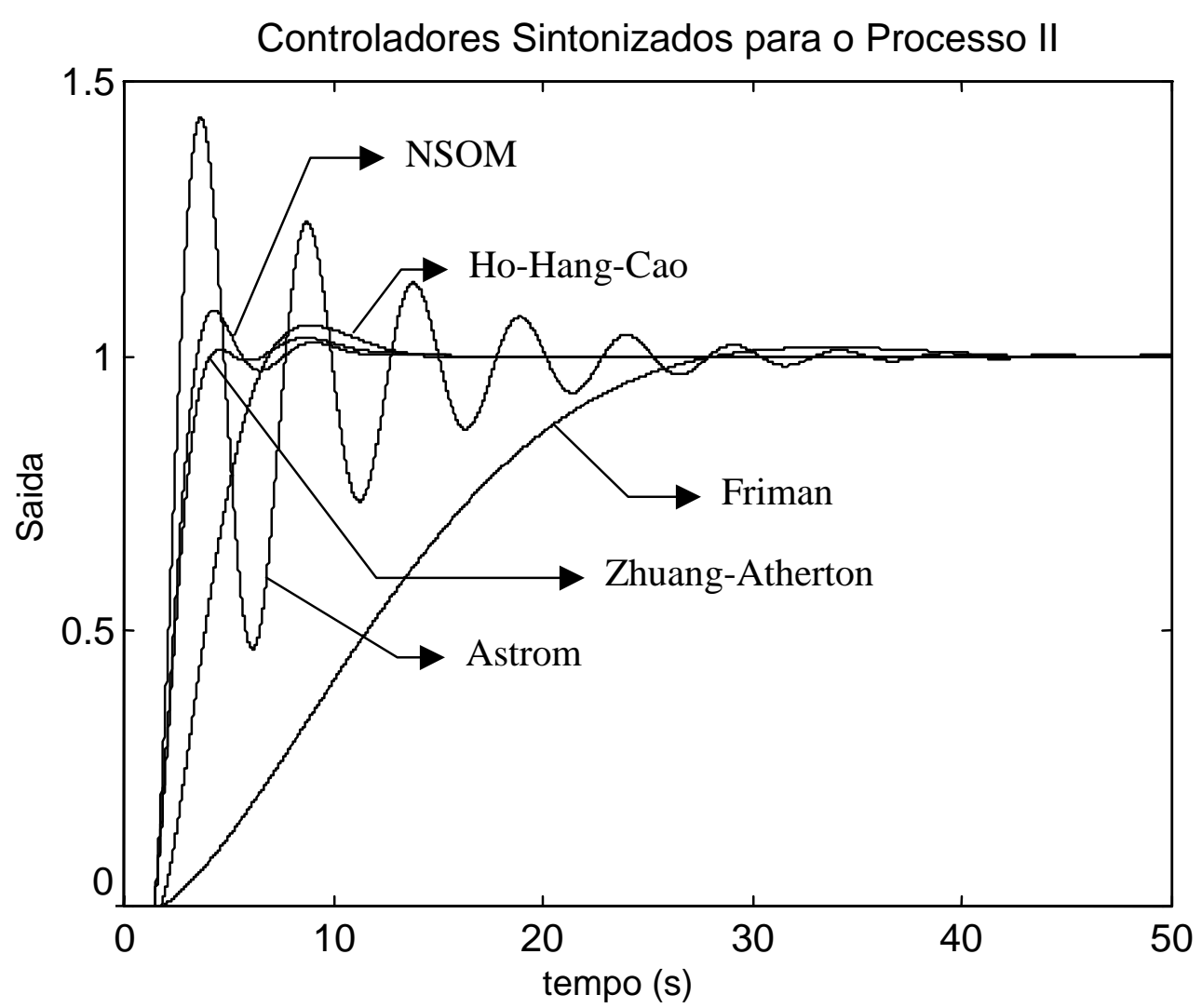

FIGURA 38. Resposta ao degrau unitário com os controladores obtidos pelos 5 métodos.

TABELA 6: Valores dos parâmetros do controlador e margens de ganho e fase para o processo II.

\begin{tabular}{|l|c|c|c|l|c|c|}
\cline { 3 - 7 } \multicolumn{2}{c|}{} & \multicolumn{6}{|c|}{ Controlador } \\
\cline { 2 - 8 } \multicolumn{2}{c|}{} & Astrom & $\begin{array}{l}\text { Zhuang- } \\
\text { Atherton }\end{array}$ & $\begin{array}{l}\text { Ho-Hang- } \\
\text { Cao }\end{array}$ & NSOM & Friman \\
\hline \multirow{4}{*}{$\begin{array}{l}\text { Parâmetros do } \\
\text { Controlador }\end{array}$} & $K_{c}$ & 1,8 & 1,0 & 0,5 & 1,1 & 0,6 \\
\cline { 2 - 8 } & $T_{i}(\mathrm{~s})$ & 2,5 & 1,2 & 1,0 & 1,3 & 1,2 \\
\cline { 2 - 8 } & $T_{d}(\mathrm{~s})$ & 0,3 & 0,4 & --- & 0,3 & --- \\
\hline $\begin{array}{l}\text { Margem de } \\
\text { Fase e Ganho }\end{array}$ & $\mathrm{A}_{\mathrm{m}}$ & 1,3 & 2,2 & 3,0 & 2,0 & 2,8 \\
\cline { 2 - 8 } & $\Phi_{m}\left(^{\circ}\right)$ & 45,4 & 61,0 & 60,0 & 60,0 & 63,9 \\
\hline
\end{tabular}




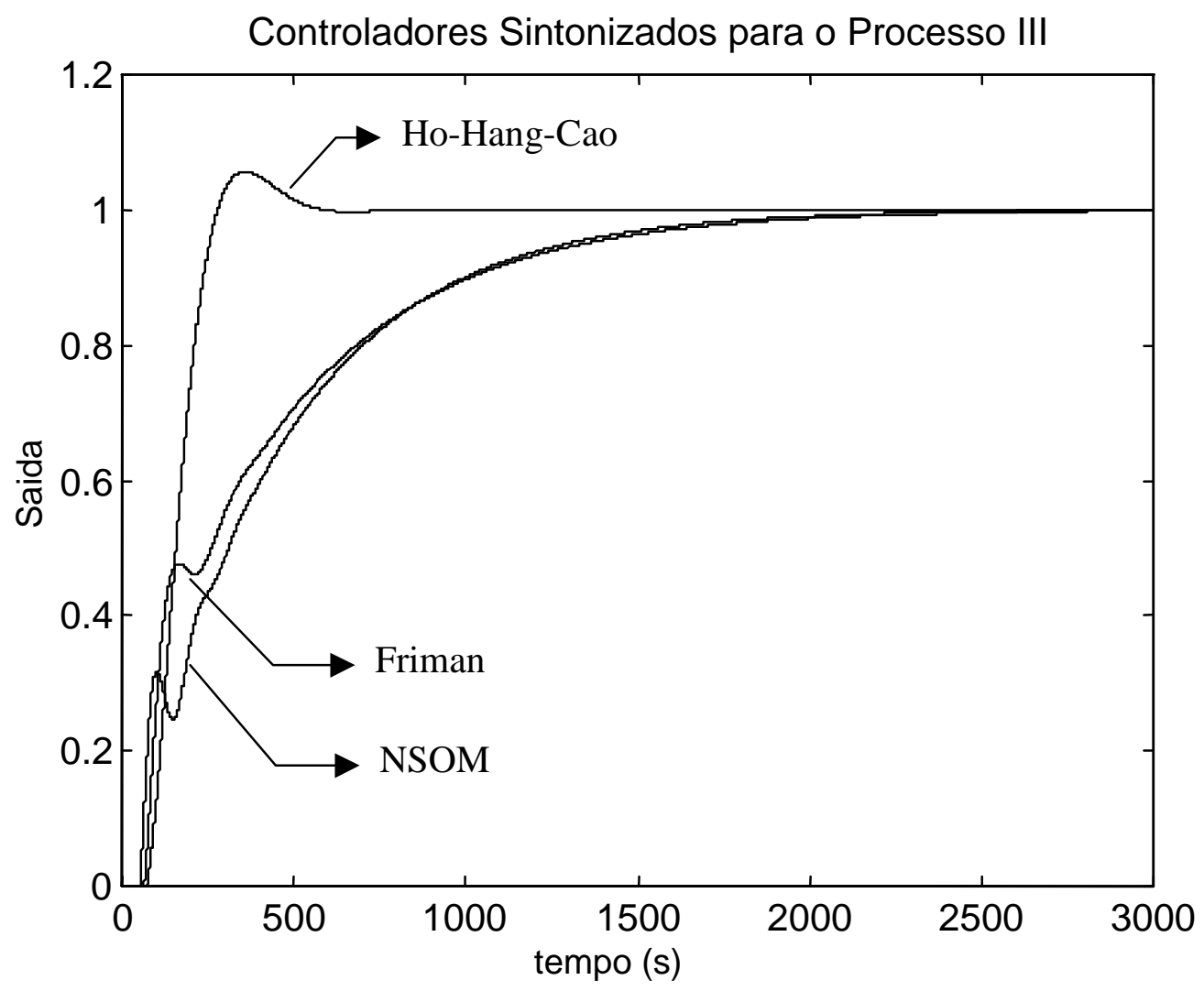

FIGURA 39. Resposta ao degrau unitário com o controlador obtido por 3 dos 5 métodos.

TABELA 7: Valores dos parâmetros do controlador e margens de ganho e fase para o processo III.

\begin{tabular}{|l|c|c|c|c|c|c|}
\cline { 3 - 7 } \multicolumn{2}{c|}{} & \multicolumn{5}{c|}{ Controlador } \\
\cline { 3 - 7 } \multicolumn{2}{c|}{} & Astrom & $\begin{array}{l}\text { Zhuang - } \\
\text { Atherton }\end{array}$ & $\begin{array}{l}\text { Ho-Hang- } \\
\text { Cao }\end{array}$ & NSOM & Friman \\
\hline \multirow{3}{*}{$\begin{array}{l}\text { Parâmetros do } \\
\text { Controlador }\end{array}$} & $K_{c}$ & --- & --- & 0,065 & 0,186 & 0,324 \\
\cline { 2 - 7 } & $T_{i}(\mathrm{~s})$ & --- & --- & 10,0 & 81,6 & 134,5 \\
\cline { 2 - 7 } Margem de & $T_{d}(\mathrm{~s})$ & --- & --- & --- & 40 & --- \\
\hline \multirow{2}{*}{ Fase e Ganho } & $A_{m}$ & --- & --- & 3,0 & 3.1 & 3,2 \\
\cline { 2 - 7 } & $\Phi_{m}\left(^{\circ}\right)$ & --- & --- & 60,0 & 89,0 & 95,8 \\
\hline
\end{tabular}




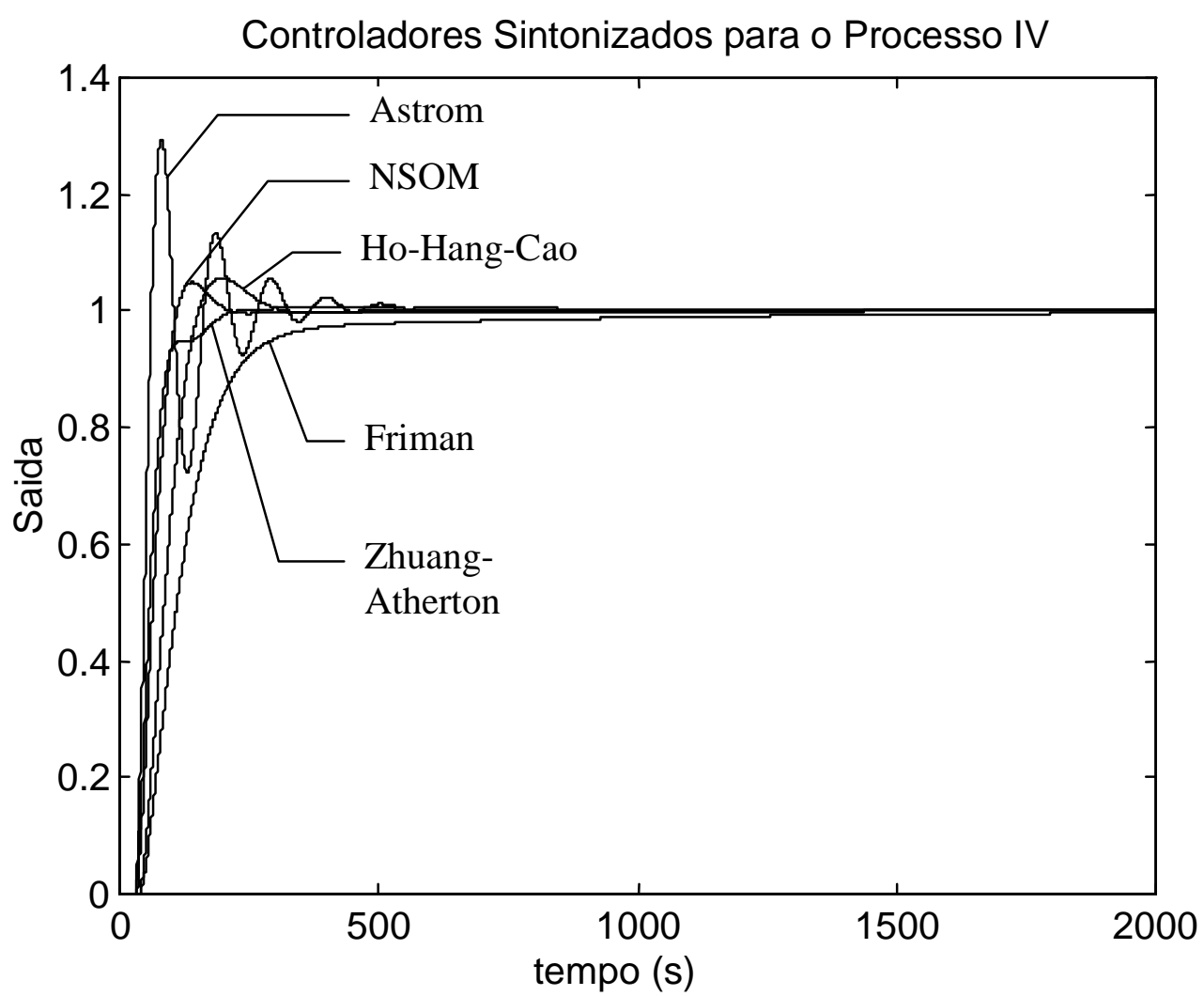

FIGURA 40. Resposta ao degrau unitário com os controladores obtidos pelos 5 métodos.

TABELA 8: Valores dos parâmetros do controlador e margens de ganho e fase para o processo IV.

\begin{tabular}{|l|c|c|c|c|c|c|}
\cline { 3 - 7 } \multicolumn{2}{c|}{} & \multicolumn{5}{c|}{ Controlador } \\
\cline { 3 - 7 } \multicolumn{2}{c|}{} & Astrom & $\begin{array}{l}\text { Zhuang - } \\
\text { Atherton }\end{array}$ & $\begin{array}{l}\text { Ho-Hang- } \\
\text { Cao }\end{array}$ & NSOM & Friman \\
\hline \multirow{3}{*}{$\begin{array}{l}\text { Parâmetros do } \\
\text { Controlador }\end{array}$} & $K_{c}$ & 18,0 & 13,0 & 10,2 & 13,7 & 7,0 \\
\cline { 2 - 7 } & $T_{i}(\mathrm{~s})$ & 432,2 & 463,2 & 484,0 & 503,6 & 578,8 \\
\hline Margem de & $T_{d}(\mathrm{~s})$ & 22 & 14 & --- & 8 & -- \\
\cline { 2 - 8 } Fase e Ganho & $A_{m}$ & 1,5 & 2,5 & 3,0 & 2,6 & 4,4 \\
\cline { 2 - 7 } & $\Phi_{m}\left(^{\circ}\right)$ & 63,9 & 67,8 & 60,0 & 60,2 & 71,4 \\
\hline
\end{tabular}




\section{Comparações e Discussões}

Processo I : Para o valor de tempo morto normalizado $\left(\varnothing_{I}=L / T\right)$ considerado vemos que levando em consideração o compromisso entre um tempo de acomodação rápido e um sobresinal pequeno (nulo se possível), a melhor resposta é obtida pelo método de ZhuangAtherton. O tempo de acomodação é o menor e o sobre-sinal nulo (porém com um pequeno sub-sinal). O método de Astrom resulta numa resposta bastante oscilatória devido ao fato de ter resultado no maior ganho para o termo proporcional do controlador PID (tabela 5) entre todos os métodos, resultando na menor margem de ganho alcançada; possui também um sobre-sinal elevado (25\%). O método NSOM já obtém uma resposta melhor porém com o tempo de acomodação maior, resultando num ganho entre o apresentado por ZhuangAtherton e Aström, esta resposta pode variar de acordo com a constante adota para o calculo de $T_{d}$. Dos métodos que sintonizam controladores PI o método de Ho-Hang-Cao obtém um resultado muito bom para o controlador PI com um tempo de acomodação idêntico ao de Zhuang-Atherton e com um sobre sinal aceitável (cerca de 5\%) que também pode ser visto pelas margens de ganho e fase alcançadas. Já o controlador PI do método de Friman não apresenta sobre-sinal mas ao custo do maior tempo de acomodação e tempo de subida entre todos eles; sua margem de ganho, consequentemente, é a mais alta sendo mais de $100 \%$ maior entre as dos outros métodos. De maneira geral todos os métodos alcançaram boas margens de fase com valores entre $60^{\circ}$ e $68^{\circ}$ (exceção do método de Friman) e boas margens de ganho (exceção do método de Aström).

Processo II : Na sintonia do processo II repete-se a situação anterior na qual a resposta pelo método de Aström é oscilatória com o maior $K_{c}$ alcançado, com sobre-sinal elevado e agora acentuado por uma margem de fase de $45^{\circ}$; a solução dada pelo método de Friman resulta no maior tempo de acomodação e de subida sem a presença de sobre-sinal agora com valores para as margens de ganho e fase próximas as atingidas pelos outros métodos; o método de Zhuang-Atherton é que fornece a melhor resposta temporal. A diferença aparece nas respostas obtidas pelos métodos de Ho-Hang-Cao e NSOM. Por outro lado, a solução dada pelo método de Ho-Hang-Cao apresenta um tempo de acomodação maior que a de ZhuangAtherton (atingindo uma margem de ganho $40 \%$ maior que deste) e o método NSOM resulta num controlador com parâmetros muito próximos aos obtidos pelo método de ZhuangAtherton e também com margens de ganho e fase próximas, porém com um pouco de sobre- 
sinal. Novamente todos os métodos alcançaram boas margens de fase com valores entre $60^{\circ}$ e $64^{\circ}$ (exceção do método de Aström) e boas margens de ganho.

Processo III : O terceiro processo é um caso a parte pois apresenta $\varnothing_{1}=8$ e nenhum dos métodos apresentados propõem-se a trabalhar com valores de tempo morto normalizado maior que 1. Ele foi adotado apenas para verificar a "robustez" do método frente a valores de entrada fora de faixa de validade (em geral $0,1 \leq \varnothing_{I} \leq 1,0$ ). Os métodos de NSOM e Friman apresentam elevados tempos de acomodação e de subida e margens de fase em torno de $90^{\circ}$. Surpreendentemente o método de Ho-Hang-Cao alcançam uma sintonia com tempo de acomodação, tempo de subida e sobre-sinal bons e margens de ganho e fase também muito boas comparáveis às obtidas na sintonia dos outros processos. É visto da tabela 7 que este desempenho é obtido com um ganho proporcional do controlador PI muito reduzido o que em termos de aplicação prática traria dificuldades de implementação, mas como a proposta deste exemplo é a de testar o desempenho do método de sintonia este método consegue sair-se muito bem. Os demais métodos (Aström e Zhuang-Atherton) falharam na sintonia deste processo (lembrando que nenhum deles propõe-se a realizar a sintonia de um processo com $\varnothing_{1}=8$ ).

Processo IV : A melhor resposta obtida para este processo novamente é a dada pelo método de Zhuang-Atherton. O método NSOM fornece um tempo de subida e de acomodação praticamente idênticos aos fornecidos pelo método de Zhuang-Atherton porém com a presença de sobre-sinal na resposta. O método de Ho-Hang-Cao fornece um tempo de subida maior que os anteriores, com sobre-sinal presente e tempo de acomodação também maior; as margens de ganho e fase atingidas são boas ( 3 e $60^{\circ}$, respectivamente). $\mathrm{O}$ método de Friman fornece a resposta com o maior tempo de subida e juntamente com a dada pelo método de Aström possui o maior tempo de acomodação. A resposta dada pelo método de Aström resulta, como nos casos anteriores, em uma resposta oscilatória; seu ganho proporcional é $38 \%$ maior que o apresentado por Zhuang-Atherton e a margem de ganho alcançada é $40 \%$ menor, o sobre-sinal também é elevado. Todos os métodos atingiram boas margens de fase com valores entre $60^{\circ}$ e $71,4^{\circ}$ e boas margens de ganho entre 2,5 e 4,4 (exceção Aström). 


\subsection{Diagramas de Simulação}

Para geração dos dados necessários para a realização da sintonia dos processos apresentados na Seção 6.1 foi utilizado o ambiente denominado Simulink ${ }^{\circledR} 1.3 \mathrm{c}$ da Mathworks que possibilita trabalhar no Matlab com uma interface gráfica.

Foi desenhada então a malha para obtenção de ciclos limites para sistemas de primeira ordem com tempo morto, que é mostrada na Figura 41. O ciclo limite é obtido através da presença de um relê na malha fechada. Para cada processo foi-se aumentando o valor da amplitude do relê, a partir do valor unitário, até obter-se o ciclo limite.

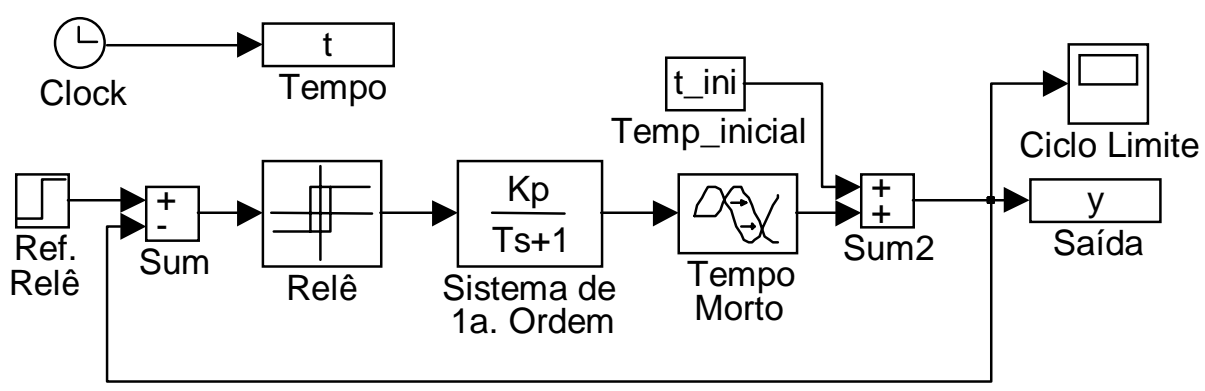

FIGURA 41. Diagrama utilizado para geração do ciclo limite dos processos I, II, III e IV.

Clicando-se duas vezes sobre o bloco Ciclo Limite abre-se uma janela onde os ciclos limites alcançados podem ser observados.

Os dados gerados estão disponíveis nas variáveis $\underline{t}$ e $\underline{y}$ para serem utilizados por um programa, feito no Matlab, que obtém os valores do período crítico e da amplitude crítica do ciclo limite alcançado. Com estes valores calculados são aplicados os esquemas de sintonia propostos por cada método obtendo-se então os valores dos ganhos do controlador PID desejado. Com estes ganhos em mãos, outro diagrama no Simulink é utilizado para obter-se as resposta ao degrau unitário dos sistemas controlados. Este diagrama é dado na Figura 42. 


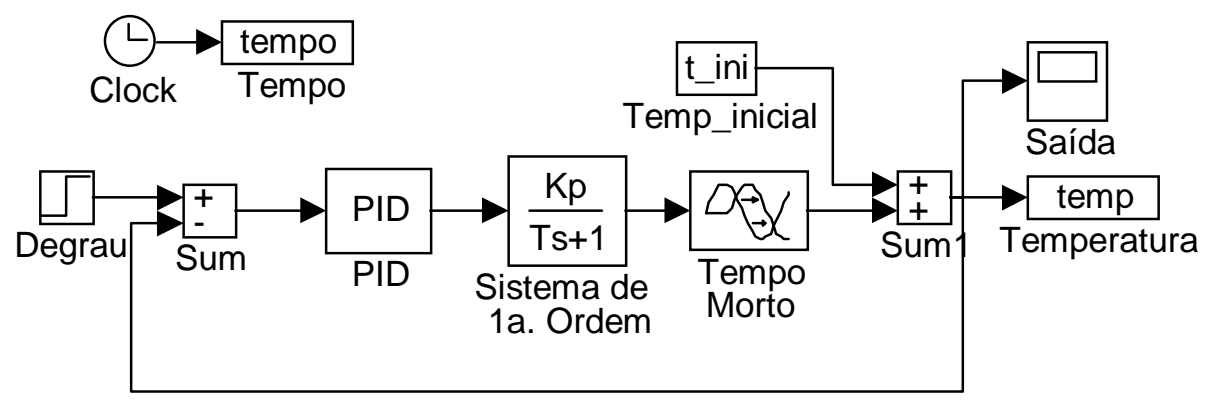

FIGURA 42 . Malha fechada com controlador PID para obtenção da resposta ao degrau.

Os diagramas anteriores não consideram aspectos encontrados na prática como o sensor de temperatura utilizado e seu circuito de entrada, o PWM para o acionamento do processo, o algoritmo PID implementado em programação e um nível (bias) aplicado à saída do relê para garantir oscilações simétricas, quando necessário. Para levarmos em consideração estes elementos os diagramas dados na Figura 43 foram utilizados. A forma adotada para implementação da ação de controle PID foi a absoluta ou posicional, dada pelas equações (2.10), (2.14) e (2.20), por ser a mais encontrada nos aparelhos comerciais disponíveis.

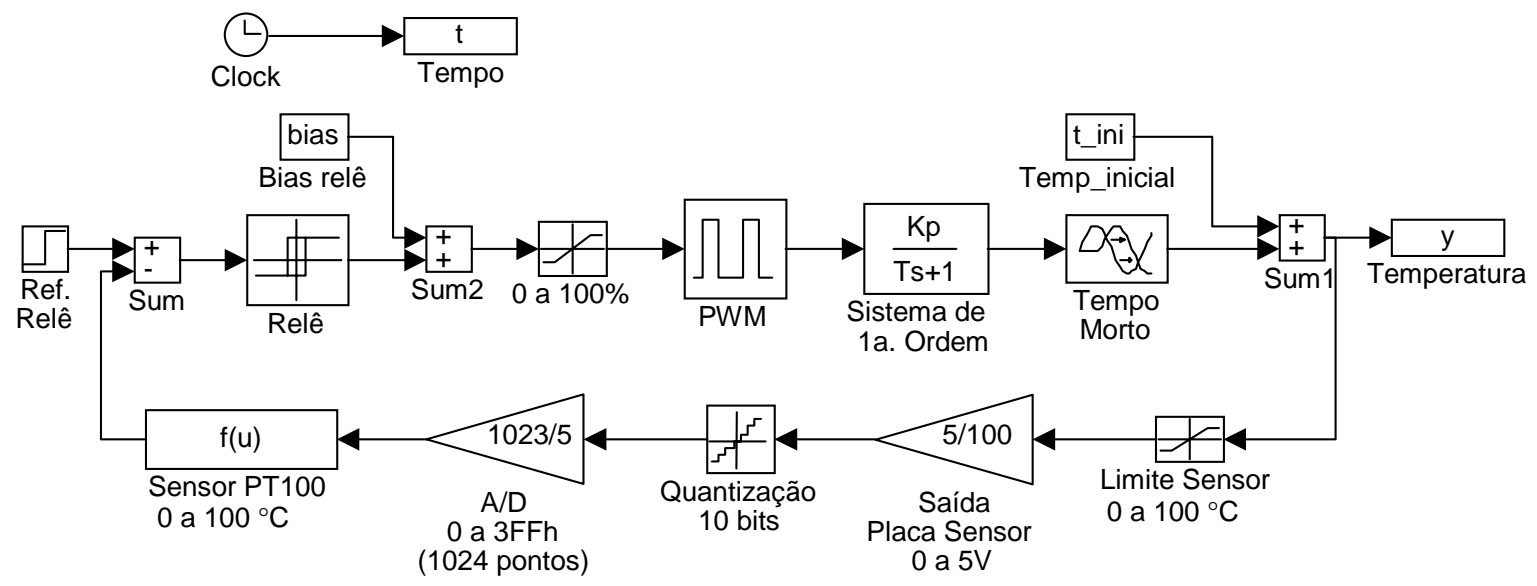

(a) 


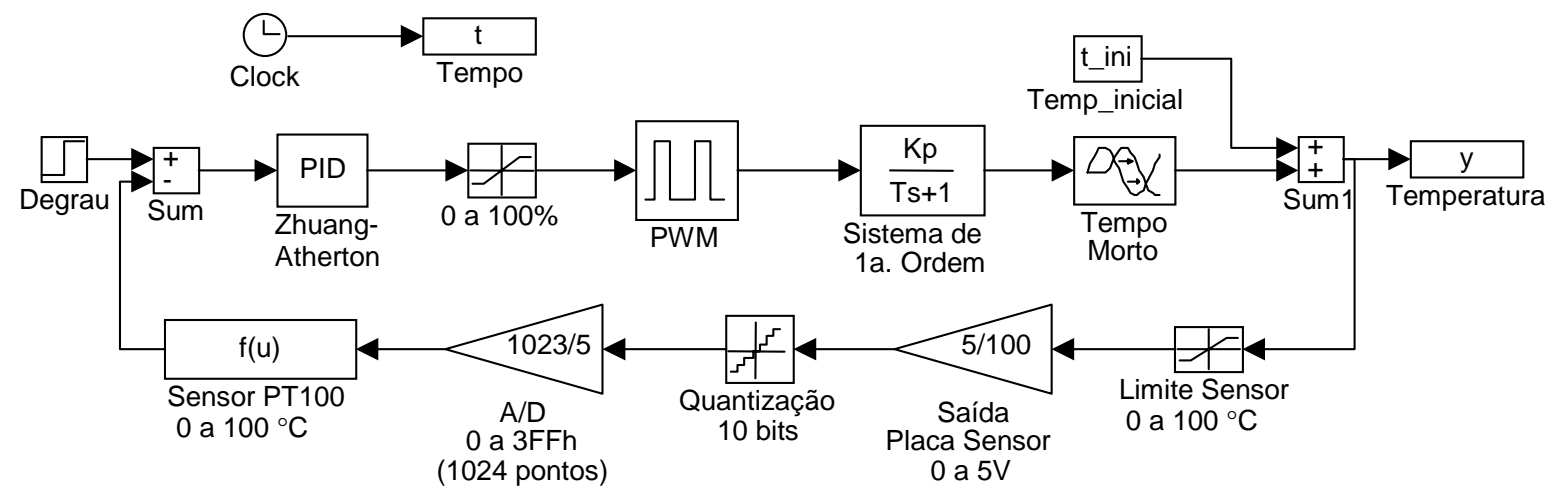

(b)

FIGURA 43. Diagrama de simulação contendo todos os elementos presentes na malha para realização: (a) do experimento a relê; (b) do controle a malha fechada com controlador PID. 


\section{Implementação da Técnica de Auto-Sintonia por Realimentação a Relê}

A implementação dos algoritmos de auto-sintonia no ambiente de microprocessadores requer a codificação destes algoritmos nas linguagens disponíveis para cada ambiente (família), como o assembly ou a linguagem $\mathrm{C}$, disponível para a maioria dos microcontroladores existentes no mercado. A escolha entre uma linguagem de baixo nível ou alto nível está principalmente condicionada à linguagem utilizada para a codificação do programa principal; nem todos os compiladores existentes aceitam que rotinas em alto nível sejam "linkadas" a programas escritos em baixo nível. Outros fatores também importantes como o tamanho da memória de programa disponível, número de bytes da memória RAM livres e velocidade de execução da malha fechada contribuem para esta escolha. De maneira geral, rotinas escritas em assembly ocupam menos memória de programa, são mais rápidas que suas equivalentes em linguagem de alto nível e requerem menos bytes de memória RAM pois permitem um controle total sobre a forma de endereçamento das posições de memória e das chamadas de subrotinas.

Normalmente, os algoritmos requerem valores medidos de grandezas como temperatura, pressão e tempo que traduzam as características desejadas destas grandezas como valores pico-a-pico, valor médio, período e outros. Isto implica na utilização de varias rotinas auxiliares. Estas rotinas auxiliares serão então executadas antes da rotina principal de auto-sintonia e fornecerão todos os valores necessários a sua execução. Dependendo do tipo de caracterização ou análise necessárias de uma determinada grandeza, as rotinas auxiliares podem apresentar uma complexidade grande e demandarem um considerável tempo de desenvolvimento.

O algoritmo implementado (método Zhung-Atherton), resultante das comparações feitas no Capítulo 6, aplica-se a processos térmicos industriais que possam ser representados por sistemas de primeira ordem mais tempo morto. Estes sistemas sob realimentação a relê exibem um ciclo limite que fornece características sobre o processo que permitem a obtenção da sintonia dos parâmetros de um controlador PID. A sintonia automática é aplicada em sistemas que estejam dentro da faixa $0,05 \leq \mathrm{L} / \mathrm{T} \leq 2,0$ (faixa para a qual o método foi desenvolvido). 


\subsection{Linguagem, Descrição dos Parâmetros do Controlador PID em termos de Bandas e Condições Necessárias para Oscilação Simétrica a Relê.}

\section{Linguagem}

Com base no exposto acima e lembrando que o controlador industrial apresentado na Seção 5.1 é dotado do microcontrolador 80C535 e seu programa base é implementado em linguagem de baixo nível (assembly do 8051 e derivados), escolheu-se implementar todas as rotinas referentes a sintonia automática em assembly também. O programa base do controlador industrial utilizado compreende rotinas de varredura dos displays, varredura das teclas, sistema de menus apresentado ao usuário, manipulação das interrupções, leitura da entrada (conversão A/D do valor do sensor) e as inicializações necessárias das variáveis. Este programa ocupa 12 Kbytes de memória de programa e utiliza 160 bytes de memória RAM.

\section{Descrição dos parâmetros do controlador PID em termos de bandas}

Nos controladores industriais é comum apresentar os parâmetros do ganho do controlador $\mathrm{PID}, K_{c}$, tempo integral, $T_{i}$, e tempo derivativo, $\mathrm{T}_{\mathrm{d}}$, de forma que expressem um significado mais prático aos operadores.

Desta forma, o ganho $K_{c}$ do controlador PID é apresentado como uma sensibilidade, uma variação percentual da saída do controlador em relação a sua entrada que é denominada banda proporcional, BP. A relação que traduz esta sensibilidade é dada por,

$$
B P(\%)=\frac{100}{K_{C}}
$$

O interessante nesta forma de apresentação do ganho do controlador é que a banda proporcional permite uma interpretação gráfica. A banda proporcional mostra a variação linear do sinal de controle aplicado ao atuador variando de 0 a $100 \%$ para uma faixa de entrada do sensor de 0 a $100^{\circ} \mathrm{C}$. A Figura 44 mostra o acionamento de uma planta térmica 
por PWM da aplicação da referência até o atingimento do regime, assim a excursão do sinal de controle será de $100 \%$ a $0 \%$ do período $\left(\mathrm{C}_{\mathrm{T}}\right)$ do $\mathrm{PWM}$.

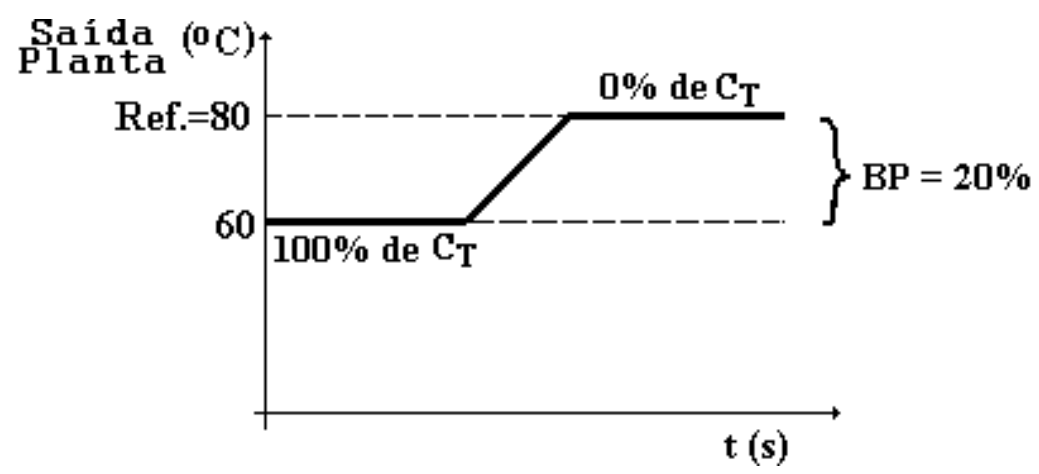

FIGURA 44. Exemplo de ganho proporcional do controlador PID apresentado como uma banda.

Para a Figura 44 pode-se escrever:

$$
\begin{aligned}
& P(t)=\left.u_{\text {pid }}(t)\right|_{T i, T d=0}=K_{c} e(t)=\frac{100}{B P}[r e f-y(t)]=\frac{100}{20}[80-y(t)] \Rightarrow \\
& P(t)=5[80-y(t)] \quad, 0 \leq P(t) \leq 100 \%
\end{aligned}
$$

onde $P(t)$ representa o sinal de controle aplicado ao atuador da planta ao longo do tempo.

Para valores da saída da planta menores ou iguais a $60^{\circ} \mathrm{C}$, a saída do controlador levará a execução de $100 \%$ do período do PWM (ou aplicação de $100 \%$ do sinal do atuador para o caso geral), para valores acima da referência será executado $0 \%$ do período do PWM (ou aplicação de $0 \%$ do sinal do atuador para o caso geral) e valores entre $60^{\circ} \mathrm{C}$ e $80^{\circ} \mathrm{C}$ provocarão na saída do atuador uma variação de seu sinal entre 0 a 100\%, definindo assim uma faixa ou banda onde o controlador atua sobre a planta.

Com o tempo integral também é possível buscar uma interpretação alternativa à versão presente no livros de teoria de controle.

A ação integral incrementa (ou decrementa) a saída do controlador proporcionalmente ao valor do erro e ao tempo de existência deste, o que leva a idéia de velocidade de eliminação do erro. Devido a esta velocidade de eliminação de erro a medida que o erro diminui esta velocidade também diminui. Como a ação integral adiciona (ou subtrai) um valor fixo à saída do controlador, após a eliminação do erro, a curva da banda proporcional é reposicionada eliminando-se o desvio existente. Devido a este efeito a ação integral também é chamada de ação de reset. A ação integral pode então ser dada pela banda integral, BI, 
que na maioria dos controladores industriais é medida em repetições por minuto. Esta medida indica quantas vezes por minuto é adicionada (ou subtraída) uma quantidade idêntica a obtida pela ação proporcional para o erro existente no dado instante.

A banda integral é dada pela relação,

$$
B I=\frac{K_{c}}{T_{i}}
$$

Para ilustrar esta ação de reset consideremos que para um erro de $20^{\circ} \mathrm{C}$ em relação à referencia, a ação proporcional provoca na saída do controlador uma variação de $20^{\circ} \mathrm{C}$. Para um controlador PI com banda integral de $0,1 \mathrm{rep} / \mathrm{min}$ e considerando que o erro permanece constante no tempo (para efeito de exemplo) a cada minuto o sinal de saída do controlador será incrementado em $10 \%$ do erro existente. Isto causa a reta observada na Figura 45 entre os tempos 0 e 10 minutos, lembrando que no caso real não se observará uma reta devido ao fato que a medida que o tempo passar o erro decrementará.
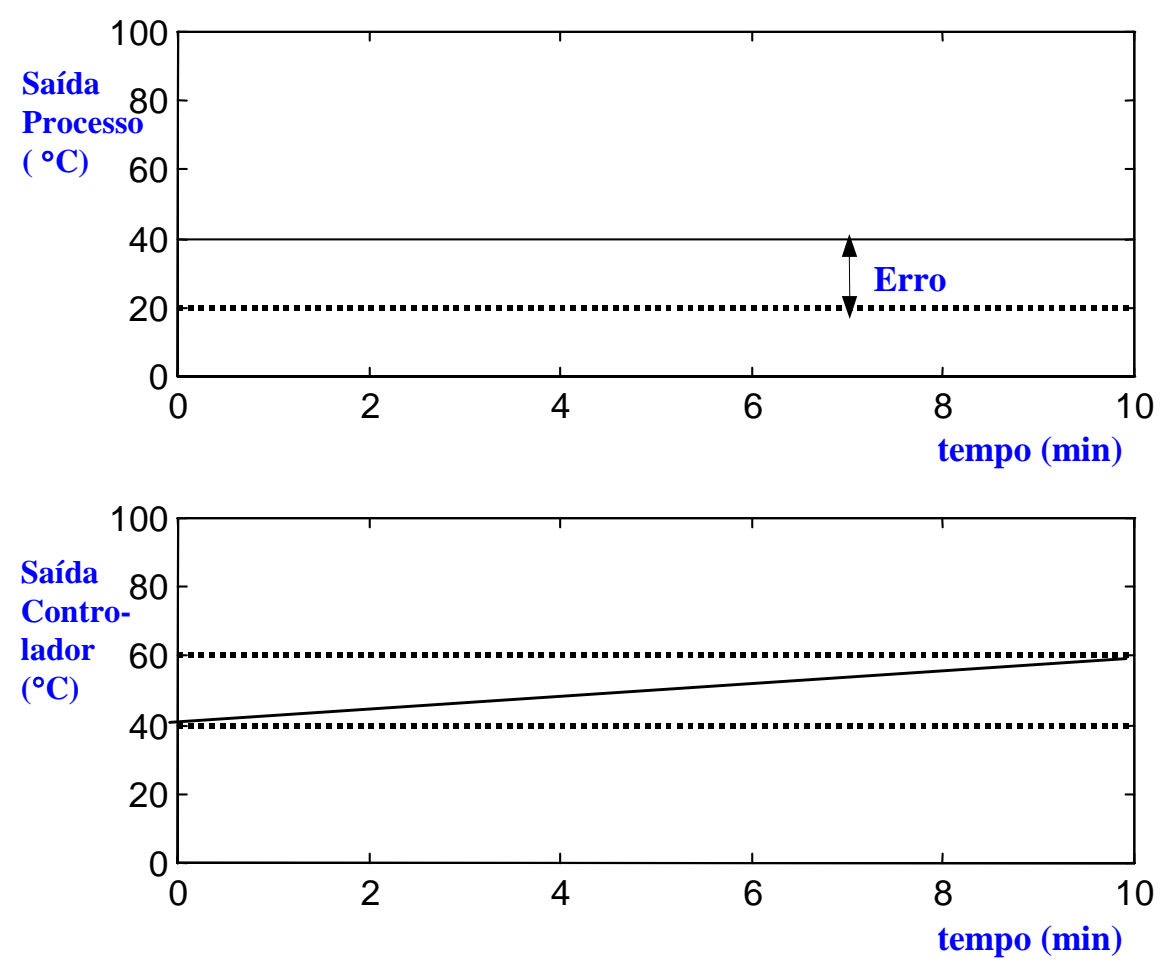

FIGURA 45. Exemplo da ação de reset do controlador PI.

Analogamente às bandas proporcional e integral, para a ação derivativa pode ser desenvolvida uma banda derivativa, $\mathrm{BD}$, que é numericamente igual ao tempo derivativo 
(medido em minutos). Este tempo indica a antecipação na correção em relação a ação proporcional. A banda derivativa é dada por

$$
B D=T_{d}
$$

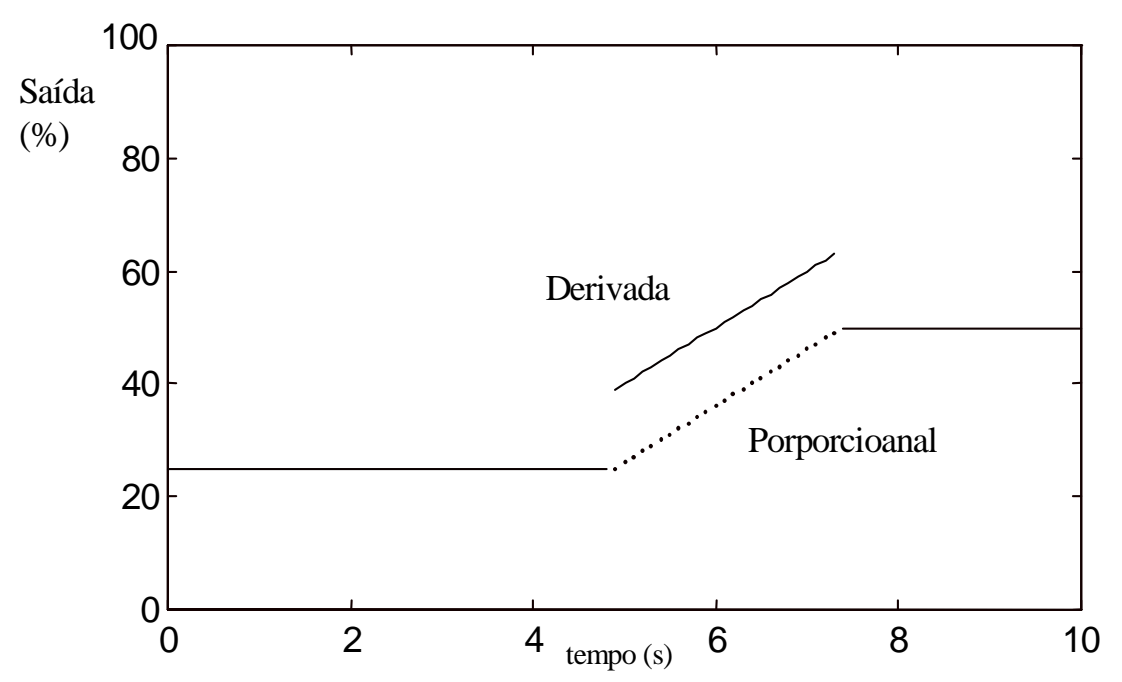

FIGURA 46. Ilustração da banda derivativa do controlador PD.

\section{Condições Necessárias para obter Oscilação Simétrica no Experimento a Relê}

Para obter ciclos limites livres de qualquer tipo de interferência alguns cuidados devem ser tomados durante o procedimento de excitação a relê, ASTROM et al. (1993). As duas precauções principais são quanto a amplitude mínima da oscilação crítica e distúrbios de carga. A utilização de um valor muito baixo para a amplitude mínima de oscilação crítica pode fazer o experimento a relê falhar pois uma pequena perturbação leva à identificação falsa de um ciclo da oscilação. Dessa forma, caso a amplitude inicial do relê resulte numa amplitude da saída menor que um mínimo estabelecido, $a_{r e f}$, a amplitude do relê pode ser corrigida a partir da amplitude da saída observada, $a$, por:

$$
d_{\text {NOVO }}=d \frac{a_{r e f}}{a}
$$


para obter-se o valor desejado da oscilação na saída. Este procedimento é realizado em tempo real, e toma um ciclo a mais para a identificação do ciclo limite. Os distúrbios de carga também podem alterar as características do ciclo limite por provocar oscilações assimétricas e consequentemente distorção do período das oscilações. Neste caso por tratarse de um nível indesejado sua correção é feita adicionando-se à saída do relê um nível (bias) que deverá corresponder ao valor médio da saída distorcida do relê. O cálculo em tempo real fica

$$
\text { bias }=d \frac{a_{p o s}-a_{n e g}}{a_{p o s}+a_{n e g}}
$$

onde $a_{p o s}$ é a amplitude do semi-ciclo positivo da oscilação e $a_{n e g}$ é a amplitude do semiciclo negativo da oscilação. Caso ocorra a correção durante o experimento um ciclo a mais para a identificação do ciclo limite será necessário. A Figura 47 mostra a saída do processo com este tipo de perturbação e com a devida correção

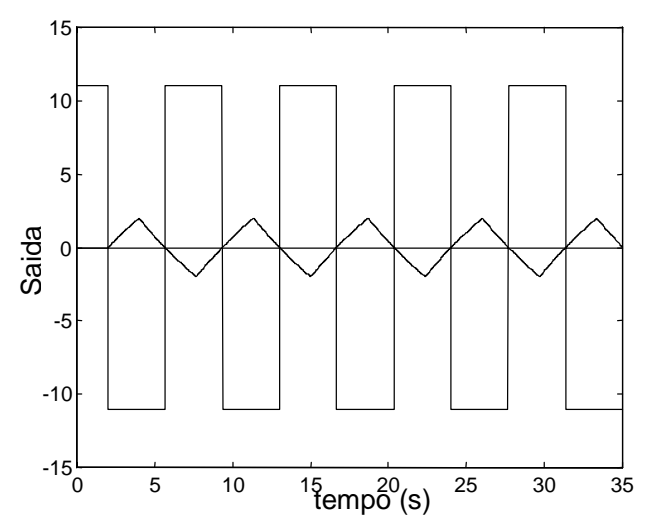

(a)

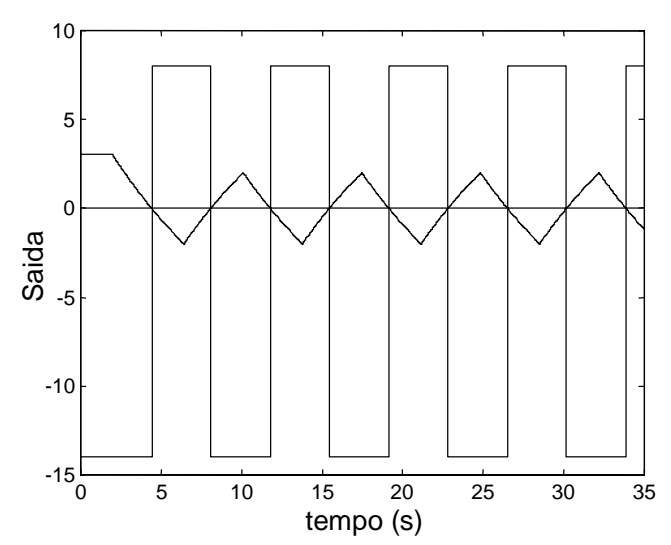

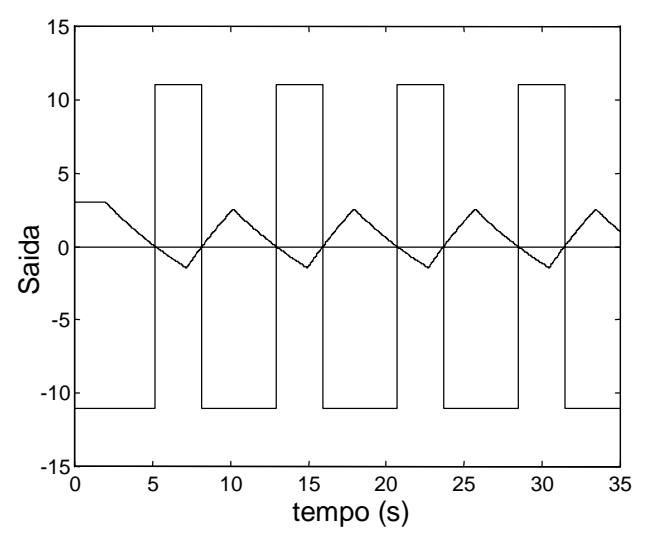

(b) 
(c)

FIGURA 47. Correção de distúrbio de carga durante o procedimento de sintonia automática para

o processo $e^{-2 s} /(10 s+1)$; (a) Sem a perturbação o relê é chaveado em 0, (b) Uma perturbação de $3^{\circ} \mathrm{C}$ é aplicada, (c) Correção: um bias de $-3^{\circ} \mathrm{C}$ é aplicado na saída do relê.

\subsection{Questões Práticas de Implementação}

\section{Ação integral}

$\mathrm{Na}$ implementação da ação integral o início de atuação da banda integral influencia a resposta do processo causando um pequeno sobre-sinal e/ou um tempo de acomodação ligeiramente maiores que os esperados. Este efeito é devido ao fato da ação integral corresponder a uma somatória de termos. Dependendo do início dado a atuação da banda integral o valor deste somatório pode ser maior ou menor que o valor ideal que causa a ação de controle desejada. Então leva-se um tempo ligeiramente maior ou menor para atingir este valor o que causa o surgimento de sobre-sinal ou amortecimento da resposta real. Sugere-se como ponto de partida para o ajuste do início de atuação da banda integral o início da banda proporcional e, por tentativa e erro fazer um ajuste fino.

\section{Reconhecimento de picos e vales}

Durante a fase de simulações do experimento a relê com o PWM inserido na malha, notouse a necessidade de, na obtenção de picos e vales da forma de onda da saída, y(t), utilizar um filtro passa-baixas. Isto por causa da influência que o PWM traz à malha devido a seu chaveamento, acrescentando picos e vales falsos. A utilização de um filtro passa-baixas suavizaria a forma de onda mas não eliminaria o efeito por completo, para isto seria necessário a utilização de um filtro de ordem elevada o que não é conveniente do ponto de vista de implementação em linguagem de baixo nível (assembly). Desta forma, adotou-se a opção de verificar a tendência de subida ou descida da onda pela contagem de um certo número de amostras após a obtenção do possível pico ou vale. Assim, se após $\underline{\mathbf{n}}$ amostras a tendências do sinal for continuar a "descer" o ponto é identificado como um pico, caso ele volte a "subir" antes de $\underline{\mathbf{n}}$ o ponto não é identificado como um pico (é um falso pico). O mesmo é válido para a identificação de vales. A Figura 48 ilustra o efeito do chaveamento. 
O número de amostras, $\underline{\mathbf{n}}$, utilizado foi determinado pela observação dos resultados obtidos em simulações para diversos valores do período do PWM.

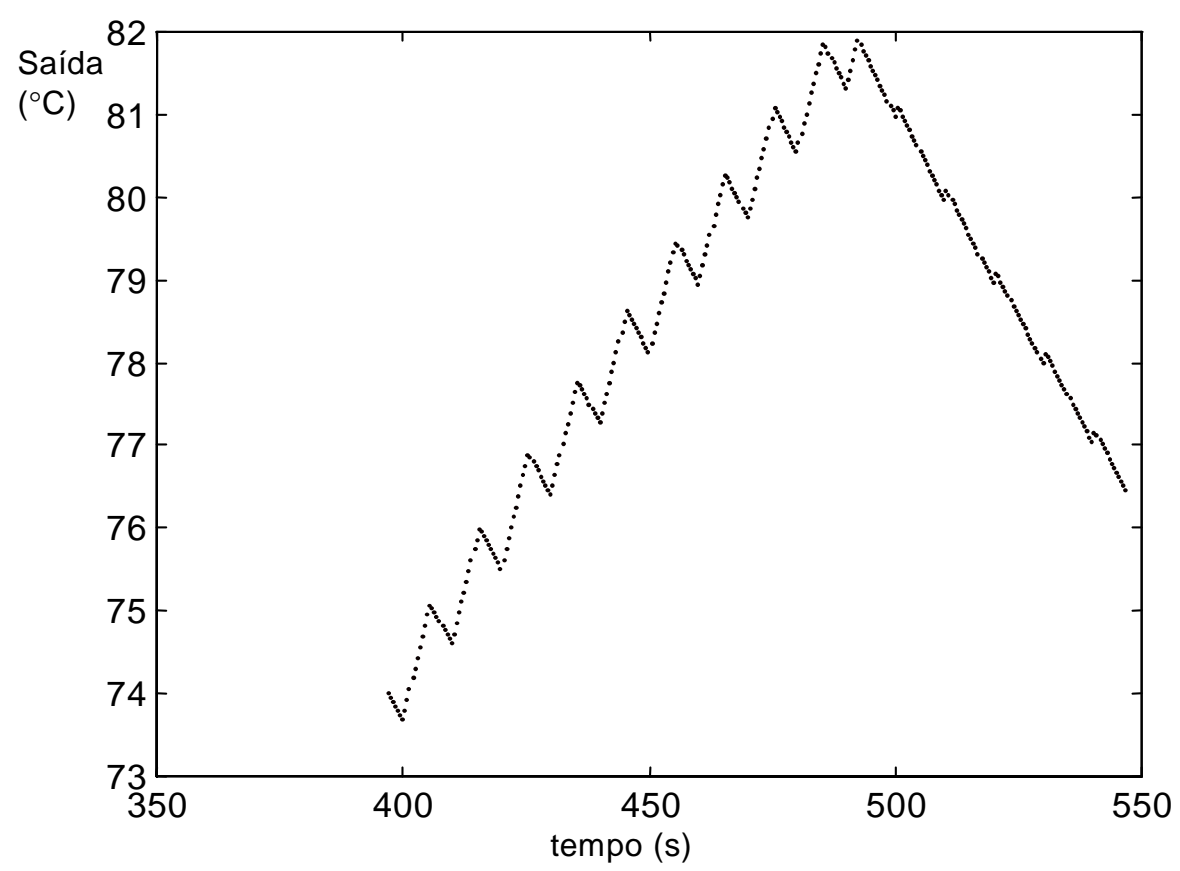

FIGURA 48. Efeito do chaveamento do PWM na forma de onda da saída do processo para $\mathrm{e}^{-80 \mathrm{~s}} /(430 \mathrm{~s}+1)$ e $C_{T}=10 \mathrm{~s}$ durante o experimento de oscilação a relê.

\section{Influência do período do PWM na resposta do controlador PID}

O período do PWM, $C_{T}$, é um parâmetro livre na sintonia automática dos controladores. Devido as diversas formas de acionamento possíveis para os processos normalmente não se inclui o acionamento no desenvolvimento dos métodos de auto-sintonia. Embora não seja considerado ele apresenta um efeito sobre a resposta do sistema e especificamente para o caso de acionamento por PWM seu efeito de chaveamento pode descaracterizar a resposta desejada caso um valor inadequado seja utilizado. A Figura 49 mostra este efeito sobre a resposta de um controlador PID. 


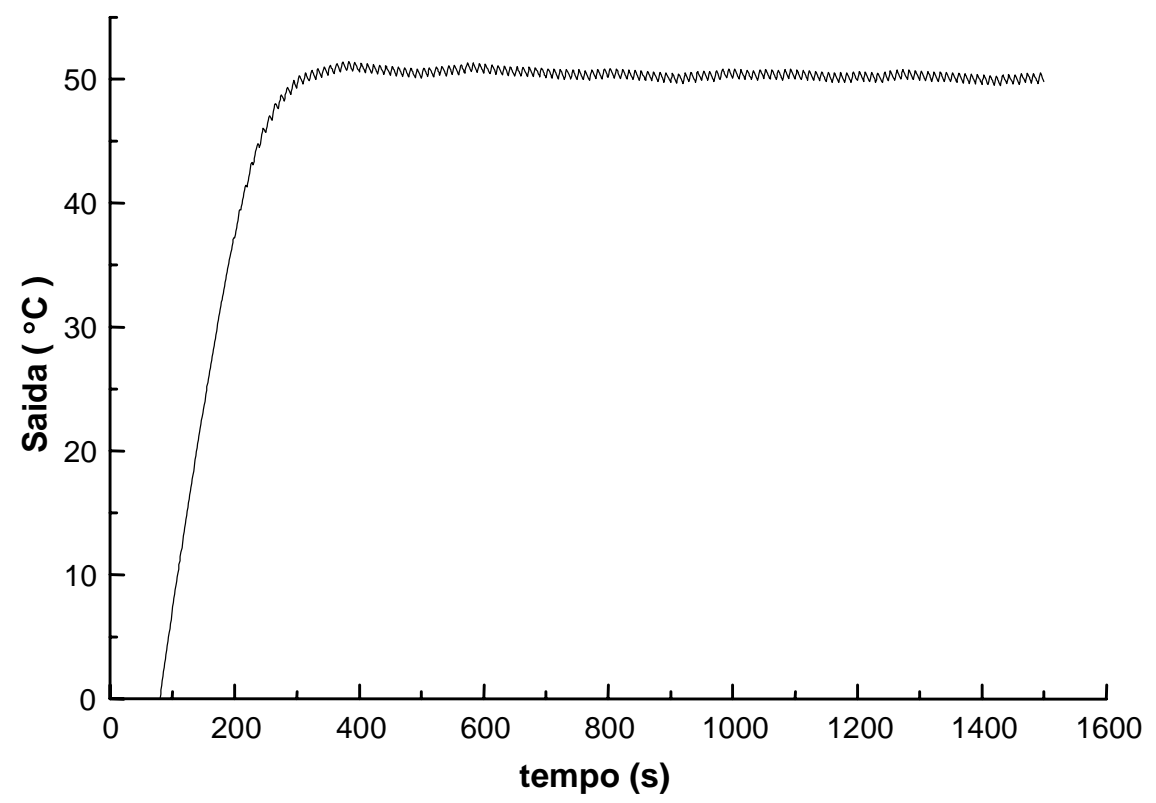

(a)

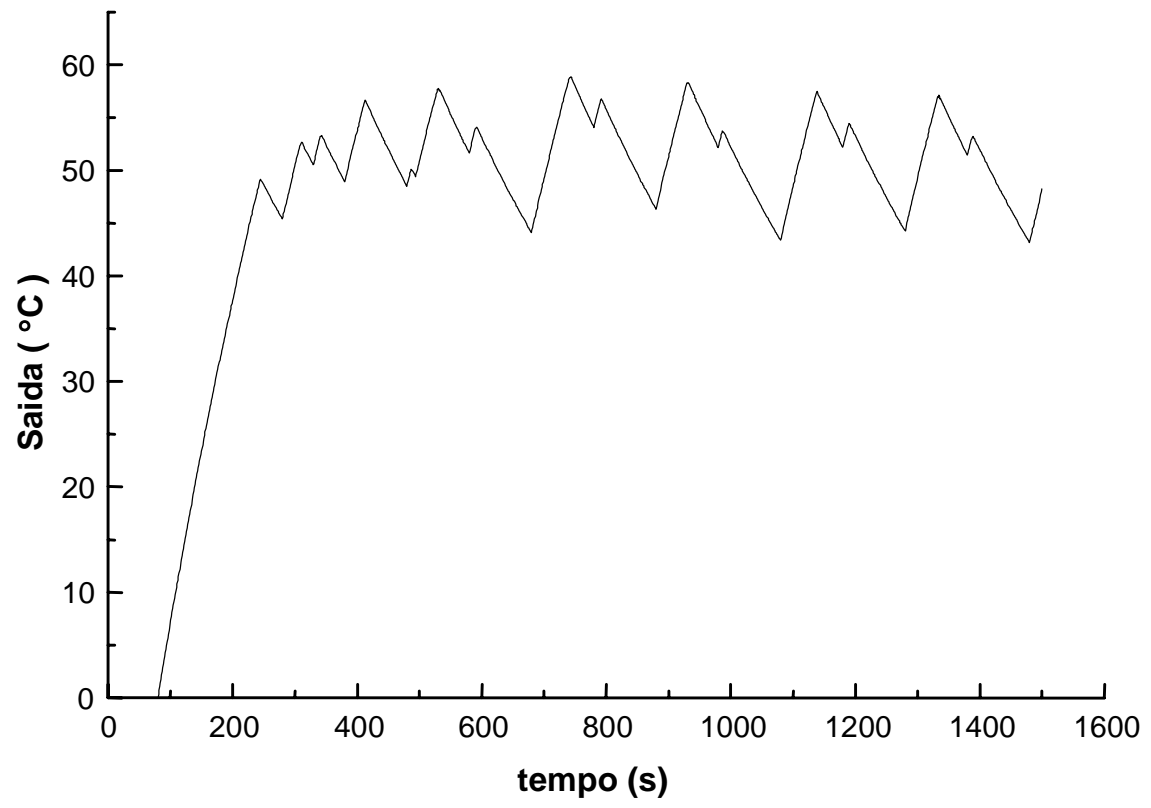

(b)

FIGURA 49. Efeito do PWM na forma de onda da saída do processo para $\mathrm{e}^{-80 \mathrm{~s}} /(430 \mathrm{~s}+1)$, controlador PID com $K_{c}=2,4 T_{i}=446, T_{d}=35$ e Ref $=50^{\circ} \mathrm{C}$ : (a) $C_{T}=10 \mathrm{~s}$; (b) $C_{T}=100 \mathrm{~s}$

\subsection{Algoritmo de Sintonia Automática e Descrição das Rotinas}

Desenvolvidas 
Foram utilizadas para a implementação do procedimento de auto-sintonia 3 rotinas: a primeira (Ident) para identificação do processo (tempo morto, constante de tempo e ganho estático), a segunda (Amp_Per) na determinação dos parâmetros $a_{O}$ e $t_{O}$ de ciclos limites e a terceira (Parametros) para calculo dos parâmetros do controlador PID. Na implementação do controlador PID foram usadas 2 rotinas: uma implementa o algoritmo PID e a outra o PWM. Para realizar somas, subtrações, multiplicações e divisões foram usadas rotinas de ponto flutuante. Abaixo segue o algoritmo das rotinas em linguagem natural e uma tabela detalhando as características mais relevantes destas rotinas.

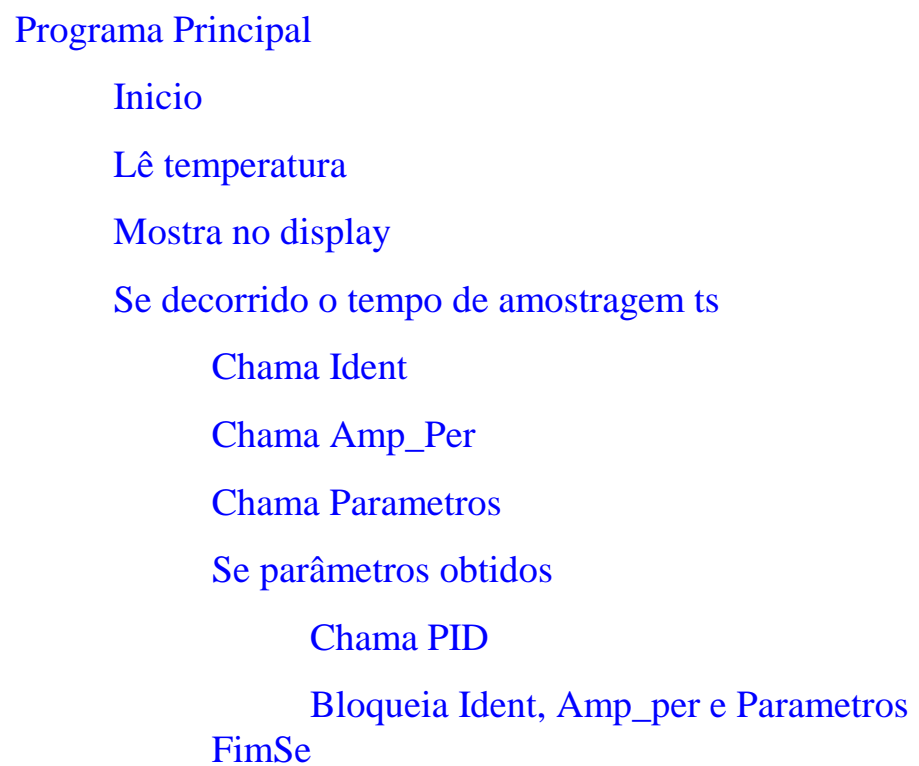

FimSe

Lê teclas

Volta Inicio

Fim

Subrotinas

Ident

Inicio

Se potencia $\neq 0$

Conta base de tempo $(=1 \mathrm{~s}$.)

Se temperatura mudar obtém L

Se temperatura igual por 10s. obtém $\mathrm{T}$ e $\mathrm{K}_{\mathrm{P}}$

FimSe 
Fim

Amp_Per

Inicio

Obtém $1^{\circ}$. pico (ou vale) verdadeiro

Obtém $1^{\circ}$. vale (ou pico) verdadeiro

Verifica se tamanho mínimo do $1^{\circ}$. semi-ciclo é correto

Se falso corrige $\left(\mathrm{d}_{\mathrm{NOVO}}=\mathrm{d}^{*} \mathrm{a}_{\mathrm{REF}} / \mathrm{a}\right)$ e reinicia

Obtém $2^{\circ}$. pico (ou vale) verdadeiro

Verifica se simetria do $1^{\circ}$. ciclo é correta

Se falso corrige $\left(\right.$ bias $\left.=\mathrm{d}^{*}\left(\mathrm{a}_{\mathrm{POS}}-\mathrm{a}_{\mathrm{NEG}}\right) /\left(\mathrm{a}_{\mathrm{POS}}+\mathrm{a}_{\mathrm{NEG}}\right)\right)$ e reinicia

Calcula $\mathrm{k}_{\mathrm{CR}}$ e $\mathrm{t}_{\mathrm{CR}}$

Chama Parametros

Fim

Parametros

Inicio

$\mathrm{k}=\mathrm{K}_{\mathrm{P}}{ } \mathrm{k}_{\mathrm{CR}}$

fi_m $=33,2 *(1-1,38 * \exp (-0,68 * k))$

$\mathrm{m}=0,613 *(1-0,262 * \exp (-0,44 * \mathrm{k}))$

$\mathrm{K}_{\mathrm{C}}=\mathrm{m} * \mathrm{k}_{\mathrm{CR}} * \cos \left(\mathrm{fi} \_\mathrm{m}\right)$

alfa $=1,687 * \mathrm{k}_{\mathrm{CR}}$

$\mathrm{T}_{\mathrm{d}}=\left(\tan \left(\mathrm{fi} \_\mathrm{m}\right)+\operatorname{sqrt}\left(4 / \mathrm{alfa}+\tan \left(\mathrm{fi} \_\mathrm{m}\right)^{\wedge} 2\right)\right) /\left(2 * \mathrm{w}_{\mathrm{CR}}\right)$

$\mathrm{T}_{\mathrm{i}}=\operatorname{alfa}^{*} \mathrm{~T}_{\mathrm{d}}$

Fim

PID

Inicio

Lê referência

Lê variável de processo (PROC)

Calcula erro

Calcula contribuição Proporcional

Calcula contribuição Derivativa

Calcula contribuição Integral

Aplica ação de controle PID

Fim 
PWM

Inicio

Se Período do PWM $\left(\mathrm{C}_{\mathrm{T}}\right)$ não terminou sai

Lê ação PID

Se ação > 100\%

Mantém saída acionada

FimSe

Se ação $<0$

Mantém saída desligada

FimSe

Se $0<$ ação < $100 \%$

Inicia contagem de $\mathrm{t}_{\mathrm{p}}$ (duty cicle)

FimSe

Fim

TABELA 9: Características das rotinas implementadas.

\begin{tabular}{|c|c|c|c|}
\hline Rotina & $\begin{array}{c}\text { Tamanho } \\
\text { (bytes) }\end{array}$ & $\begin{array}{c}\text { Posições RAM } \\
\text { (bytes) }\end{array}$ & $\begin{array}{c}\text { Tempo } \\
\text { execução } \\
\text { (ms) }\end{array}$ \\
\hline Ident & 417 & 6 & 9,898 \\
\hline Amp_Per & 747 & 10 & 1,451 \\
\hline Parametros & 539 & -- & 24,480 \\
\hline Banda_prop & 61 & 4 & 0,515 \\
\hline PID & 1423 & 23 & 18,216 \\
\hline PWM & 153 & 6 (Banco 2) & 0,047 \\
\hline Float's & 1585 & 12 (Banco 0,1) & 1,7 (fldiv) \\
\hline Total & $4925(4,8 \mathrm{~Kb})$ & 61 & 56,307 \\
\hline
\end{tabular}




\section{Resultados Experimentais}

\subsection{Identificação de Modelo do Processo e Experimento a Relê}

As estimativas apresentadas na Tabela 10 para o tempo morto e constante de tempo do processo foram levantadas em experimentos realizados em laboratório para o mini-forno. Antes do início da oscilação a relê, é aplicado um degrau de potência à planta e a resposta a este degrau é observada para a estimativa de um modelo do processo. O tempo morto é tomado como o tempo entre o início do experimento e a primeira modificação no valor de temperatura da saída do processo. A medida entre o tempo da primeira modificação no valor de temperatura da saída do processo e do regime atingido é divida por quatro para obter-se a constante de tempo (lembrando que decorridos $4 T$ a saída do processo atinge $98,2 \%$ do valor final). O valor da estimativa para o ganho estático do processo, $K_{p}$, é calculado tendo-se os valores de temperatura inicial e final e o valor do degrau aplicado. No experimento a relê para o teste 1 , foi usado $d=25^{\circ} \mathrm{C}$ (amplitude do relê) e para os testes 2 , 3,4 e 5 o valor empregado foi $d=35^{\circ} \mathrm{C}$. Os parâmetros do controlador PID foram calculados segundo o método proposto por Zhuang-Atherton. A Figura 50 mostra a resposta da temperatura durante a fase de sintonia automática para o mini-forno.

TABELA 10: Resultados experimentais para estimativas de $L, T, \mathrm{~K}_{\mathrm{P}}$, parâmetros críticos $\left(\mathrm{a}_{\mathrm{o}}\right.$ e $\left.\mathrm{t}_{\mathrm{o}}\right)$ e respectivos parâmetros do controlador PID calculados para o mini-forno.

\begin{tabular}{|c|c|c|c|c|c|c|c|c|c|c|}
\hline & $\begin{array}{c}\text { Temperatura } \\
\text { Inicial }\left({ }^{\circ} \mathrm{C}\right)\end{array}$ & $\begin{array}{c}\text { Temperatura } \\
\text { Final }\left({ }^{\circ} \mathrm{C}\right)\end{array}$ & $\begin{array}{c}L \\
(\mathrm{~s})\end{array}$ & $\begin{array}{c}T \\
(\mathrm{~s})\end{array}$ & $K_{p}$ & $\begin{array}{c}a_{O} \\
(\mathrm{~s})\end{array}$ & $\begin{array}{c}t_{O} \\
(\mathrm{~s})\end{array}$ & $K_{c}$ & $\begin{array}{c}T_{i} \\
(\mathrm{~s})\end{array}$ & $\begin{array}{c}T_{d} \\
(\mathrm{~s})\end{array}$ \\
\hline Teste 1 & 25,9 & 60,3 & 41 & 266 & 0,74 & 1,2 & 269 & 13,6 & 989 & 30 \\
\hline Teste 2 & 23,1 & 54,0 & 30 & 208 & 0,63 & 1,7 & 219 & 13,4 & 685 & 25 \\
\hline Teste 3 & 25,7 & 57,6 & 36 & 261 & 0,68 & 1,6 & 228 & 14,3 & 811 & 25 \\
\hline Teste 4 & 23,9 & 56,8 & 25 & 249 & 0,70 & 1,5 & 245 & 15,2 & 951 & 27 \\
\hline Teste 5 & 21,6 & 53,3 & 37 & 253 & 0,68 & 1,8 & 247 & 12,7 & 786 & 28 \\
\hline
\end{tabular}




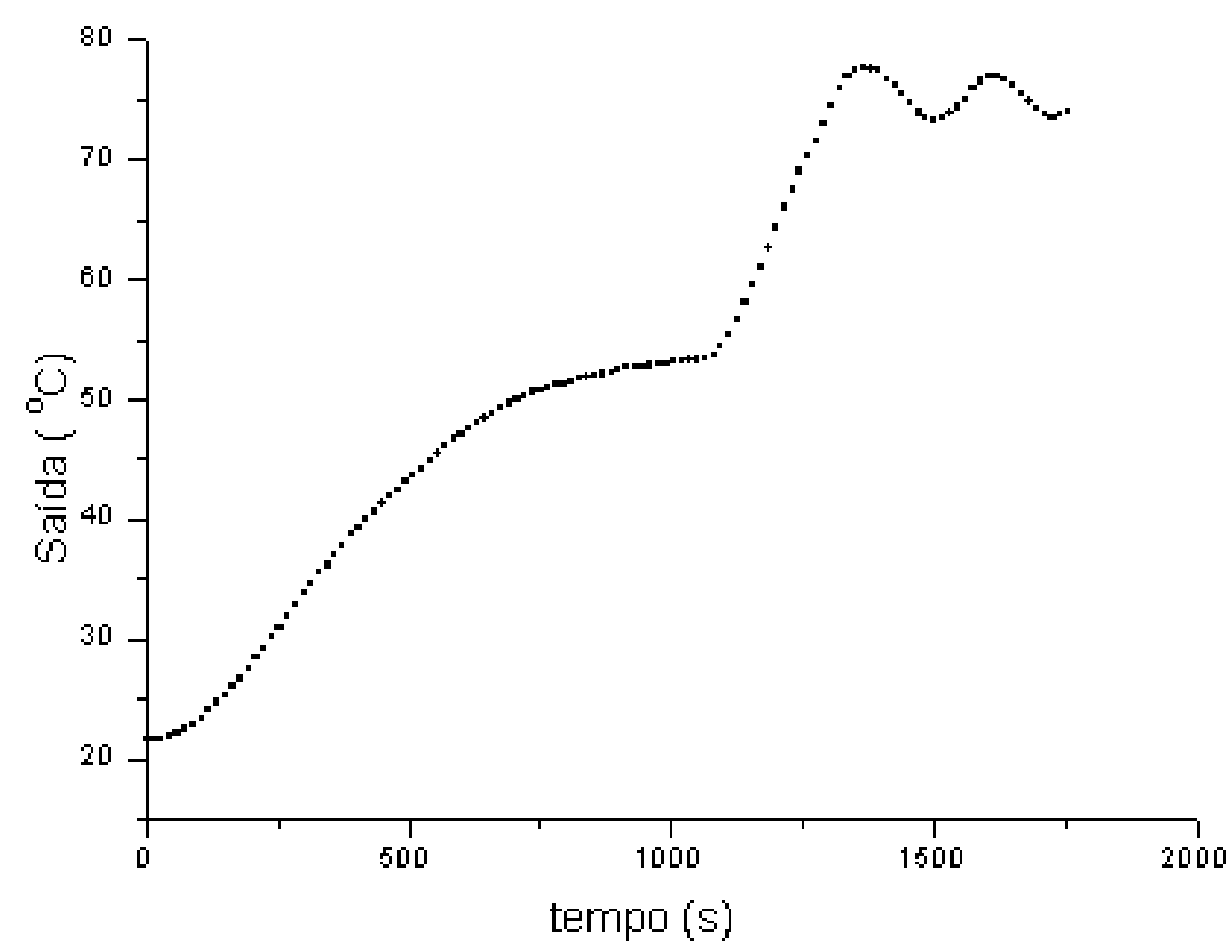

FIGURA 50: Sintonia automática do mini-forno (teste 5 da Tabela 10); de 0 a 1050s fase de estimação dos parâmetros do modelo de primeira ordem mais tempo morto, de 1050s a 1755s fase de sintonia automática dos parâmetros do controlador PID.

\subsection{Estabilidade}

A estabilidade do sistema foi analisada com os controladores PID's obtidos no experimento a relê, considerando-se variações nos parâmetros do processo para observar o comportamento resultante. Como estamos interessados em investigar a estabilidade é utilizado o diagrama de Nyquist que permite a leitura qualitativa da situação de estabilidade do sistema pela observação de envolvimentos ou não do ponto $-1+\mathrm{j} 0$. As variações consideradas nos parâmetros do processo são as observadas em diversos experimentos realizados, onde estimou-se estes parâmetros (Seção 8.1) a partir das respostas temporais ao degrau. Devido a forma direta de obtenção destas estimativas (e não através de um método convergente) os valores observados na Tabela 10 apresentam uma discrepância com relação ao modelo levantado no Capítulo 5 (equações 5.2 e 5.3). Os diagramas de Nyquist correspondentes à pior e à melhor situação de estabilidade são dados na Figura 51. O modelo nominal é o obtido com a média dos parâmetros dos cinco experimentos apresentados na Tabela 10. O pior caso é tomado como a combinação dos parâmetros $K_{p}, L$ 
e $T$ que resultem na curva de Nyquist mais próxima ao ponto $-1+\mathrm{j} 0$ pelo eixo real negativo. O melhor caso como a combinação que resulte na curva de Nyquist mais distante do ponto $1+\mathrm{j} 0$ pelo eixo real negativo.

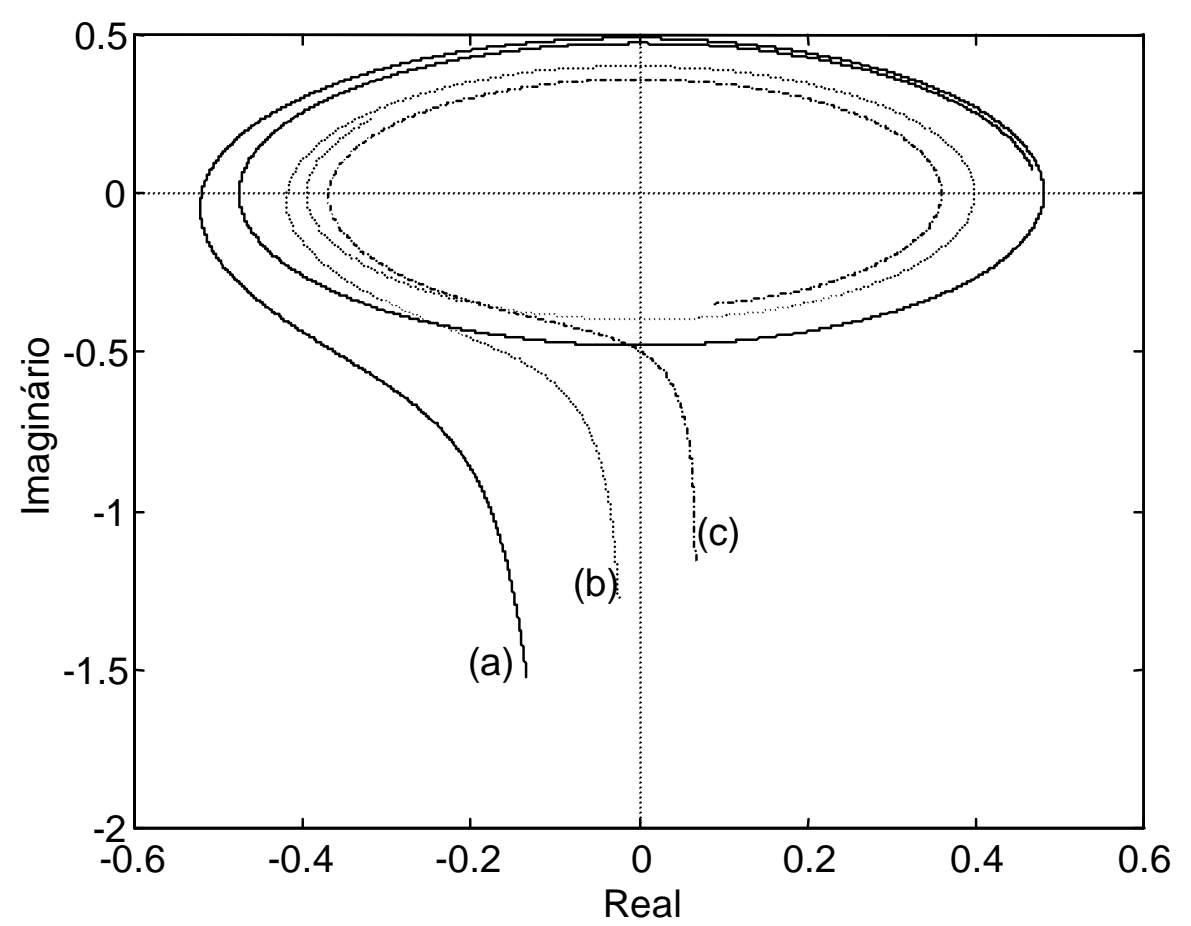

FIGURA 51: Diagrama de Nyquist do controlador $K_{c}=13,8, T_{i}=829,5 \mathrm{~s}, T_{d}=27 \mathrm{~s}$ e processo com variação nos parâmetros; (a) Pior caso: $L=41 \mathrm{~s}, T=207,7 \mathrm{~s}, K_{p}=0,74, A_{m}=2,0$ e $\phi_{m}=$ $79,6^{\circ}$; (b) Nominal: $L=34 \mathrm{~s}, T=247,1 \mathrm{~s}, K_{p}=0,69, A_{m}=2,7$ e $\phi_{m}=84,9^{\circ}$; (c) Melhor caso: $L$ $=25 \mathrm{~s}, T=265,7 \mathrm{~s}, K_{p}=0,63, A_{m}=3,3$ e $\phi_{m}=89,0^{\circ}$.

O desempenho do sistema com o controlador PID sintonizado pode ser avaliado observando-se a resposta ao degrau simulada com mudança do valor da referência apresentada nas Figuras 52 e 53. As figuras mostram que o controlador garante uma resposta temporal satisfatória dentro do modelo adotado e das variações nos parâmetros do processo e parâmetros críticos $\left(\mathrm{a}_{\mathrm{o}}\right.$ e $\left.\mathrm{t}_{\mathrm{o}}\right)$ ocorridas nos experimentos realizados. 


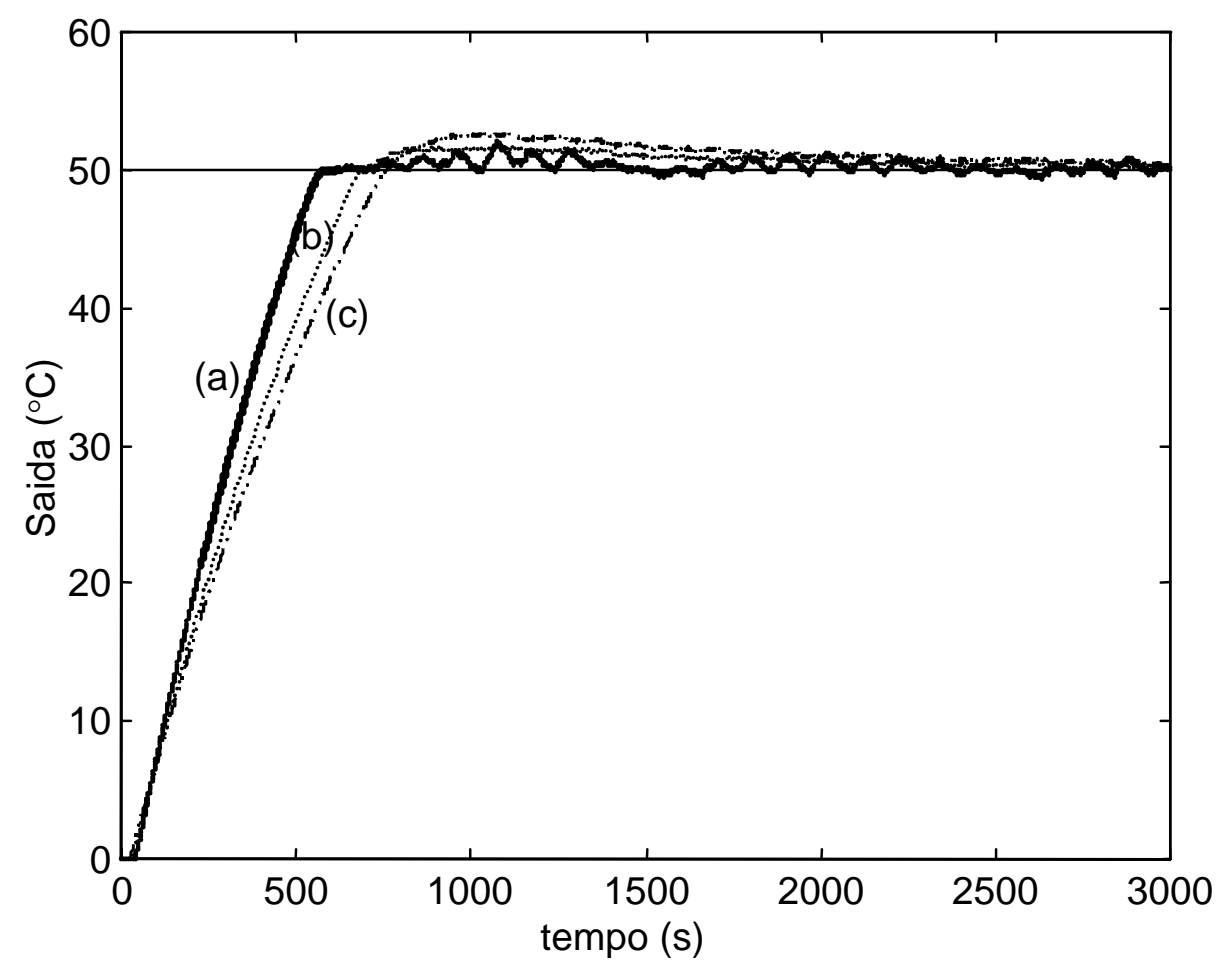

FIGURA 52: Resposta ao degrau simulada (referência $=50^{\circ} \mathrm{C}$ ) com o controlador $K_{c}=13,8, T_{i}=$ $829,5 \mathrm{~s}, T_{d}=27 \mathrm{~s}$; (a) Pior caso; (b) Nominal; (c) Melhor caso.

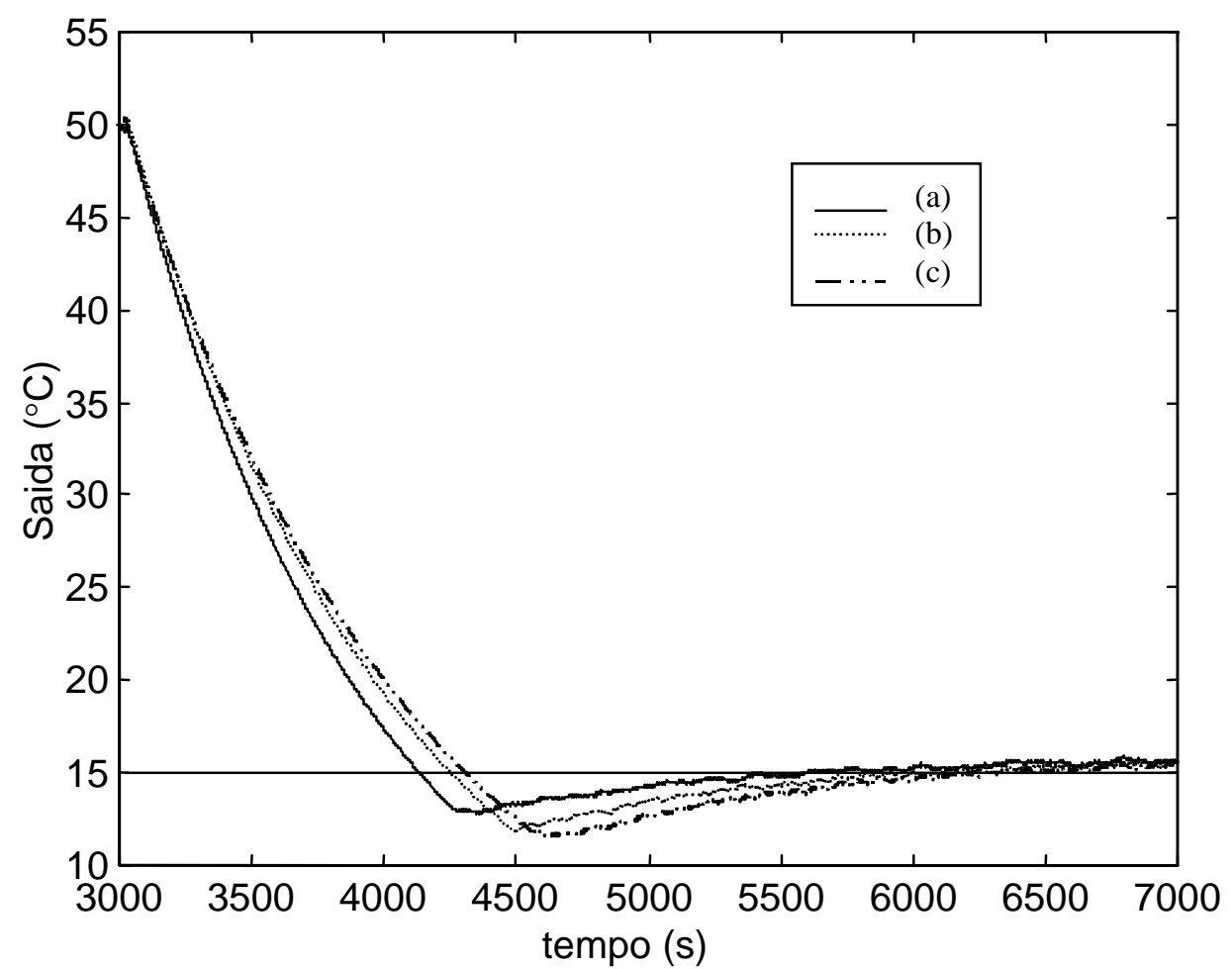

FIGURA 53: Mudança da referência ( para $15^{\circ} \mathrm{C}$ ) em $3000 \mathrm{~s}$ com controlador para o mesmo caso da Figura 52. 
Para verificarmos na prática a condição de estabilidade dos controladores obtidos nos experimentos o controlador PID obtido no teste 5 foi programado no controlador de temperatura industrial CMT300. A resposta de temperatura resultante do mini-forno é apresentada na Figura 54.

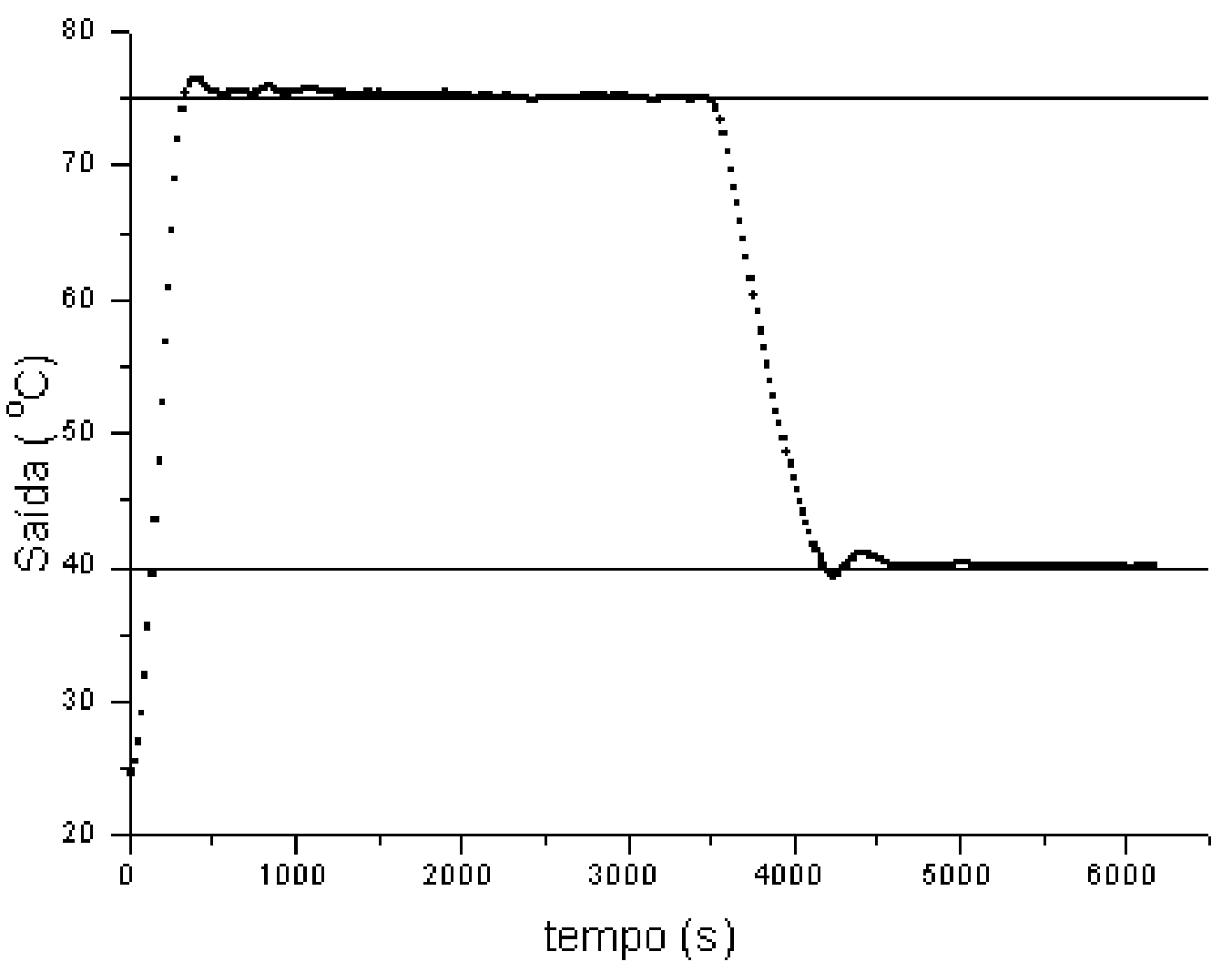

FIGURA 54: Resposta do mini-forno com mudança da referência (de $75,0^{\circ} \mathrm{C}$ para $40,0^{\circ} \mathrm{C}$ ) com controlador PID do teste 5 programado no controlador de temperatura industrial. 


\section{Conclusões}

Os resultados de simulação mostram que o método da margem de fase e ganho proposto por Zhuang-Atherton forneceu as respostas transitórias e as margens de ganho e fase mais adequadas. Este método calcula os parâmetros do controlador PID segundo o critério ITSE de otimização. Os resultados obtidos mostram uma velocidade de subida rápida, praticamente nenhum sobre-sinal, margem de fase entre 61 e 68 graus (uma variação de apenas $7^{\circ}$ dentro da faixa testada) e margem de ganho entre 2,2 e 2,5 (também pequena). $\mathrm{O}$ método pede apenas o conhecimento do ganho estático do processo para poder ser aplicado.

O método de Aström-Hagglund resultou em parâmetros do controlador PID que levaram à presença de sobre-sinal elevado e oscilação na resposta da malha fechada, levando aos ganhos proporcionais mais altos obtidos em comparação aos outros métodos e para o processo II a margem de fase mais baixa alcançada. Os sobre-sinais podem ser reduzidos alterando-se os parâmetros de projeto mas a resposta temporal resulta em tempos de acomodação extremamente elevados ou respostas sub-amortecidas com oscilações presentes. A margem de fase ficou entre 45 e 64,5 graus (19,5 de variação) e as margens de ganho foram as menores alcançadas, entre 1,3 e 1,5. Necessita também apenas de $K_{P}$ para ser aplicado. Tendo em vista o comportamento muito sensível da resposta temporal em função dos parâmetros de projeto este não é um método recomendável ao uso em aplicações industriais.

As respostas obtidas pelo método denominado NSOM proposto por Loron apresentaram tempos de subida e de acomodação próximos aos apresentados por ZhuangAtherton, mas com a presença de sobre-sinal (cerca de 5\%) em todos os casos. As margens de fase atingidas apresentam uma variação muito boa entre 59,9 e 60,2 graus apenas, dentro da faixa testada (exceto para o processo III), e as margens de ganho ficaram entre 2,0 e 2,6. A menos da presença de sobre sinal os controladores PID's sintonizados obtiveram boas respostas temporais. O método realizou a sintonia de um processo com tempo morto normalizado $(L / T)$ de valor 8 (processo III), completamente fora da faixa de aplicação sugerida $0,1 \leq \varnothing_{1} \leq 1,0$. Este método necessita do conhecimento de todos os parâmetros do processo para poder ser aplicado.

O método proposto por Ho-Hang-Cao para a sintonia de controladores PI apresentou respostas temporais com tempo de acomodação e subida maiores que os apresentados por Zhuang-Atherton e com a presença de sobre-sinal (cerca de 5\%). Os ganhos proporcionais resultaram entre os menores obtidos entre os métodos. Em termos das variações alcançadas 
para as margens de fase e ganho este método apresenta um resultado excelente pois os valores atingidos ficaram em 60 graus e 3,0, respectivamente, para todos os processos testados. Os resultados obtidos são muito bons caso comparemos as respostas deste controlador PI com as respostas obtidas pelo método NSOM que sintoniza controladores PID; apenas em dois dos quatro processos testados (processos II e IV) este método apresenta tempo de subida e acomodação maiores que os apresentados pelo NSOM. Este método também realizou a sintonia para $L / T=8$ e necessita do conhecimento de todos os parâmetros do processo para poder ser aplicado. Como a ação derivativa não é sintonizada por este método sua aplicação industrial fica restrita somente àqueles processos em que o controlador PI seja suficiente para atender as especificações de desempenho desejadas.

As simulações mostram que o controlador PI sintonizado pelo método apresentado por Friman resulta em uma resposta transitória com o maior tempo de acomodação e de subida entre todos os métodos. Resultou em ganhos proporcionais pequenos em comparação aos demais métodos (exceto para o processo III, $L / T=8$ ) e nas maiores margens de fase; ou seja, em geral obtém uma sintonia conservadora sem sobre-sinal a custa de tempos de acomodação e subida elevados. Em comparação ao método proposto por HoHang-Cao que também sintoniza controladores PI, tem uma resposta transitória menos "agressiva". As variações atingidas pelas margens de ganho e fase foram 64 e 77 graus $\left(13^{\circ}\right.$ de variação) para a margem de fase e 2,8 e 7,8 (variação de 5) para a margem de ganho. Realizou a sintonia para $L / T=8$ e não necessita do conhecimento dos parâmetros do processo para poder ser aplicado, no entanto precisa de um controlador PI inicial que provoque as oscilações críticas. Quanto a sua aplicação industrial tem a mesma restrição apresentada pelo método proposto por Ho-Hang-Cao.

Das observações expostas o método de sintonia automática mais adequado à implementação industrial em ambiente de microcontroladores para processos térmicos de primeira ordem mais tempo morto é o da margem de ganho e fase proposto por ZhuangAtherton. Este método é aplicável em processos que estejam dentro da faixa $0,05 \leq \mathrm{L} / \mathrm{T} \leq$ 2,0 .

Do ponto de vista de implementação o principal cuidado a ser levado em consideração é a possibilidade de ocorrência de oscilações assimétricas durante o procedimento de oscilação a relê. Os principais fatores que podem levar a esta condição são o desgaste ou falha de sensores e atuadores e a presença de perturbações ambientais durante o experimento (ventilação por exemplo). A utilização de um nível (bias) DC na saída do relê permite que o experimento seja realizado porém com um ciclo a mais de duração para 
identificação e correção da assimetria. A implementação do procedimento de oscilação a relê é simples e direta em termos de programação no ambiente de microcontroladores mesmo em linguagem de baixo nível (assembly). A utilização de um procedimento de estimação para os parâmetros do processo, mesmo que grosseiro, demanda um tempo a mais para a realização da sintonia automática que irá depender fundamentalmente da constante de tempo do processo.

As diferenças entre os controladores PID sintonizados nos experimentos apresentados na Tabela 10 são causadas principalmente pela discrepância no valor estimado para o ganho estático do processo durante a fase de estimação dos parâmetros do processo. Na estimação do ganho estático implementada, o regime atingido pela temperatura do processo foi reconhecido quando o valor da temperatura permaneceu inalterado por 10 segundos. A consideração de um tempo de reconhecimento maior poderia levar a uma uniformidade dos valores apresentado na Tabela 10 para a coluna de $K_{P}$, no entanto isto acarretaria uma duração mais longa para a sintonia automática e dependendo do valor da constante de tempo valores muito elevados poderão ocorrer. A resposta experimental tomada do mini-forno (Figura 54) com o controlador PID obtido no teste 5 da Tabela 10 mostra que os controladores obtidos estão dentro da faixa de estabilidade e desempenho prevista.

Os parâmetros dos controladores PID obtidos na Tabela 8 apresentam diferenças significativas em relação aos obtidos nos experimentos de 1 a 5 . Esta discrepância é devida às diferenças ocorridas entre os valores da amplitude e período críticos medidos nos experimentos e àqueles observados nas simulações. Esta discrepância resulta de dinâmicas não levadas em consideração no modelo de primeira ordem mais tempo morto utilizado para simulação e na determinação de $L, T$ e $K_{P}$ (baseados em entradas do tipo degrau) durante a sintonia automática, mas que estão presentes no comportamento do mini-forno. Apesar disto como mostra a Figura 54 os controladores obtidos apresentam uma resposta temporal estável e satisfatória. 


\section{Referências}

Bibliografia citada

[01] Astrom, K. J; Hagglund, T. (1984). Automatic Tuning of Simple Regulators with Specifications on Phase and Amplitude Margins. Automatica, 20, n ${ }^{\circ}$ 5, pp 645-651.

[02] Astrom, K.J, Hagglund, T. (1995). Automatic Tuning of PID Controllers. Instrument Society of America.

[03] Astrom, K.J; Hagglund, T; Hang, C.C; Ho, W.K. (1993). Automatic Tuning and Adaptation for PID Controllers - a survey. Control Eng. Practice, 1, n 4, pp 699-715.

[04] Astrom, K.J; Hagglund, T.; Wallenborg, A (1993). Automatic Tuning of Digital Controllers with Applications to HVAC Plants. Automatica, 29, n ${ }^{\circ}$ 5, pp 1333-1343.

[05] Atherton, D. (1982). Nonlinear Control Engineering. Van Nostrand Reinhold London, Student Edition.

[06] Bassa, J. M. (1993). Controle Convencional e Avançado. Curso ministrado na Usina Química de Paulínia em 29 de Setembro.

[07] Friman, M. (1997). Automatic Re-Tuning of PI Controllers in Oscillating Control Loops. Ind. Eng. Chem. Res., 36, pp 4255-4263.

[08] Fung, H. W.; Wang, Q. G.; Lee, T. H. (1998). PI Tuning in Terms of Gain and Phase Margins. Automatica, 34, n ${ }^{\circ}$ 9, pp 1145-1149.

[09] Hang, C.C, Astrom, K.J, Ho, W.K. (1991). Refinements of the Ziegler-Nichols formula. IEE Proceedings-D, 138, $\mathrm{n}^{\circ} 2$, pp 111-117.

[10] Hang, C.C.; Astrom K. J.; Ho W. K. (1993). Relay Auto-tuning in the Presence of Static Load Disturbance. Automatica, 29, n ${ }^{\circ} 2$, pp 563-564. 
[11] Ho, W. K., Hang, C. C. and Cao, L. S. (1995). Tuning of PID Controllers Based on Gain and Phase Margins Specifications. Automatica, 31, n ${ }^{\circ}$ 3, pp 497-502.

[12] ISA 89: Advanced Control Conference. NEC, Birmingham, 5 April 1989, pp 12-14

[13] Isermann, Rolf (1989). Digital Control Systems. 2a . edn, vol. 1. Springer-Verlag Berlin Heidelberg.

[14] Khan, B. Z. and Lehman, B. (1996). Setpoint PI Controllers for Systems with Large Normalized Time. IEEE Transc. On Control Syst. Technology, 4, n 4, pp 459-466.

[15] Kressler, C. (1958). Das symmetrische optimum. Regelungstetechnik, 6, pp 395-400.

[16] Leva, A. (1993). PID autotuning algorithm based on relay feedback. IEE Proceedings- $D, \mathbf{1 4 0}, \mathrm{n}^{\circ}$ 5, pp 328-338.

[17] Loron, L. (1997). Tuning of PI Controllers by the Non-symmetrical Optimum Method. Automatica, 33, ${ }^{\circ} 1,103-107$.

[18] Nishikawa, Y; Sannomiya, N; Ohta, T; Tanaka, H. (1984). A Method for Auto-tuning of PID Control Parameters. Automatica, 20, n ${ }^{\circ} 3$, pp 321-332.

[19] Ogata, K. (1993). Engenharia de Controle Moderno. 2a ${ }^{\mathrm{a}}$ edn. Prentice-Hall

[20] Poulin, E.; Pomerleau, A.; Desbiens, A.; Hodouin, D. (1996). Development and Evaluation of an Auto-tuning and Adaptive PID Controller. Automatica, 32, n ${ }^{\circ}$ 1, pp 71-82.

[21] Sung, S. W.; Lee, I. B.; Lee, J. (1998). New Process Identification Method for Automatic Desing od PID Controllers. Automatica, 34, n ${ }^{\circ}$ 4, pp 513-520.

[22] Using Simulink (1997). $2^{\text {a }}$. edn. MathWorks Inc.

[23] Voda, A. A.; Landau, I. D. (1995). A Method for the Auto-calibration of PID Controllers. Automatica, 31, ${ }^{\circ} 1$, pp 41-53. 
[24] Wang, L.; Barnes, T. J. D.; Cluett, W. R. (1995). New Frequency-domain Design Method for PID Controllers. IEE Proc.-Control Theory Appl., 142, n ${ }^{\circ} 4$, pp 265-271.

[25] Yasuda, Y.; Crotty, S. (1990). A PID Controller with Overshoot Suppression Algorithm. ISA 1990, pp 1849-1857.

[26] Zhuang, M. and Atherton, D. P. (1993). Automatic tuning of optimum PID controllers. IEEE Proceedings-D, 140, $\mathrm{n}^{\circ} 3$, pp 216-224.

[27] Ziegler, J. G.; Nichols, N. B. (1942). Optimum settings for automatic controllers. ASME Trans., 64, pp 759-768.

Bibliografia consultada

[28] Besharati, A R.; Lun, W. L.; Tsang, K. M. (1997). Self-tuning PID Controller using Newton-Rapshon Search Method. IEEE Transactions on Industrial Electronics, $\mathbf{4 4 ,} \mathrm{n}^{\circ} 5$, pp 717-725.

[29] Ho, W.K; Hang, C. C; Zhou, J. H (1995). Performance and Gain and Phase Margins of Well-Known PI Tuning Formulas. IEEE Transactions on Control Systems Technology, 3, n ${ }^{\circ} 2$, pp 245-248.

[30] Ho, W.K; Gan, OP; Tay, E.B; Ang, E. L. (1996). Performance and Gain and Phase Margins of Well-Known PID Tuning Formulas. IEEE Transactions on Control Systems Technology, 4, $\mathrm{n}^{\circ}$ 4, pp 473-477.

[31] Ho, W.K; Xu, W. (1998). PID Tuning for Unstable Processes based on Gain and Phase-margins Specifications. IEE Proc.-Control Teory Appl., 145, n ${ }^{\circ}$ 5, pp 392-396.

[32] Ho, W.K; Lim, K.W.; Xu, W. (1998). Optimal Gain and Phase Margin Tuning for PID Controllers. IEE Proc.-Control Teory Appl., 145, n ${ }^{\circ}$ 5, pp 392-396. 
[33] László Tauszig, José Eustáqio da Silva, Samuel Vieira, Manoel A P. Castanho e Adieci Vigannico da Silva (1993). Temperatura: certificação de instrumentos e sensores e o atendimento da ISO 9000. Instec Instrumentação e controle de processos, Setembro 1993, pp 22-29.

[34] Lee, T.H. et al (1995). A Knowledge-based Approach to Dead-time Estimation for Process Control. Int. J. Control, 61, ${ }^{\circ}$ 5, pp 1045-1072.

[35] Leva, A., Maffezzoni, C., Scattolini, R. (1994). Self-tuning PI Regulators for Stable Systems with Varying Delay. Automatica, 30, n ${ }^{\circ} 7$, pp 1171-1183.

[36] Palmor; Z. J; Blau, M. (1994). An Auto-tuner for Smith Dead Time Compensator. Int. J. Control, 60, $\mathrm{n}^{\circ} 1$, pp 117-135.

[37] Park, J.H.; Sung, S.W.; Lee, I.B. (1997). Improved Relay Auto-tuning with Static Load Disturbance. Automatica, 33, ${ }^{\circ} 4$, pp 711-715.

[38] Sundaresan, K. R.; Krishnaswamy, P. R. (1978). Estimation of Time Delay, Time Constant Parameters in Time, Frequency and Laplace Domains. The Canadian Journal of Chemical Engeneering, 56, pp 257-262. 


\section{Apêndice A}

\section{Análise de Sistemas de Controle Não-Lineares por Função Descritiva}

Este apêndice resume os conceitos necessários para utilização de não linearidades na malha fechada para a obtenção de ciclos limites apresentados em Ogata, 1993, os quais são a base para muitos métodos de sintonia automática.

\section{A.1 Introdução a Sistemas Não-Lineares}

Os sistemas reais não são absolutamente lineares, embora sejam modelados por equações lineares, devido principalmente à simplicidade matemática. Esta simplificação pode ser satisfatória desde que estejam de acordo com os resultados experimentais. Uma das características mais importantes de sistemas não-linreares é a dependência do comportamento da resposta do sistema em relação à amplitude e tipo de entrada. Assim, um sistema pode comportar-se de forma completamente diferente em resposta a entradas em degrau de diferentes amplitudes; e desta maneira temos uma característica importante em sistemas não-lineares que é o fato de que o princípio da superposição não é verificado.

\section{A.1.1 Dependência frequência-amplitude.}

Considere a oscilação livre de um sistema mecânico constituído por uma massa, um amortecedor viscoso e uma mola não-linear. A equação diferencial que descreve a dinâmica deste sistema pode ser escrita como

$$
m \ddot{x}+b \dot{x}+k x+k^{\prime} x^{3}=0
$$

onde $k x+k^{\prime} x^{3}$ : força da mola não-linear ; $x$ : deslocamento da massa; $m:$ massa e $b:$ coef. de atrito viscoso do amortecedor.

Os parâmetros $m, b$ e $k$ são constantes positivas, enquanto que $k$ ' pode ser positivo ou negativo. O grau da não-linearidade do sistema é caracterizado pela magnitude de $k^{\prime}$. A equação (A1) é conhecida como equação de Duffing e uma investigação experimental mostra que quando a amplitude decresce, a freqüência da oscilação natural ou decresce ou 
cresce, dependendo de $k^{\prime}>0$ ou $k^{\prime}<0$, respectivamente. Quando $k^{\prime}=0$ a frequencia permanece inalterada quando a amplitude da oscilação natural decresce (sistema linear). A Figura A1 mostra a relação de amplitude-frequência para os três casos em que $k$ ' é maior, igual ou menor que zero.

Em experimentos de sistemas não-lineares a dependência amplitude-frequência pode ser facilmente detectada. Esta é uma das características mais fundamentais de oscilações em sistemas não-lineares. Um gráfico como o da Figura A1 revela a presença de uma nãolinearidade e também o grau desta não-linearidade.

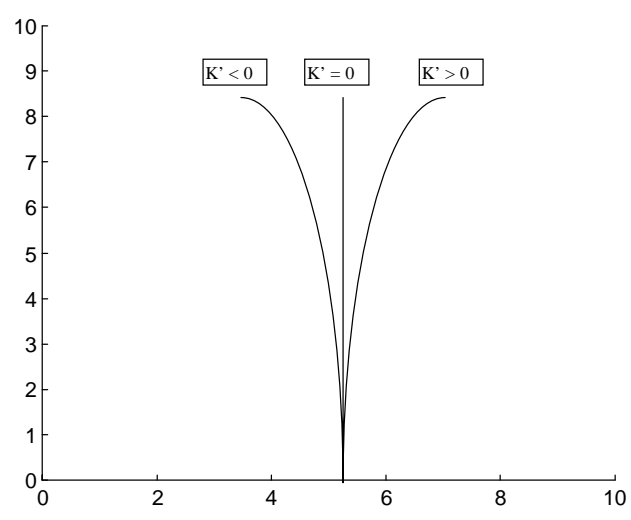

FIGURA A1. Curvas de amplitude em função da frequencia para oscilações naturais para o sistema dado por (A1).

\section{A.1.2 Oscilações auto-excitadas ou ciclos limites}

Um fenômeno que é observado em certos sistemas não-lineares é uma oscilação autoexcitada ou ciclo limite. Considere um sistema descrito pela seguinte equação:

$$
m \ddot{x}-b\left(1-x^{2}\right) \dot{x}+k x=0
$$

onde $m, b$ e $k$ são grandezas positivas. Esta equação é chamada equação de Van der Pol. Ela é não-linear no termo de amortecimento. Ao examinar este termo, observamos que para pequenos valores de $x$ o amortecimento será negativo e adicionará energia ao sistema, enquanto que para valores grandes ele será positivo, removendo energia do sistema. Portanto, pode-se esperar que tal sistema apresente uma oscilação mantida. Como este não é um sistema forçado, esta oscilação é denominada oscilação auto-excitada ou ciclo limite. 


\section{A.2 Sistemas de Controle com Pequenas Não-Linearidades}

Muitos tipos diferentes de não-linearidades podem estar presentes em sistemas de controle reais e podem ser separadas em duas classes, as inerentes aos sistemas de controle e as intencionalmente inseridas nos sistemas.

\section{A.2.1 Não-linearidades inerentes}

As não-linearidades inerentes são inevitáveis em sistemas de controle e são de origem física e/ou químicas e dependem das condições de operação dos sistemas. São exemplos,

1. Saturação

2. Zona Morta

3. Histerese

4. Folga

5. Atrito estático, atrito de Coulomb e outros não lineares

6. Mola não-linear

7. Compressibilidade de fluidos

De forma geral, a presença destas não-linearidades no sistema de controle afeta prejudicialmente o desempenho do sistema.

\section{A.2.2 Não-linearidades intencionais}

Alguns elementos não-lineares são intencionalmente introduzidos em um sistema para melhorar seu desempenho ou simplificar sua construção. Em sistemas de controle ótimo frequientemente emprega-se controladores não-lineares para satisfazer-se certos critérios de otimização. Deve-se notar que embora elementos não-lineares intencionais melhorem o desempenho do sistema sob certas condições específicas de operação, podem também degradar o desempenho do sistema sob outras condições de operação.

\section{A.2.3 Abordagens usadas na análise e projeto de sistemas de controle não- lineares}


Não há método geral para lidar-se com todos os sistemas não-lineares porque as equações diferenciais não-lineares praticamente não permitem um método geral de estudo. Assim, podemos tomar cada equação não-linear, ou grupo de equações similares, e tentar desenvolver um método de análise que se aplicará satisfatoriamente para aquele grupo particular.

Uma maneira de se analisar e projetar um grupo particular de sistemas de controle não-lineares, em que o grau de não-linearidade é pequeno, é usar técnicas de linearização equivalentes e resolver o problema linearizado obtido. O método da função descritiva a ser descrito é um destes métodos de linearização equivalente. O estabelecimento de critérios de estabilidade é muito mais fácil do que a obtenção de soluções analíticas das equações diferenciais. O método da função descritiva nos permite estudar a estabilidade de muitos sistemas de controle não-lineares simples do ponto de vista do domínio da frequencia, dá informações sobre a estabilidade para um sistema de qualquer ordem, mas não informação sobre as características de resposta temporal.

\section{A.3 Funções Descritivas}

Tome-se como entrada para um elemento não-linear uma onda senoidal. A saída do elemento não-linear é, em geral, não senoidal. Suponha que a saída é periódica com o mesmo período que a entrada ( a saída contem harmônicas superiores, além da componente fundamental).

$\mathrm{Na}$ análise por função descritiva, supomos que apenas a componente harmônica fundamental da saída é significativa. Tal suposição é freqüentemente válida, uma vez que harmônicas superiores na saída de um elemento não-linear são frequentemente de menor amplitude do que a amplitude da componente de harmônica fundamental. Além disso, a maioria dos sistemas de controle são filtros passa-baixas, com o resultado de que as harmônicas superiores são muito atenuadas quando comparadas com a componente harmônica fundamental.

A função descritiva ou função descritiva senoidal de um elemento não-linear é definida como a relação complexa entre a componente harmônica fundamental da saída e a amplitude da entrada. Isto é,

$$
N=\frac{Y_{1}}{X} \angle \Phi_{1}
$$


onde $N$ : função descritiva; $X$ : amplitude da senóide de entrada; $Y_{1}$ : amplitude da componente harmônica fundamental da saída; $\varnothing_{1}$ : defasagem da componente harmônica fundamental da saída.

Se não houver elemento de armazenamento de energia incluído no elemento nãolinear, então $N$ é uma função apenas da amplitude da entrada para o elemento. Por outro lado, se um elemento armazenador de energia foi incluído, então $N$ é uma função tanto da amplitude como da freqüência da entrada.

Ao se calcular a função descritiva para um dado elemento não-linear, necessitamos achar a componente harmônica fundamental da saída. Para a entrada senoidal $x(t)=X \operatorname{senwt}$ para o elemento não-linear, a saída $y(t)$ pode ser expressa como uma série de Fourier:

$$
y(t)=A_{o}+\sum_{n=1}^{\infty}\left(A_{n} \cos n w t+B_{n} \operatorname{sen} n w t\right)=A_{o}+\sum_{n=1}^{\infty} Y_{n} \operatorname{sen}\left(n w t+\Phi_{n}\right)
$$

onde

$$
\begin{aligned}
& A_{n}=\frac{1}{\pi} \int_{0}^{2 \pi} y(t) \cos n w t d(w t) \\
& B_{n}=\frac{1}{\pi} \int_{0}^{2 \pi} y(t) \operatorname{sen} n w t d(w t) \\
& Y_{n}=\sqrt{A_{n}^{2}+B_{n}^{2}} \\
& \Phi_{n}=\tan ^{-1}\left(\frac{A_{n}}{B_{n}}\right)
\end{aligned}
$$

Se a não-linearidade é anti-simétrica, então $A_{o}=0$. A componente da harmônica fundamental da saída é

$$
y_{1}(t)=A_{1} \cos w t+B_{1} \operatorname{sen} w t=Y_{1} \operatorname{sen}\left(w t+\Phi_{1}\right)
$$

A função descritiva é então dada por

$$
N=\frac{Y_{1}}{X} \angle \Phi_{1}=\frac{\sqrt{A_{1}^{2}+B_{1}^{2}}}{X} \angle \operatorname{tg}^{-1}\left(\frac{A_{1}}{B_{1}}\right)
$$

De onde vê-se que quando $\varnothing_{1}$ é não nulo $N$ é complexo 


\section{A.3.1 Não-linearidade tipo liga-desliga (relê)}

A característica de entrada-saída desta não-linearidade é dada na Figura A2(a). A saída deste elemento é uma constante positiva ou uma constante negativa. Portanto para uma entrada senoidal, o sinal de saída torna-se uma onda quadrada. A Figura A2(b) mostra estas formas de onda.

Aplicando-se (A3) temos que a saída é uma função ímpar e portanto $A_{n}=0(n=0,1$, $2, \ldots)$, assim

$$
y(t)=\sum_{n=1}^{\infty} B_{n} \operatorname{sen} n w t
$$

A componente harmônica fundamental de $y(t)$ é

$$
y_{1}(t)=B_{1} \operatorname{sen} w t=Y_{1} \operatorname{sen} w t
$$

onde $\quad Y_{1}=\frac{1}{\pi} \int_{0}^{2 \pi} y(t) \operatorname{sen} w t \mathrm{~d}(\mathrm{wt})=\frac{2}{\pi} \int_{0}^{\pi} y(t) \operatorname{sen} w t \mathrm{~d}(\mathrm{wt})$

Substituindo $y(t)=d$ nesta última equação, resulta

$$
Y_{1}=\frac{2 d}{\pi} \int_{0}^{\pi} \operatorname{sen} w t \mathrm{~d}(\mathrm{wt})=\frac{4 \mathrm{~d}}{\pi}
$$

Portanto, $\quad y_{1}(t)=\frac{4 d}{\pi} \operatorname{sen} w t$

A função descritiva $N$ é então dada por

$$
N=\frac{Y_{1}}{X} \angle 0^{\circ}=\frac{4 d}{\pi \mathrm{X}}
$$




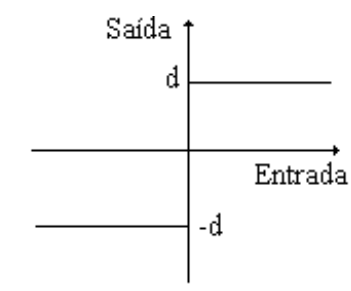

(a)
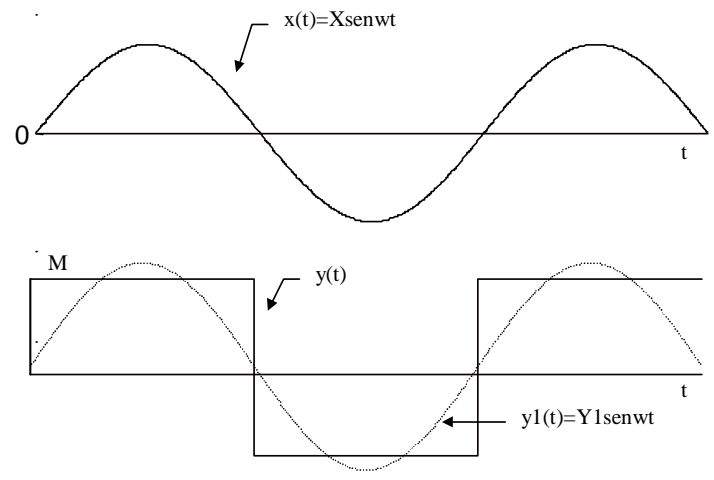

(b)

FIGURA A2. (a) Característica de entrada-saída para não-linearidade tipo liga-desliga; (b) formas de onda de entrada e saída.

Claramente a função descritiva para a não-linearidade tipo liga-desliga é uma grandeza real e uma função apenas da amplitude de entrada $X$. Um gráfico desta função descritiva versus d/X é visto na Figura A3.

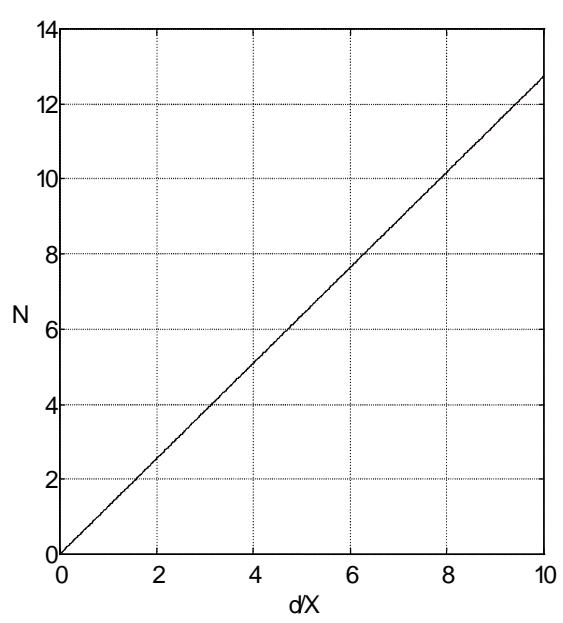

FIGURA A3. Função descritiva da não-linearidade tipo liga-desliga.

\section{A.3.2 Não-linearidade tipo liga-desliga com histerese (relê com histerese)}

A curva característica de entrada-saída deste tipo de não-linearidade é dado na Figura A4(a). Para uma entrada senoidal, o sinal de saída torna-se uma onda quadrada, com um atraso de fase de valor $w t_{1}=\operatorname{sen}^{-1}(h / X)$, conforme mostrado na Figura A4(b). Portanto a função descritiva para este elemento não-linear é 


$$
N=\frac{4 d}{\pi \mathrm{X}} \angle-\operatorname{sen}\left(\frac{h}{X}\right)
$$

É mais conveniente fazer um gráfico de

$$
\frac{h}{d} N=\frac{4 h}{\pi \mathrm{X}} \angle-\operatorname{sen}\left(\frac{h}{X}\right)
$$

em função de $h / X$ ao invés de $N$ em função de $h / X$, porque $h N / d$ é uma função apenas de $h / X$. Um gráfico de $h N / d$ em função de $h / X$ é visto na Figura A5.
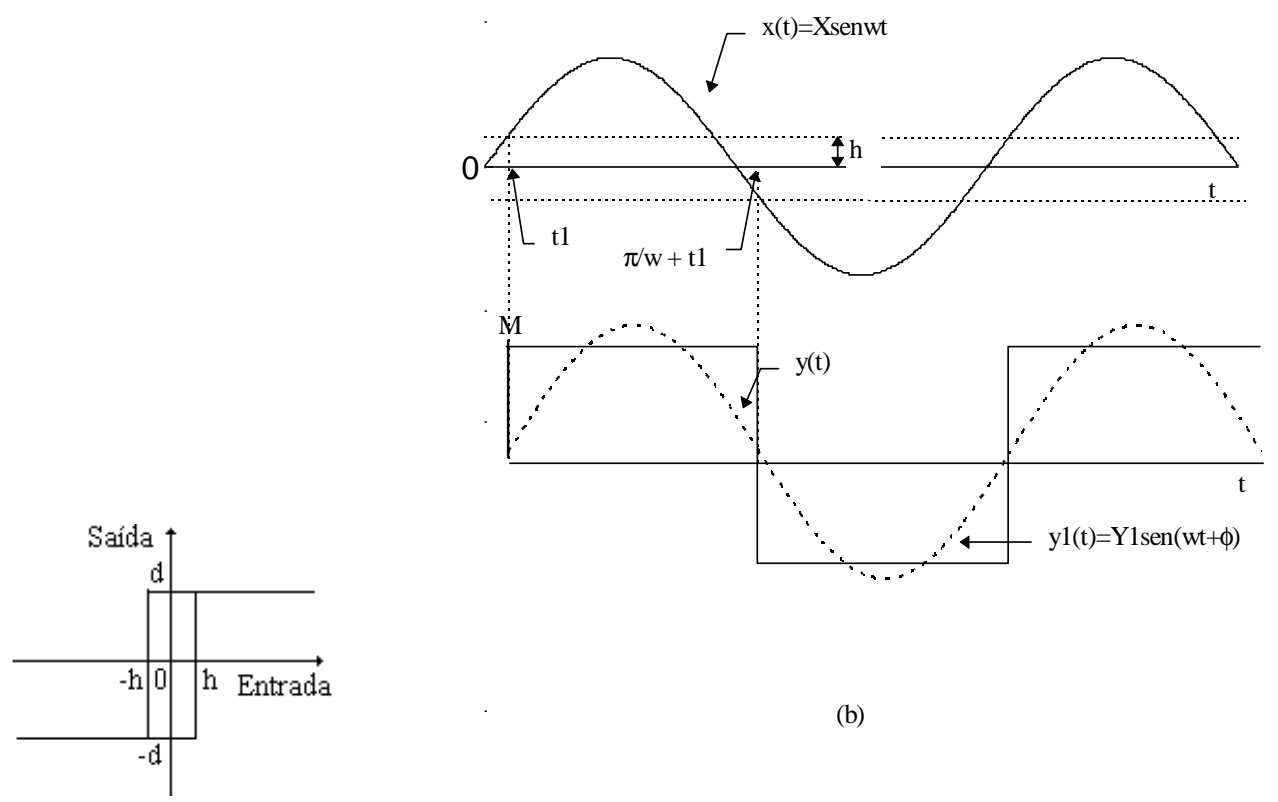

(b)

(a)

FIGURA A4. (a) Curva entrada-saída para não-linearidade tipo liga-desliga com histerese; (b) formas de onda de entrada e saída. 


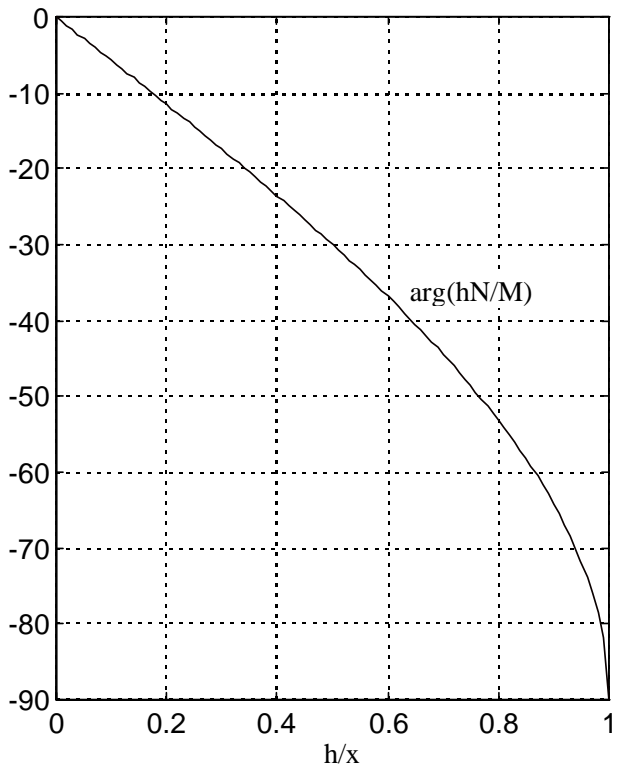

(a)

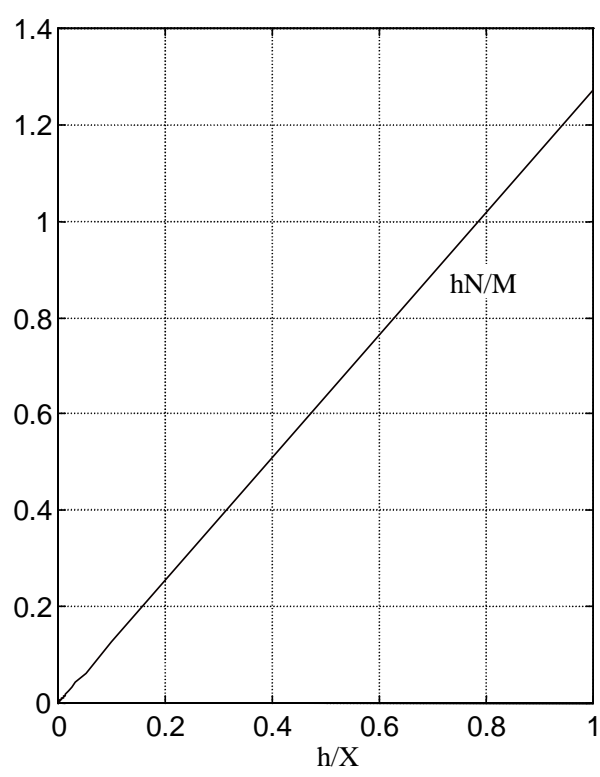

(b)

FIGURA A5. Função descritiva da não-linearidade tipo liga-desliga com histerese, (a) Fase, em graus e (b) Amplitude

\section{A.4 Estabilidade de Sistema de Controle Não-lineares através da Função Descritiva}

Para o diagrama de blocos da Figura A6, se os harmônicos superiores gerados pelo elemento não-linear são suficientemente atenuados pelos elementos lineares de tal forma que apenas a componente harmônica fundamental da saída do elemento não-linear é significativa, então a estabilidade do sistema pode ser prevista por uma análise por função descritiva.

Caso a situação acima seja obedecida a função descritiva $N$ pode ser tratada como um ganho de variável real ou complexa. Então a resposta em freqüência da malha fechada torna-se

$$
\frac{C(j w)}{R(j w)}=\frac{N \cdot G(j w)}{1+N \cdot G(j w)}
$$

com equação característica dada por

$$
1+N G(j w)=0 \quad \text { ou } \quad G(j w)=-\frac{1}{N}
$$


Se a equação (A4) é satisfeita, então a saída do sistema exibirá um ciclo limite. Esta situação corresponde ao caso em que o lugar geométrico de $\mathrm{G}(\mathrm{jw})$ passa pelo ponto crítico. (Na análise convencional para sistemas lineares o ponto crítico é $-1+$ j0).

Então na análise por função descritiva, todo o lugar geométrico $-1 / N$ torna-se o lugar geométrico de pontos críticos. Assim, a posição relativa dos lugares geométricos de $-1 / \mathrm{Ne}$ de $G(j w)$ proverá a informação de estabilidade.

Para determinar a estabilidade do sistema, faz-se um gráfico dos lugares geométricos de $-1 / N$ e de $G(j w)$ se o lugar geométrico de $-1 / N$ não é interceptado pelo lugar geométrico de $G(j w)$,então o sistema é estável (não há ciclo limite em regime estacionário).

Caso ocorra a interceptação do lugar geométrico de $-1 / N$ pelo lugar geométrico de $G(j w)$ o sistema resultará instável e a saída do sistema quando perturbada crescerá indefinidamente (na prática pode ocorrer saturação de atuadores, limitação pela potência da fonte de energia ou mesmo danificação dos componentes do sistema).

No caso de interceptação dos lugares geométricos de - $1 / N$ e $G(j w)$, a saída pode ainda apresentar uma oscilação mantida ou ciclo limite. Esta oscilação mantida é caracterizada pelo valor de $X$ no lugar geométrico de $-1 / N$ e o valor de w no lugar geométrico de $G(j w)$.

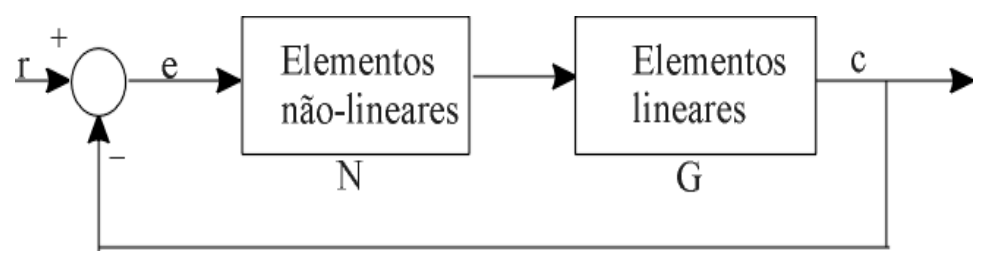

FIGURA A6. Sistema de controle não-linear.

\section{A.4.1 Estabilidade de ciclos limites}

A estabilidade de um ciclo limite pode ser prevista da seguinte forma: tomemos como exemplo o sistema visto na Figura A7. Os pontos de $-1 / N$ que são internos ao lugar geométrico de $\mathrm{G}(\mathrm{jw}$ ) correspondem ao ponto crítico ou ao ponto $-1+\mathrm{j} 0$ no plano complexo para sistemas lineares e então são "circundados" pelo lugar geométrico de $G(j w)$ no significado de Nyquist. Por semelhança ao caso em que o lugar geométrico de malha aberta de um sistema linear circunda o ponto $-1+\mathrm{j} 0$, a amplitude de entrada $X$ para estes pontos de operação aumentará e o ponto de operação mover-se-á em direção ao ponto B. Os pontos externos ao lugar geométrico de $G(j w)$ não correspondem ao ponto crítico e não são 
"circundados" pelo lugar geométrico de $G(j w)$, então a amplitude da senóide de entrada do elemento não-linear decrescerá para estes pontos de operação.

Com esta análise resulta que o ponto A possui características divergentes e corresponde a um ciclo limite instável que não pode ser observado experimentalmente; o ponto B possui características convergentes e corresponde a um ciclo limite estável que pode ser observado experimentalmente.

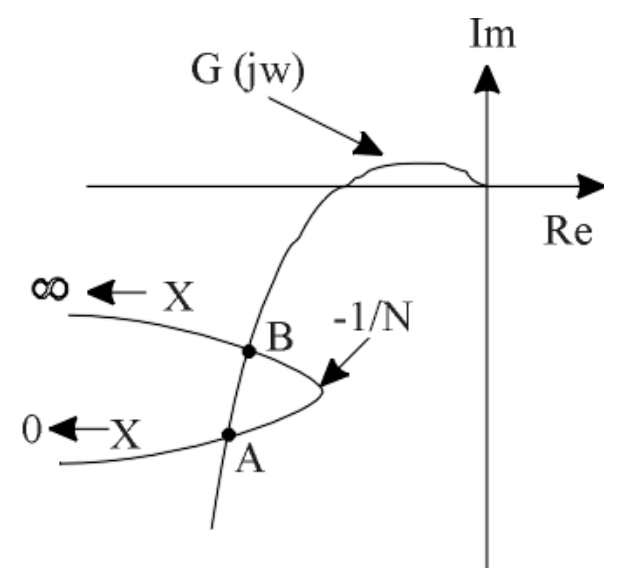

FIGURA A7. Análise da estabilidade de operações de ciclo limite para sistemas não-lineraes.

\section{A.5 Precisão da análise por função descritiva}

Se os lugares geométricos de $-1 / N$ e $G(j w)$ interceptam-se quase perpendicularmente, então a precisão da análise por função descritiva é muito boa (se as harmônicas de ordem superior são todas atenuadas, a precisão é excelente).

Se o lugar geométrico de $G(j w)$ é tangente ou quase tangente ao lugar geométrico de $-1 / N$, então a precisão da informação obtida na análise por função descritiva depende de quão bem $G(j w)$ irá atenuar as harmônicas de ordem superior; o ciclo limite pode ocorrer ou não dependendo da natureza de $G(j w)$ e diz-se que o sistema está a ponto de apresentar um ciclo limite. 


\section{Apêndice B}

\section{Plataforma de Desenvolvimento}

\section{B.1 Pacote AvCASE 8051 Family}

Como plataforma de trabalho para simulação, depuração e compilação dos programas em desenvolvimento esta sendo utilizado o pacote da Avocet Systems Inc. AvCASE 8051 Family que permite trabalhar tanto com programas elaborados em assembly quanto em linguagem C. Este pacote possui um assembler e um linker que permitem diversas opções para a compilação e "linkagem" dos programas escritos diretamente em assembly e um simulador para teste das rotinas elaboradas. Para programas escritos em linguagem $\mathrm{C}$ há uma interface que facilita o trabalho de edição dos programas, compilação, compilação para assembly e definição de dependências entre rotinas em $\mathrm{C}$ e assembly. $\mathrm{O}$ compilador $\mathrm{C}$ gera o programa em binário com o conjunto de instruções da família de microcontroladores 8051 e permite que microcontroladores derivados sejam usados pelo uso de arquivos que atualizam os registradores específicos; o simulador também trabalha com programas escritos em linguagem C. Há ainda um programa que permite que uma placa de desenvolvimento, dotada do microcontrolador 8051, seja ligada ao PC e que os programas elaborados sejam descarregados na placa para teste em hardware.

O pacote roda sob MS-DOS 5.0 ou superior, necessita de 600K RAM, 5M de hard disk e suporta mouse.

\section{B.1.1 Simulador}

O programa AVS51.exe é um depurador que permite a simulação do comportamento da família 8051 de microcontroladores sob o controle da ação do código de programação. Permite a depuração de programas escritos em assembly e linguagem C. Possibilita a simulação de dispositivos periféricos e sinais externos aplicados as portas do microcontrolador. 
Suas principais características são:

- Simulação precisa da estrutura interna do microcontrolador incluindo dispositivos periféricos (portas paralelas, porta serial e conversor A/D) e o sistema de interrupção.

- Compatibilidade com vários compiladores C existentes (Archimedes 8051 C compiler, C IAR Systems 8051 C compiler e Franklin/Keil Software C compiler).

- Interface com menus "pull-down", linha de comando, teclas de atalho para os comandos mais utilizados e janelas flutuantes.

- O conteúdo dos registradores e memória podem ser visualizados em vários formatos (decimal inteiro, hexadecimal, ASCII, binário ou decimal com ponto flutuante).

- Breakpoints (paradas em pontos específicos do código) condicionais e incondicionais.

- Análise de desempenho função por função: tempo de execução total de cada rotina e percentagem do tempo de execução de cada rotina em relação ao tempo total de execução do programa. Os resultados são também mostrados em histogramas.

Para mais detalhes consultar o manual do simulador. A figura abaixo mostra uma das possíveis formas de apresentação do simulador. 


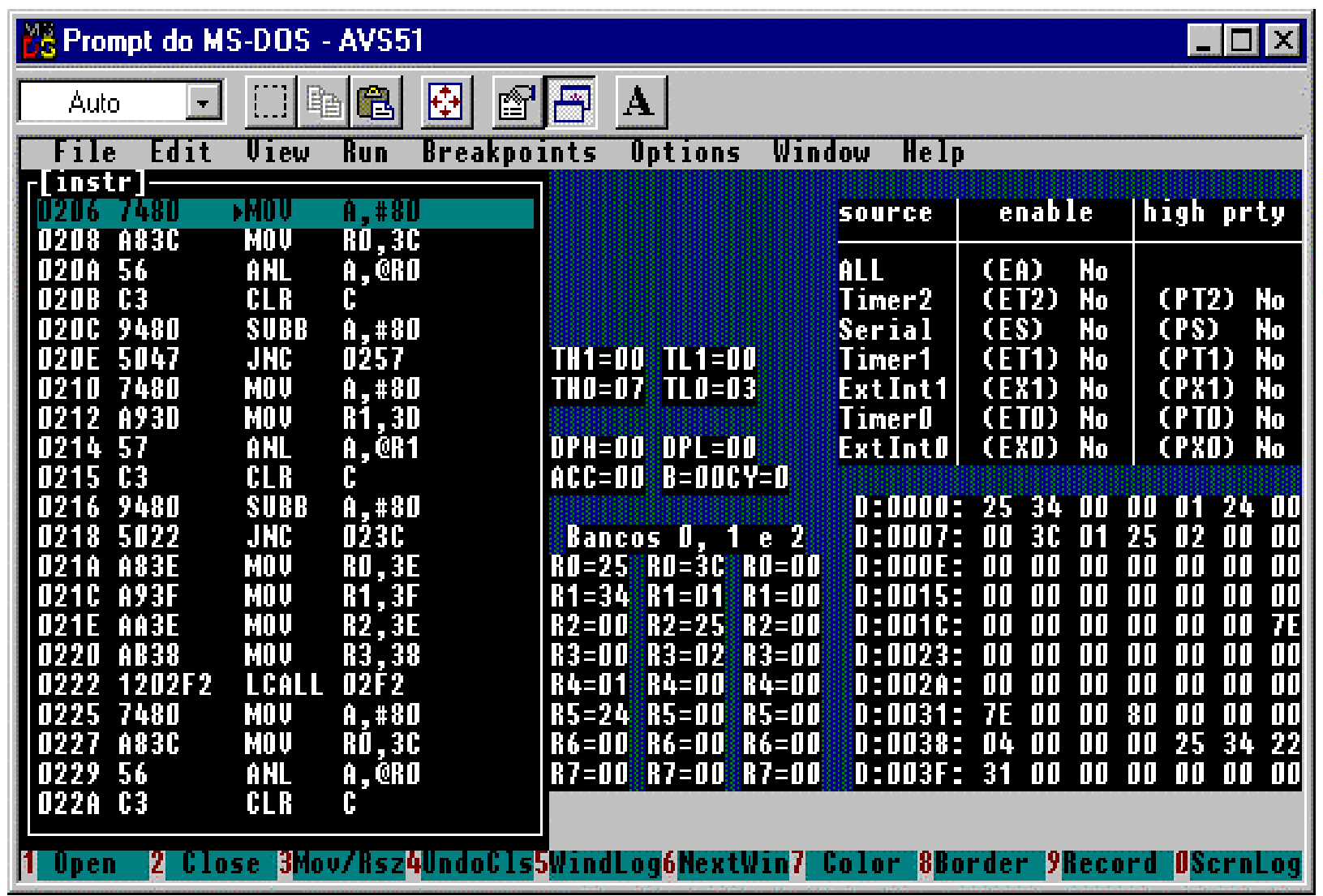

FIGURA B1. Ambiente de simulação com diversas janelas ativas.

\section{B.1.2 Compilador C}

Através de um único comando (AVC51.exe) os arquivos editados em linguagem C são compilados, "assemblados" e "linkados" sendo que diversas opções estão disponíveis para a compilação como modelo de memória a ser usada, geração do código em assembly, otimização do código para velocidade e muitas outras. Os programas escritos em linguagem $\mathrm{C}$ podem chamar rotinas elaboradas em assembly e programas escritos em assembly podem ter rotinas escritas em linguagem $\mathrm{C}$ bastando que os comandos necessários sejam colocados nos arquivos fontes e que as opções adequadas sejam dadas na linha de comando no momento da compilação.

A ação normal do comando AVC51 é compilar todos os arquivos *.C listados, "assemblar" todos os arquivos *.asm e "linkar" os resultados juntos com outros arquivos objetos especificados, usando o código "startup" e as bibliotecas apropriadas para o corrente modelo de memória. Outras opções como faixa de endereços para as memórias RAM, ROM e XRAM, o nível de informação mostrado no monitor a respeito do andamento do processo 
de compilação, geração de arquivo para depuração pelo simulador e outras podem ser ajustadas num arquivo de configuração localizado no diretório raiz do compilador.

O número de arquivos gerados depende das opções utilizadas mas pelo menos estes serão sempre produzidos: o arquivo carregável ( ou imagem, *.hex) e o arquivo mostrando como as várias seções do código e dos dados estão organizadas na memória (*.map).

Como exemplo da linha de comando e das mensagens apresentadas durante o execução da compilação, para compilar o arquivo sample1.c presente no diretório AVCASE51ISAMPLES deve-se digitar a seguinte linha de comando:

\section{C:\AVCASE51 ISAMPLES>avc51 sample1}

que resultará nas informações sobre o andamento da compilação,

AvCase-C 8051 Cross-Compiler, V2.123

Copyright (C) 1993, Avocet Systems, Inc. \& HI-TECH Software

Compiling sample1.c.

Preprocessor

First Pass

Code Generator

Optimizer

Assembler

Linking

\section{C:\AVCASE51\SAMPLES>}

Para maiores detalhes dos modelos de memória disponíveis, de toda a lista de opções para compilação, dos tipos de dados suportados e das bibliotecas consultar o manual do compilador C. 


\section{B.1.3 Assembler}

$\mathrm{O}$ arquivo executável AVA51.exe transforma um arquivo fonte editado em linguagem assembly para um arquivo objeto relocável (*.obj). Este assembler compreende um préprocessador de macro e o assembler propriamente dito; ele pode gerar arquivos intermediários que juntamente com outros arquivos gerados pelo linker fornecem informações sobre a utilização da memória e dos procedimentos e símbolos existentes no programa.

A avaliação suportada para as expressões permite que qualquer combinação de constantes e endereços seja utilizada em expressões, seguindo a precedência dos operadores aritméticos e booleanos, tanto para endereçamento quanto para obtenção de valores constantes.

Possui um grande número de opções que tornam o trabalho de desenvolvimento do software mais ágil e prático permitindo, por exemplo, gerar informações para uso no programa simulador, otimizar os saltos condicionais e incondicionais, ajustar um procedimento para ser utilizado por um código em linguagem $\mathrm{C}$ e muitas outras.

Um exemplo de como fica uma linha de comando para "assemblar" e "linkar" o arquivo exemplo sample3.asm é mostrado abaixo onde os arquivos *.obj, *.hex, *.map e *.prn serão produzidos.

C:\AVCASE51ISAMPLES>ava51 sample3a

AVCASE 8051-Family Assembler, Version 4.04

Copyright (C) 1990 by Avocet Systems, Inc. All Rights Reserved.

Preprocessing : sample3a.asm

Macro expansion: sample3a.mxp

Assembling : sample3a.mxp

Object File : sample3a.obj

List File : sample3a.prn

Cross Ref File : (none) 
No lines contained errors.

No lines contained warnings.

C:\AVCASE51ISAMPLES >avl51 sample3a=sample3a

AvCase 8051-Family Linker, Version 4.06L

Copyright (C) 1991, Avocet Systems, Inc. All rights reserved.

Reading symbols from: sample3a.obj

Reading text from : sample3a.obj

C:\AVCASE51\SAMPLES>

Os detalhes de cada uma das opções possíveis para o assembler e das diretivas de compilação podem ser obtidas no manual.

\section{B.2 Código Esqueleto da Rotina de Controle PID}

O código para a rotina de controle PID resultante das seções expostas anteriormente (considerando a aproximação de Tustin em (2.17) ) é dado em pseudo-código como,

Ler SP (valor da referência)

Ler PROC (valor da variável de processo)

erro $=$ SP - PROC

ai $=\left(2 * \mathrm{~T}_{\mathrm{d}}-\mathrm{N} * \mathrm{ts}\right) /\left(2 * \mathrm{~T}_{\mathrm{d}}+\mathrm{N} * \mathrm{ts}\right) \quad$; coeficientes para parte derivativa

$\mathrm{bi}=2 * \mathrm{~K} * \mathrm{~N} * \mathrm{~T}_{\mathrm{d}} /\left(2 * \mathrm{~T}_{\mathrm{d}}+\mathrm{N} * \mathrm{ts}\right)$

ai2 $=\mathrm{K}^{*} \mathrm{ts} / \mathrm{Ti}$

; coeficiente para parte integral

$\mathrm{P}=\mathrm{K} *($ beta* $\mathrm{SP}-\mathrm{PROC})$

; contribuição proporcinal

$\mathrm{D}=\mathrm{ai} * \mathrm{D}-\mathrm{bi}^{*}\left(\mathrm{PROC}-\mathrm{PROC}_{\text {anterior }}\right) \quad$; contribuição derivativa

$\mathrm{u}=\mathrm{P}+\mathrm{I}+\mathrm{D}$

; valor do sinal de controle

Escreve u

; aplica sinal de controle

$\mathrm{I}=\mathrm{I}+$ ai2 2 erro

; contribuição integral 
$\mathrm{PROC}_{\text {anterior }}=$ PROC $\quad$; salva valor da variável de processo

\section{B.3 Código Esqueleto da Rotina de Auto-sintonia}

Tendo em vista os resultados obtidos na Figura 40 o método mais adequado para obter-se a sintonia do processo mini-forno é o método de Zhuang-Atherton, e portanto este será codificado. Este algoritmo consta de um laço de programa que identifica os máximos e mínimos da variável de saída do processo quando um relê está presente na malha fechada para obtenção do valor da amplitude da oscilação crítica e mede o tempo entre estes picos e vales do sinal para obter o período da oscilação crítica. Com estes valores medidos aplica-se as equações (3.91), (3.92) e (3.93) para obter-se os parâmetros do controlador PID.

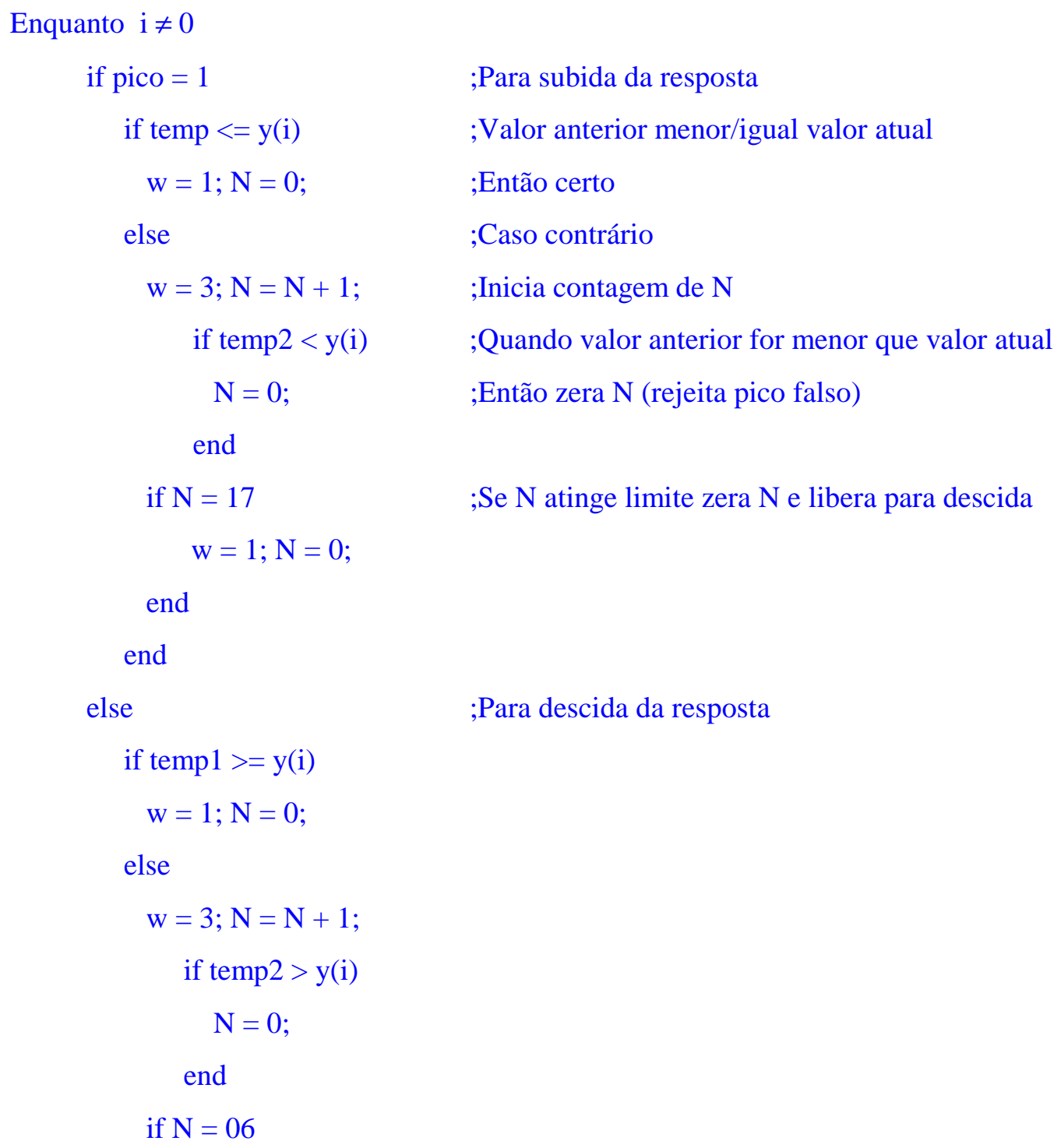




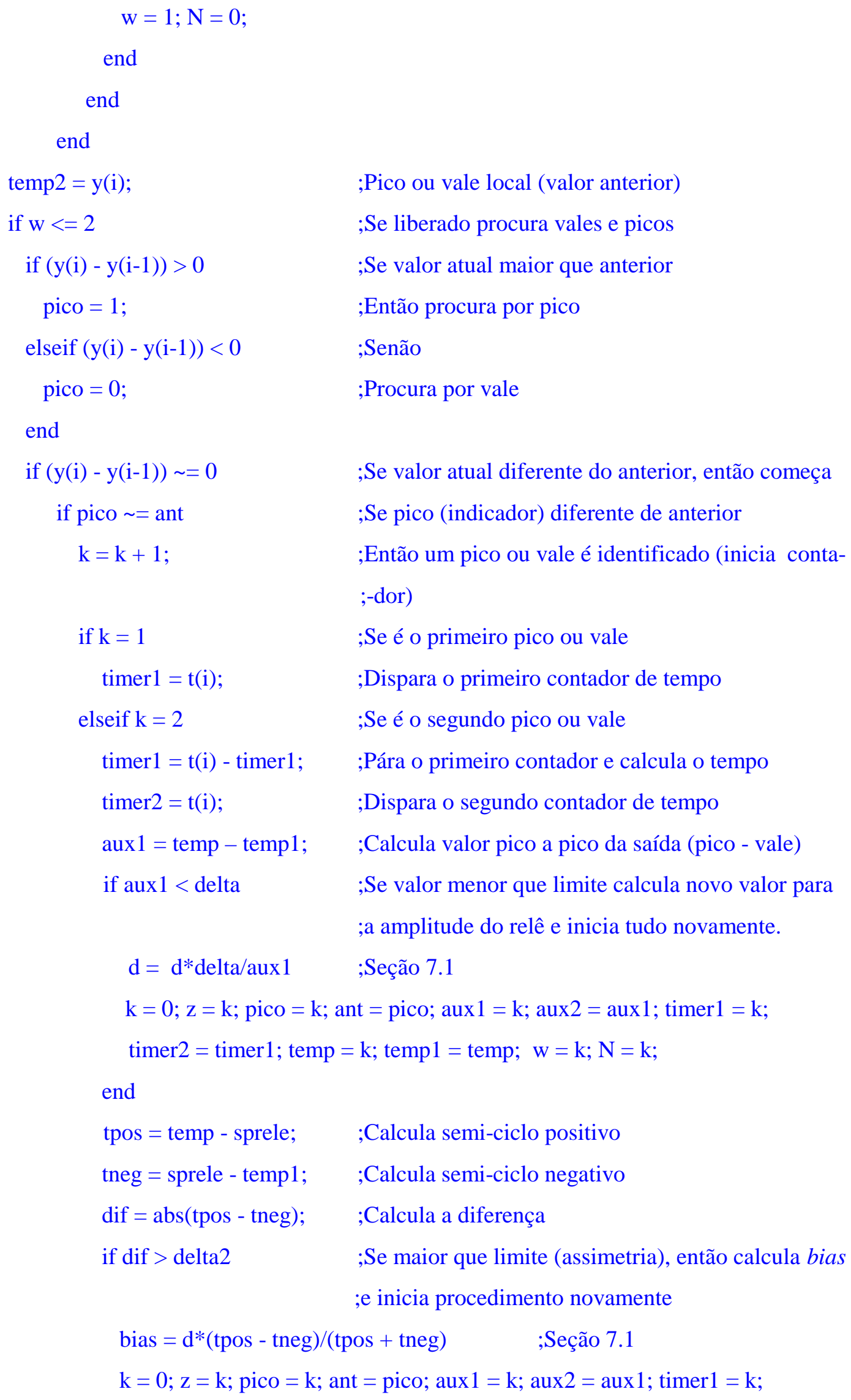




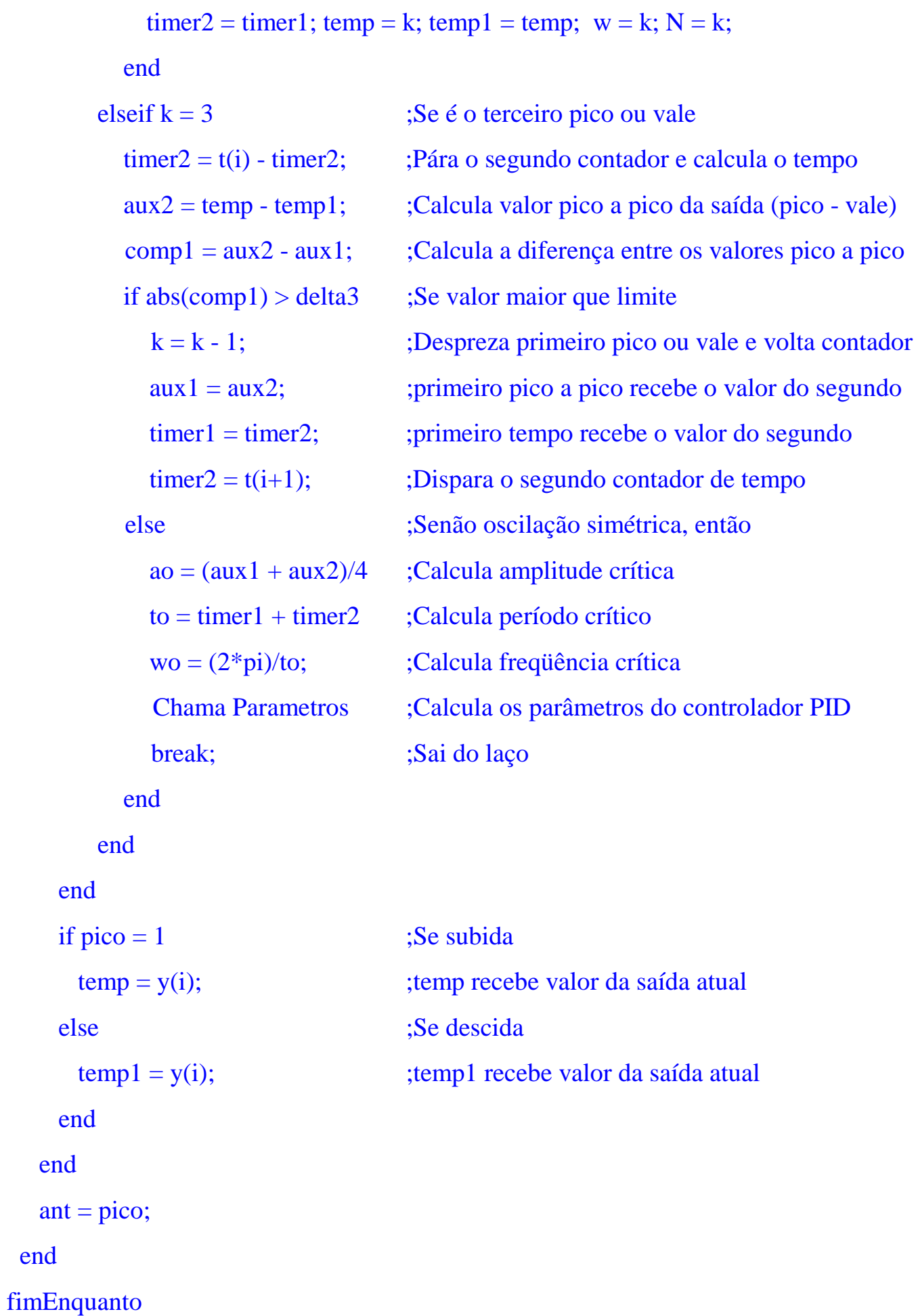

Variáveis utilizadas,

ant : valor anterior de pico.

ao : amplitude da oscilação crítica. 
aux1 : primeiro valor pico a pico (pico - vale).

aux2 : segundo valor pico a pico (pico - vale).

bias : valor do bias calculado.

delta : estabelece o limite mínimo para oscilação válida.

delta2 : estabelece o limite máximo para identificar assimetria.

delta3 : estabelece o valor mínimo para aceitar o primeiro pico/vale.

$\mathrm{i}$ : indice de tempo.

$\mathrm{k}$ : contador de pico/vale.

$\mathrm{N}$ : número de amostras a esperar na identificação de pico/vale falso.

Parametros : subrotina que obtém os valores dos ganhos do controlador PID a partir de ao e to, de acordo com o método adotado.

pico : indica se a saída esta subindo ou descendo.

sprele : set-point (referência) da oscilação a relê.

temp : variável auxiliar que indica o valor do pico.

temp1 : variável auxiliar que indica o valor do vale.

temp2 : variável auxiliar na detecção de pico/vale falso.

tempo1: fornece o tempo entre pico/vale e vale/pico.

tempo 2 : fornece o tempo entre vale/pico e pico/vale.

timer1 : valor de tempo entre pico/vale.

timer2 : valor de tempo entre pico/vale.

to : período da oscilação crítica.

tpos : semi-ciclo positivo da oscilação.

tneg : semi-ciclo negativo da oscilação.

w : libera ou não o procedimento de identificação.

y(i) : saída do processo. 